Florida International University

FIU Digital Commons

FIU Electronic Theses and Dissertations

University Graduate School

3-26-1997

\title{
Psychosocial variables associated with the co- occurance of risky sexual behavior with alcohol consumption among university students
}

Morris F. Burnham

Florida International University

DOI: $10.25148 /$ etd.FI14051886

Follow this and additional works at: https://digitalcommons.fiu.edu/etd

Part of the Social Welfare Commons

\section{Recommended Citation}

Burnham, Morris F., "Psychosocial variables associated with the co-occurance of risky sexual behavior with alcohol consumption among university students" (1997). FIU Electronic Theses and Dissertations. 1892.

https://digitalcommons.fiu.edu/etd/1892

This work is brought to you for free and open access by the University Graduate School at FIU Digital Commons. It has been accepted for inclusion in FIU Electronic Theses and Dissertations by an authorized administrator of FIU Digital Commons. For more information, please contact dcc@fiu.edu. 
FLORIDA INTERNATIONAL UNIVERSITY

Miami, Florida

\section{PSYCHOSOCIAL VARIABLES ASSOCIATED WITH THE \\ CO-OCCURRENCE OF RISKY SEXUAL BEHAVIOR \\ WITH ALCOHOL CONSUMPTION AMONG \\ UNIVERSITY STUDENTS}

A dissertation submitted in partial satisfaction of the

$$
\begin{aligned}
& \text { requirements for the degree of } \\
& \text { DOCTOR OF PHILOSOPHY }
\end{aligned}
$$

IN

SOCIAL WELFARE

by

Morris F. Burnham

1997 
This dissertation, written by Morris F. Burnham, and entitled PSYCHOSOCIAL VARIABLES ASSOCIATED WITH THE CO-OCCURRENCE OF RISKY SEXUAL BEHAVIOR WITH ALCOHOL CONSUMPTION AMONG UNIVERSITY

STUDENTS, having been approved in respect to style and intellectual content is referred to you for judgement.

We have read this dissertation and recommend that it be approved.

Miriam Potocky

Lilly M. Langer

Karen M. Sowers-Hoag, Major Professor

Date of Defense: March 26, 1997

The dissertation of Morris F. Burnham is approved.

Dean Mark Rosemberg

College of Urban and Public Affairs

Dr. Richard L. Campbell

Dean of Graduate Studies

Florida International University, 1997 
CCOPYRIGHT 1997 by Morris F. Burnham

All rights reserved 
I dedicate this dissertation to all those who have or have had careers and yet seek a new path for themselves, in the belief that it is never too late to become what you always wanted to be. 


\section{ACKNOWLEDGMENTS}

I wish to thank the members of my committee, Dr. Karen Sowers-Hoag, Dr. Miriam Potocky, and Dr. Lilly Langer, for their time, effort, and commitment not only to me, but to students and to the academic process. Thank you for the support and encouragement each of you have provided me.

A special thanks goes to my major professor, Dr. Sowers-Hoag, for her unwavering patience and faith in me to complete this study and accomplish my goals.

An additional thank you is extended to Dr. Langer for making available these data from the NIAAA Health Behavior study, of which she was principal investigator.

I acknowledge the love and support from my family (extended family included), and friends who have reached out to me with encouragement and council during this degree process. Thanks goes to Cindy Lee for her cheerful and swift assistance in typing parts of the manuscript. I especially acknowledge my ex-wife, Sally Burnham, whose efforts resulted in my coming out of a period of stagnation. I also acknowledge my mother, Ethelyn Burnham, and express gratitude for the increased closeness between us which has resulted from this process.

Lastly, but most importantly, I acknowledge and thank God. Without having God as my partner, I could not have persevered nor been able to find the emotional balance needed to complete this work. 


\author{
ABSTRACT OF THE DISSERTATION \\ PSYCHOSOCIAL VARIABLES ASSOCIATED WITH THE \\ CO-OCCURRENCE OF RISKY SEXUAL BEHAVIOR \\ WITH ALCOHOL CONSUMPTION AMONG \\ UNIVERSITY STUDENTS \\ by \\ Morris F. Burnham \\ Florida International University, 1997 \\ Professor Karen M. Sowers-Hoag, Major Professor
}

This study examined the association of theoretically guided and empirically identified psychosocial variables on the co-occurrence of risky sexual behavior with alcohol consumption among university students. The study utilized event analysis to determine whether risky sex occurred during the same event in which alcohol was consumed. Relevant conceptualizations included alcohol disinhibition, self-efficacy, and social network theories. Predictor variables included negative condom attitudes, general risk taking, drinking motives, mistrust, social group membership, and gender. Factor analysis was employed to identify dimensions of drinking motives. Measured risky sex behaviors were (a) sex without a condom, (b) sex with people not known very well, (c) sex with injecting drug users (IDUs), (d) sex with people without knowing whether they had a 
STD, and (e) sex with using drugs. A purposive sample was used and included 222 male and female students recruited from a major urban university. Chi-square analysis was used to determine whether participants were more likely to engage in risky sex behavior in different alcohol use contexts. These contexts were only when drinking, only when not drinking, and when drinking or not. The chi-square findings did not support the hypothesis that university students who use alcohol with sex will engage in riskier sex. These results added to the literature by extending other similar findings to a university student sample. For each of the observed risky sex behaviors, discriminant analysis methodology was used to determine whether the predictor variables would differentiate the drinking contexts, or whether the behavior occurred. Results from discriminant analyses indicated that sex with people not known very well was the only behavior for which there were significant discriminant functions. Gender and enhancement drinking motives were important constructs in the classification model. Limitations of the study and implications for future research, social work practice and policy are discussed. 


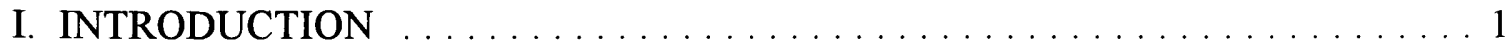

Scope of the Problem ............................ 2

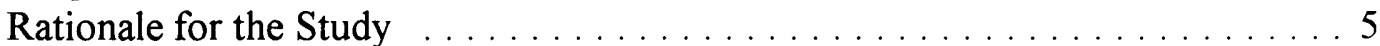

Significance of the Study to Social Work . . . . . . . . . . . . . . 11

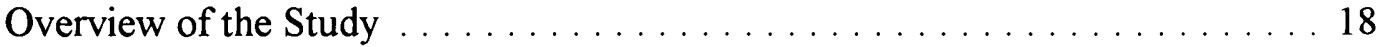

II. REVIEW OF THE LITERATURE $\ldots \ldots \ldots \ldots \ldots$

Alcohol Disinhibition Theory . . . . . . . . . . . . . . . . . . 19

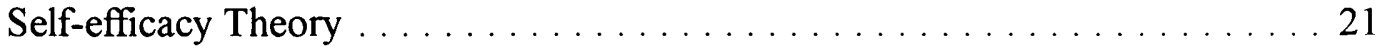

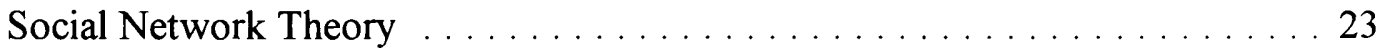

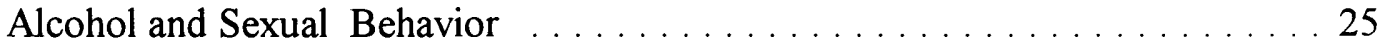

Condom Attitudes . . . . . . . . . . . . . . . . . . . . . . 27

General Risk Taking . . . . . . . . . . . . . . . . . . . . . . . . . . . 30

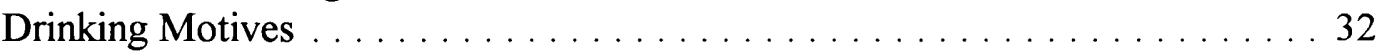

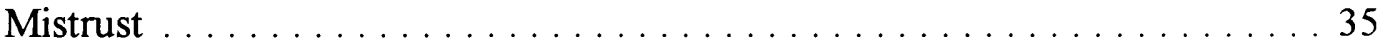

Social Group Participation . . . . . . . . . . . . . . . . . . . . 42

Implications of the Literature Review . . . . . . . . . . . . . . . . . . 45

Research Hypotheses . . . . . . . . . . . . . . . . . . . . . . . 46

III. METHODOLOGY . . . . . . . . . . . . . . . . . . . . . . . . . 49

Research Design . . . . . . . . . . . . . . . . . . . . . . . . . . 49

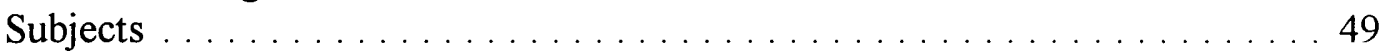

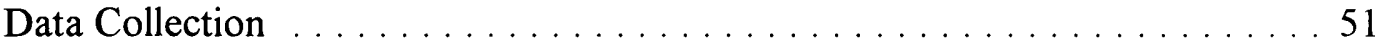

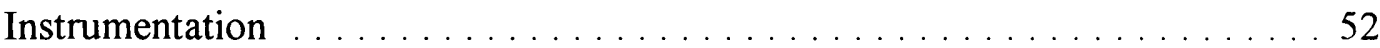

Data Analysis . . . . . . . . . . . . . . . . . . . . . . . . . 57

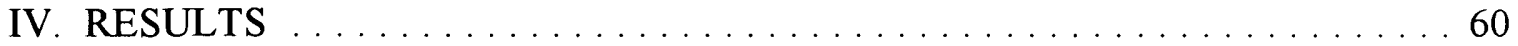

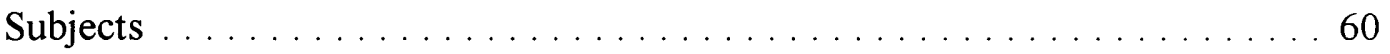

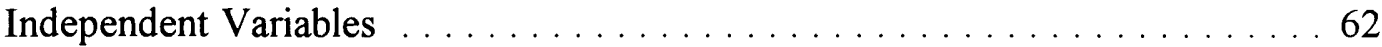

Dependent Variables . . . . . . . . . . . . . . . . . . . . . . 79

Research Hypotheses . . . . . . . . . . . . . . . . . . . . . . . . 8 81

V. DISCUSSION . . . . . . . . . . . . . . . . . . . . . . . 106

Association of Alcohol and Risky Sex Behavior . . . . . . . . . . . . 106

Psychosocial Variables Associated with Alcohol and Risky Sex . . . . . . . 108

Limitations of the Study . . . . . . . . . . . . . . . . . . . . . . . . . . 111

Implication for Social Work Research $\ldots \ldots \ldots \ldots \ldots \ldots \ldots \ldots \ldots \ldots$

Implications for Social Work Practice and Policy . . . . . . . . . . . . . 114

LIST OF REFERENCES . . . . . . . . . . . . . . . . . . . . . . . . . . . 120

APPENDIX . . . . . . . . . . . . . . . . . . . . . . . . . . 135 


\section{LIST OF TABLES}

TABLE

PAGE

1 Sample Demographics

2 Condom Attitudes Descriptive Statistics.

3 General Risk Taking Descriptive Statistics. 65

4 Drinking Motives Factor Analysis Extracted Factors

5 Drinking Motives Factor Loadings.

6 Self-enhancement Drinking Motives Descriptive Statistics. 71

7 Partner-enhancement Drinking Motives Descriptive Statistics .73

8 Coping Drinking Motives Descriptive Statistics. .74

9 Independent Variable Scales Descriptive Statistics 77

10 Independent Variables Correlation Matrix 78

11 Risky Sex Behaviors Among University Students Percentage Distribution 80

12 Gender Differences on Dependent Variables. .82

13 Racial/Ethnic Differences on Dependent Variables 84

14 Risky Sex Behaviors Among University Students Alcohol Use Contexts.

15 Sex Without a Condom Discriminant Analysis. .88

16 Sex Without a Condom Classification Results. .90

17 Sex Without a Condom Mean and Frequency Distribution. 92

18 Sex With People Not Known Well Discriminant Analysis...

19 Sex With People Not Known Well Classification Results. .95

20 Sex With People Not Known Well Mean and Frequency Distribution 
21 Sex With IV Drug User Mean and Frequency Distribution ..............................99

22 Sex Not Knowing if Partner Had STD Discriminant Analysis.......................... 100

23 Sex Not Knowing if Partner Had STD Classification Results......................... 102

24 Sex Not Knowing if Partner Had STD Mean and Frequency Distribution..........103

25 Sex With Using Drugs Mean and Frequency Distribution............................... 105 


\section{Chapter I}

Psychosocial Variables Associated with the

$$
\begin{aligned}
& \text { Co-occurrence of Risky Sexual Behavior } \\
& \text { with Alcohol Consumption among }
\end{aligned}
$$

$$
\text { University Students }
$$

Statement of Purpose

This research examined several factors which were hypothesized to mediate between the observed association of alcohol consumption with risky sex behavior. Sexual activity co-occurring with alcohol use may increase the propensity to engage in risky sex and therefore increase risk to HIV infection. The alcohol disinhibition theory as it explains the association of alcohol and risky sex was examined. Research studies on alcohol and risky sex have shown correlations of alcohol consumption and risky sexual behavior (e.g., Strunin \& Hingson, 1992), however, it is not clear that alcohol use is a precursor to risky sexual behavior (Cooper, Skinner, \& George, 1990; Leigh \& Stall, 1993; Senf \& Price, 1994).

This study tested five theory- and research-based psychosocial variables which were hypothesized to influence an individual to engage in risky sex with alcohol consumption. These included negative condom attitudes, general risk taking, drinking motives, mistrust, and social group participation. These variables draw on the theories of alcohol disinhibition, self-efficacy, and social networks. While it has not been established that attitudes precede behavior change (Becker \& Joseph, 1988), research does indicate that negative condom attitudes predicted lower condom use (Hingson, Strunin, Berlin, \& 
Heeren, 1990). It may be that the five factors of negative condom attitudes, general risk taking, drinking motives, mistrust, and social group participation are relevant to low condom use rates despite high levels of AIDS-related knowledge. It was intended that the outcomes of this research would provide information which could be integrated into prevention intervention and social policy considerations regarding HIV/AIDS among adolescents and young adults.

\section{Scope of the Problem}

The HIV/AIDS pandemic has resulted in 5.8 million deaths worldwide with an estimated 27.9 million HIV infections (Centers for Disease Control and Prevention [CDC], 1996a). As of July 1996 there have been more than 548,000 AIDS cases reported in the U.S. with 343,000 AIDS deaths (CDC, 1996b). The true prevalence of HIV infection in the U.S. remains largely unknown. Only 26 states report HIV infection to the CDC (two additional states report only pediatric HIV infection). An estimate by the CDC (1990) of the prevalence of HIV infections as of July 1989 was calculated to be 1 million persons. A more recent report (Karon, et al., 1996) estimated that in 1992 there were up to 900,000 persons living with HIV in the U. S. This estimate excludes the reported AIDS cases which were 253,569 through 1992 (CDC, 1995).

A person with HIV infection may be tested at any point in the clinical spectrum of the disease. Also, the AIDS latency period can be many years. As a result, many persons diagnosed with AIDS in their late 20 s and early 30 s were infected with HIV in their teens and early 20 s. Of the total U.S. AIDS cases, $41 \%$ were in the 20 - to 34 -year-old group at the time of diagnosis, with $37 \%$ being in the 25 - to 34 -year-old group (CDC, 1996b). 
The Department of Health and Human Services (DHHS) (1996a) reported that AIDS is the leading cause of death among those between 25 and 44 years of age, and accounts for more than 40,000 deaths each year in the U.S.

Men having sex with men represent the most prevalent risk exposure category. Of the cumulative AIDS cases among males over 12 years of age through June 1996, 59\% were exposed to HIV by sexual contact with other men (CDC, 1996b). For women, sexual transmission is also a significant exposure category. Of the cumulative AIDS cases among females over 12 years of age through June 1996, 38\% were exposed by heterosexual contact. Additional cases may increase this exposure category rate since $12 \%$ of the female AIDS cases were reported without an identified exposure category (CDC, 1996b). More critically, among females 20 to 24 years of age, heterosexual transmission of HIV is $52 \%$. These rates are extremely significant in light of the increasing female representation of reported AIDS cases. Of the AIDS cases reported during 1981-1987, females represented 8\% compared to $18 \%$ for the period $1993-1995$ (CDC, 1995) and 20\% from July 1995 through June 1996 (CDC, 1996b).

These data indicate significant risk of exposure to HIV/AIDS among homosexual or heterosexual adolescents and young adults who engage in unprotected sexual intercourse. Investigation of potential influences to such risky sexual behavior is warranted. Sexual activity co-occurring with alcohol use may increase the propensity to engage in risky sex and therefore increase risk to HIV infection. While some studies have shown correlations of alcohol consumption and risky sexual behavior (Strunin \& Hingson, 1992), it is not clear that alcohol use is a causal factor for risky sexual behavior 
(Senf \& Price, 1994). It is this association which needs to be examined in order to determine what other variables may be significant factors in the relationship between alcohol consumption and risky sex behavior.

Alcohol is the most widely used drug in the United States. According to the Preliminary Estimates from the 1995 National Household Survey on Drug Abuse (Substance Abuse and Mental Health Services Administration [SAMHSA], 1996) 111 million persons representing $52 \%$ of the population reported that they had consumed alcohol in the past month. Of those persons aged 18 to 34 years, $62 \%$ reported being current drinkers. The rate of binge drinking (five or more drinks per occasion at least once in the past month) for this group of young adult drinkers was $44 \%$. This represented the highest rate of binge drinking of any age group of drinkers. The higher the education level the more likely was current alcohol use. In the cohort of 18 to 34 year olds in this study, $72 \%$ of those who had a college degree were current drinkers as compared to only $54 \%$ of those who had not completed high school.

The use of alcohol has long been linked with sexual behavior and disinhibition, however, most studies are correlational and not experimental (Leigh \& Morrison, 1991). A causal relationship has not been established. Leigh and Morrison warn that "if drinking itself is assumed to cause high-risk sexual behavior, then other possible factors contributing to the relationship between alcohol use and sexual risk-taking may not be exposed" (p. 62). The continued sexual transmission of the HIV virus into younger populations of all sexual orientations has created serious concern regarding the alcoholsex link and a need to discover other factors which may contribute to the association of 
alcohol and risky sexual behavior.

\section{Rationale for the Study}

This study is based on theoretical formulations of alcohol disinhibition, selfefficacy, and social networks. It is also based on the research findings on (a) alcohol consumption with sex behavior, (b) condom attitudes, (c) general risk taking, (d) drinking motives, (e) mistrust, and (f) social group participation.

\section{Alcohol Disinhibition}

Alcohol disinhibition theory attempts to explain the relationships found among alcohol use and high-risk sexual behavior by asserting that alcohol impairs perception and thought through a unique process. Crowe and George (1989) contended that disinhibition is both a physiological process, i.e., cognitive impairment, as well as a psychological process involving expectancies, i.e., social learning.

Steele and Josephs (1990) asserted that alcohol restricts attention to the most salient cues in the drinker's environment, and that this disinhibition process is a general process influencing social behavior. In other words, alcohol interferes with a person's ability to attend simultaneously to sets of cues which are conflicting. Only the more salient stimuli are effectively processed freeing the person from more distant inhibitions and potential cue conflict. The authors showed that as the inhibition conflict increased in strength, the alcohol effect was to make social behavior more extreme by blocking a form of response conflict. If the person were sober, the extreme behavior would be inhibited by further access to other cues and meanings, a response conflict which is not accessible under intoxicated conditions. George and Norris (1991) posited that a combination of 
alcohol expectancies and cue conflict may offer the best explanation for the association of risky sex and alcohol use.

\section{Self-efficacy}

Self-efficacy, the central component of social cognitive theory, represents one's beliefs about their capabilities to pursue certain courses of action (Bandura, 1986). Bandura further explains that observed behaviors are often not optimal even though people possess requisite knowledge because self-referent thought mediates between knowledge and behavior. Converting AIDS-related knowledge into anti-infective behavior is difficult because self-protective behavior may conflict with previously held beliefs, motives, and interpersonal pressures. The self-efficacy model is a triadic reciprocal model which includes behaviors, cognitions, and environmental influences which interact as determinants of each other (Bandura).

Attitudes and motives are components of individual cognitions which influence self-efficacy. Positive and negative outcome expectancies along with self-efficacy determine behavior (Bandura, 1986). Condom attitudes and expected outcomes of condom use are therefore important influences on behavior. O'Leary, Goodhart, Jemmott, and Boccher-Lattimore (1992) have shown that college students practicing riskier sex reported more negative expected outcomes from condom use, and lower perceived self-efficacy to perform safe sex. Attitudes of mistrust may be fostered by selfinefficacy which occurs due to the existence of system barriers. An inability to influence events and conditions in one's environment can give rise to self-inefficacy, futility, and anxiety. Bandura places motives within social cognitive theory by defining motives as 
symbolic representations of expected outcomes. In this way motives act as behavior inducements (Bandura). Drinking motives form a part of the expected outcomes from the anticipated behavior of alcohol use with sex, and influence such behavior.

\section{$\underline{\text { Social Networks }}$}

Within the social learning paradigm, social networks can be viewed as a mediator of social support. The concept can also be useful to examine dysfunctional impacts such as influences toward involving alcohol with risky sexual behavior. Hirsch (1979) defined social networks as the current set of others with whom one has significant social interactions.

The impact of social networks is influenced by interpersonal and intra-personal factors. Interpersonal factors include advice and feedback provided by the network to a member (Tolsdorf, 1976), and intra-personal factors include the level of identification assumed by the member with the network (Walker, MacBride, \& Vachon, 1977). Holohoan and Wilcox, (1978) found that friendship formation patterns in university residences differed as a function of both dormitory type, which dictated the structure of the network, and social competence of the member.

Boeringer, Shehan \& Akers (1991) asserted that the social groups with which one identifies or interacts, influence or control social reinforcements. In the college setting, the fraternity or sorority can act as a primary group of social influence. Boeringer et al. argued further that the fraternity context affects the social learning processes of its membership which in turns affects sexual behavior. Stombler (1994) posited that college campus organizations have the ability to structure peer cultures which cultivate a 
masculine definition of women. Through a structure of gender inequality, men are positioned to exploit women physically, emotionally, and sexually (Stombler).

\section{Alcohol and Sex Behavior}

Research on the co-occurrence of alcohol and risky sex behavior includes studies which have investigated possible intervening variables which might account for the alcohol-risky sex association. One such factor is AIDS-related knowledge. However, research findings support going beyond the variable of knowledge of HIV/AIDS. Increasing knowledge has been shown by itself to be ineffective in modifying risky sexual practices. Fisher and Misovich (1990) found that despite increases in knowledge about AIDS, rates of unsafe sex remained high among college students. Others have found similar results (Di Clemente, 1991; \& Mickler, 1993). Researchers have also investigated AIDS-related attitudes. Leviton, et al. (1990) assessed both AIDS-related knowledge and attitudes. The results indicated that since knowledge was high among the study participants at initial testing, little change in knowledge was found upon subsequent testing. However, with regards to attitudes, significant changes were found in the posttest measurement. The study suggested that it is not information but attitudes which need to be targeted for interventive efforts. However, the study did not investigate the association between attitude change and behavior and therefore did not provide any evidence that a change in attitude would result in behavior change. Becker and Joseph (1988) reviewed published reports which described AIDS-related behavior change. The authors concluded that little evidence has been published which supports the assertion that changes in knowledge and attitudes will result in behavior change which substantially 
reduces AIDS risk.

\section{Condom Attitudes}

Rather than examine general measures of AIDS-related knowledge and attitudes, some researchers have examined more specific differences which might account for the continuation of risky sexual behaviors in spite of the knowledge and perceived risks of HIV/AIDS. One such variable is the specific attitude toward condom use. Hingson, Strunin, Berlin, and Heeren (1990) found that negative condom attitudes predicted lower condom use among adolescents. Cole and Slocumb (1995) found that attitude toward condoms was the most powerful predictor of safe sex practices among the male university students they surveyed. Sheer and Cline (1994) found condom attitude was an intervening variable secondary to risk taking and motives. Such non-experimental correlational research does not establish the temporal relationship among the variables of condom attitude and condom use behavior, therefore, it is not known which occurs first, the condom attitude or the condom behavior. However, such empirical evidence suggests that a model of risky sexual behavior include condom attitudes.

\section{General Risk Taking}

In order to address the question of why people practice risky sex, a relevant issue to explore is individual variability in risk taking. Arnett (1991) investigated risk-taking behaviors among college graduates which included frequent high-speed driving, driving under the influence of alcohol, and sex without contraception for unmarried persons. Arnett related these behaviors to their consequences and found that previous experience of negative consequences did not deter these types of behaviors. Gillis, Meyer-Baulburg, and 
Exner reported at the 1992 International Conference on AIDS that risk taking increased the explained variance in their model of risky sexual behavior (Sheer \& Cline, 1994). The results of a literature review on the association of general risk taking and sexual behavior indicated inconsistent findings. Some studies found that risk taking was associated with sexual risk (Sheer \& Cline, 1994). Other studies failed to find such relationships (Graves, 1995). It is therefore important to include risk taking in AIDS research to further refine the relevance of this factor.

\section{Drinking Motives}

An additional parameter which might influence risky sexual behavior with alcohol is drinking motives. Cooper (1994) found support for a two-dimensional model of drinking motives. Internal or direct motives are defined as those within the individual, and are described as either enhancement (positive) or coping (negative). The external or indirect motives include social (positive) and conformity (negative). Cooper used these dimensions of drinking motives to predict levels of alcohol and other drug use. However, the result of a review of the literature did not reveal any studies in which drinking motives have been used to predict the co-occurrence of alcohol use and risky sex. Drinking motives may represent a significant individual difference which influences sexual behavior and attitude outcomes.

\section{$\underline{\text { Mistrust }}$}

Mistrust of health and HIV/AIDS risk messages can thwart the effectiveness of prevention efforts. Nickerson, Helms, and Terrell (1994) found that higher levels of racial mistrust were associated with more negative attitudes of seeking counseling help from 
Whites. Biafora et al. (1993a) found that racial mistrust was correlated with deviant behavior among Black adolescents. Dusenberg, Diaz, Epstein, Botwin, and Caton (1994) found that African-Americans and Latinos were more likely than Whites to believe that AIDS was deliberately created to eliminate undesirable groups. It is important to determine whether high levels of mistrust influence risky sexual behavior. Risk reduction messages may be required which specifically address mistrust instead of assuming that all targeted populations will accept such messages as truth.

\section{Social Group Participation}

Social networks are potential sources of influence for alcohol consumption and sexual behavior. Treboux and Busch-Rossnagel (1990) found that among adolescents, social networks were a significant source of sexual behavior influence. Wechsler, Dowdall, Davenport, and Castillo (1995) found that among college students, those who lived at a fraternity/sorority residence were four times more likely to be binge drinkers. With respect to sexual attitudes, Whitbeck and Hoyt (1991) found those college men who belonged to a fraternity held more permissive sexual attitudes than non-fraternity men. Additional research is needed which explores the more specific association between fraternity/sorority membership with risky sex behavior while using alcohol.

$$
\text { Significance of the Study to Social Work }
$$

\section{Practice}

This study was designed to investigate individual psychosocial attributes which underlie alcohol use with risky sex. Central to the social work profession is prevention intervention. Interventions may be viewed as efforts to reduce the number of cases of a 
disorder or problem in a particular population or group. Thus construed, interventions can be considered prevention, and can be categorized into levels, primary, secondary, and tertiary (Skidmore, Thackeray, \& Farley, 1997). Primary prevention efforts are targeted to those who are not yet symptomatic. These efforts are intended to prevent incidence, promote health, and protect and enhance individuals. Secondary prevention efforts are targeted to either those who display precursors of dysfunction (i.e., identified attributes ), or those who show early symptoms of dysfunction. These efforts concentrate on early detection, elimination, and arrestment of the growth of the dysfunction. Tertiary prevention efforts are targeted to those who experience a limitation of behavior or express later signs of dysfunction. These efforts are aimed at rehabilitation or treatment, as these individuals are manifesting problem behavior such as alcohol misuse and high-risk sexual activities. Social work interventions have also been described on the functional basis of prevention, restoration, and remediation (Hepworth, Rooney \& Larsen, 1997). Restoration and remediation interventions are used when those targeted are manifesting problem symptomatology.

In the early stages of the AIDS epidemic social workers emerged as service providers, resource brokers, and as leaders and developers of prevention programs (Ryan, 1987). Social workers will continue to have frequent contact with populations that have an over-representation of HIV infection and AIDS (Reamer, 1993). The pressure and trend to decrease social program funding throughout our nation coupled with the rapid rise in AIDS cases in younger populations makes it vital to deliver effective HIV prevention programs. Effective prevention interventions must tap individual attributes of 
those at risk since approaches of increasing AIDS-related knowledge and improving general attitudes has not been shown to modify risky behavior.

This research sought to identify the relevance of five predictors of alcohol/risky sex including negative condom attitudes, general risk taking, drinking motives, mistrust, and social group participation among university students. The existing literature includes correlational evidence of alcohol use with risky sex at the general level. The implication is that alcohol has a direct effect upon risky sex behavior even though causation has not been shown. However, this direct effect can be questioned since the evidence is at the general level and results have been mixed. The information needed would be to determine whether the times when individuals were drinking were the same times when risky sex was performed, i.e., event analysis. There are some studies which incorporated event analysis, for which significant findings of alcohol/risky sex associations have not been found (e.g., Graves, 1995; Langer \& Tubman, in press; Tubman \& Langer, 1995). Graves examined only the most recent sexual event in the past year with a new partner. Langer and Tubman examined the general occurrence of risky sexual behaviors under four events in a high-risk sample of adolescents in substance abuse treatment. These events included three alcohol-use contexts (only when drinking, only when not drinking, and whether drinking or not), and whether the individual engaged in the risky sex behavior at all. Tubman and Langer used event analysis to examine risky sex behavior occurring specifically across two alcohol-use contexts of alcohol use or no alcohol use. The study reported on the results from a sample of adolescents in substance abuse treatment. As pointed out by Leigh and Stall (1993) information about the specific event which is limited to the co-occurrence of 
alcohol/sex does not provide knowledge of other potential individual factors which may mediate engaging in risky sex. Leigh and Stall call for additional research based on event analysis which examines individual factors comparing risky sex events under substance using conditions to non-substance using conditions. This study addressed this knowledge gap and sought to increase the knowledge base by determining the individual factors mediating the general occurrence of risky sex behaviors under discrete alcohol use or nonalcohol use conditions in a university sample of young adults. This study was intended to expand the research of Graves by going beyond the most recent sexual event with a new partner to the general participation in risky sexual behaviors. This study sought to partially replicate the study of a high-risk adolescent sample reported by Langer and Tubman to a sample of university students.

The information obtained by this study can be helpful in designing HIV/AIDS prevention programs in schools and colleges, psycho-education interventions in treatment facilities and communities, and strategies for outreach programs. Results from this study will also be important in improving the efficacy of existing models used to design sex education interventions. Specifically, the potential for practice is to go beyond knowledge enhancement strategies to the identification of techniques that are aimed at the five predictor variables. For example, communication messages targeted for communities at a grassroots level might include strategies addressing mistrust issues. Community programs can have the power of formal and informal networks of influence for transmitting beneficial messages (Bandura, 1989). This power can be used to confront mistrust issues. Outreach programs might include considering the dimensions of negative 
condom attitudes and the identification of barriers to initiating condom use in conjunction with self-efficacy enhancement. The goal of which would be to empower individuals in the use of effective interpersonal appeals for condom use. Primary AIDS prevention campaigns might also portray risk cautiousness as a peer norm with respect to group influences upon individual behavior. Catania, Kegeles, and Coates (1990) found group influence over the labeling of behavior and the tendency toward health decisions. Primary and secondary prevention interventions, including sex education models, might explore the dimensions of drinking motives, and their connection to unsafe sex practices. Policy

The results of the study can also be important to social policy in many prevention areas including HIV/AIDS, sex education, and substance abuse. The national effort to combat the spread of HIV infection is through two sources, the CDCs Center for HIV/STD/TB Prevention, and the Ryan White Comprehensive AIDS Resources Emergency (CARE) Act. The CDCs current prevention efforts center on public service announcements promoting sexual abstinence and the correct use of condoms, combined with support to communities in AIDS prevention strategies (DHHS, 1996a).

The Ryan White CARE Act (P. L. 101-381) is the primary federal AIDS initiative and is divided into four titles. While all titles apply to those affected by HIV/AIDS, only Title III applies to prevention efforts. Title I allows for emergency relief to cities, Title II provides formula-based grants to communities, and Title IV creates access to clinical trials. Title III provides grants to public and private nonprofit agencies who provide primary health care services to persons with HIV/AIDS, and to at-risk populations 
including substance abusers. The prevention efforts include education, counseling, testing and treatment (DHHS, 1996b).

High-risk sexual behavior prevention policy initiatives fall under sex education, HIV/AIDS education, and adolescent pregnancy prevention programs. With respect to sex education, Yarber, (1992) reported that even though there are no federal requirements, 34 states have mandates for HIV/AIDS education in the public schools, and 17 states have specified sex education programs as part of school curricula. DHHS has numerous programs aimed at the problem of teen pregnancy. The primary focus stems from the Adolescent Family Life Act of 1981 which funds projects that provide abstinence-focused education to prevent pregnancy and HIV/STD infection (DHHS, 1996c).

With respect to the use of alcohol and other drugs, various agencies promote and fund prevention programs. Organized under SAMHSA is the Center for Substance Abuse Prevention (CSAP) and the Center for Substance Abuse Treatment (CSAT). The National Institute on Drug Abuse (NIDA), the National Institute on Alcohol Abuse and Alcoholism (NIAAA), and the National Institute of Mental Health (NIMH) are organized under the National Institutes of Health $(\mathrm{NIH})$. All of these institutions have funded alcohol and other drug prevention programs which target youth, families, adults, and communities. Many of the programs and grants are related to HIV/AIDS. Additional major substance abuse prevention legislation is the Safe and Drug-Free Schools and Communities Act (P. L. 99-570, as amended) (Saunders, 1995). This act has provided grants to state and local educational agencies to develop prevention, early intervention, referral, and educational programs. 
DHHS has established the Office of AIDS Research (OAR) to coordinate all NIH HIV/AIDS research. The NIH recently reported that the fiscal 1996 AIDS research budget is $\$ 1.4$ billion and released a blueprint for restructuring the NIH AIDS research. This blueprint included a directive that the OAR create a comprehensive prevention strategy which would include biomedical, behavioral, and social interventions (DHHS, 1996d). This blueprint is a step toward going beyond education and training in prevention efforts to include research-based psychosocial interventions.

All of these programs are primarily categorical programs which address specific problem behaviors. Each area has a separate legislative base with monies and regulations to go along with the programs. An alternative approach would be a comprehensive program implementation rather than the categorical funding which may cause inefficiencies and duplications of interventions. Results from this study can inform such integration of policy programs.

\section{$\underline{\text { Research }}$}

All professional bodies are to some degree accountable to their various publics. During this current period of social welfare program cutbacks, the social work profession is being called upon to provide increasing accountability (Ell, 1996; Videka-Sherman \& Viggiani, 1996). It is important to develop correlational knowledge which can serve as an increased knowledge base. Future program implementation can be the object of experimental research which has been guided by this and other research. This study has provided information about condom attitudes, general risk taking, drinking motives, mistrust, and social group participation as they relate to alcohol use with risky sex. The 
results of this study can be used as a basis for improving prevention interventions and therefore is important to social work research.

\section{Overview of the Study}

Chapter One introduces the purpose of the study, the problem, theoretical underpinnings, and the variables to be used in the study. Chapter One also discusses the significance of the proposed research to social work. Chapter Two provides a review of the literature of the theoretical conceptualizations and variables used in the study, and concludes with a presentation of the research hypotheses. Chapter Three discusses the research design and methodology. Chapter Four provides the results of the study.

Chapter Five includes a discussion of the results as well as the limitations of the study, and implications for future research. 


\section{Chapter II}

\section{Review of the Literature}

This chapter presents a review of relevant theoretical and research literature with respect to the co-occurrence of alcohol consumption and risky sexual behavior. The theoretical underpinnings of the study include alcohol disinhibition, self-efficacy, and social network theories. A conceptual framework for the study which supports using the predictor variables is informed by self-efficacy and social network theories as well as by relevant research findings. The link between alcohol and sexual behavior is explored followed by other variables included in this research. This chapter includes the implications of the literature review, and concludes with the explication of the research hypotheses for the study.

\section{Alcohol Disinhibition Theory}

Alcohol disinhibition theory attempts to explain the relationships found among alcohol use and high-risk sexual behavior by asserting that alcohol impairs perception and thought through a unique process. Crowe and George (1989) reviewed physiological and psychological literature and concluded that alcohol disinhibits psychologic sexual response at low amounts, and suppresses physiologic sexual response at high amounts of alcohol. They also contended that disinhibition is both a physiological process, i.e., cognitive impairment, as well as a psychological process involving expectancies, i.e., social learning. They described expectancies in two forms. The first is a self-excusing mechanism whereby the drinker blames the behavior on alcohol. The second is a social excusing in that the person expects that society will excuse the behavior because of alcohol. 
Steele and Josephs (1990) contended that the validation of any theory which attempts to explain concurrent behaviors with alcohol consumption is made difficult for two reasons. First, there are a great variety of behavioral effects of alcohol across people, suggesting that alcohol itself cannot be a sole direct cause. For example, alcohol can effect aggression in some and altruism in others, relieve anxiety in some, yet increase anxiety in others, and inflate ego in some and increase depression in others. Such variability leads one to suggest that there are individual differences. This leads to the second difficulty. Even though there are individual differences in alcohol reactivity, some effects of alcohol can be observed in all drinkers. In addition, these effects may occur only intermittently. One explanation of disinhibition theory termed alcohol myopia by Steele and Josephs attempts to address this puzzlement. The central tenets of this theory are that alcohol restricts attention to the most salient cues in the drinker's environment, and that this disinhibiting process is a general process influencing social behavior. In other words, alcohol interferes with a person's ability to attend simultaneously to sets of cues which are conflicting. Only the more salient stimuli are effectively processed freeing the person from more distant inhibitions and potential cue conflict. The authors showed that as the inhibition conflict increased in strength, the alcohol effect was to make social behavior more extreme by blocking a form of response conflict. If the person were sober, the extreme behavior would be inhibited by further access to other cues and meanings, a response conflict which is not accessible under intoxicated conditions.

George and Norris (1991) posited that a combination of alcohol expectancies and cue conflict may offer the best explanation for the association of risky sex and alcohol use. 
However, they also point out that alcohol expectancy research has over relied on data from men. In addition, they criticized the excuse-making explanation on the part of men because it assumes that men consider alcohol to be a viable excuse which may or may not be true.

Reinarman and Leigh (1987) reviewed the literature on disinhibition theory and concluded that disinhibition is not so much a physiological process as it is a socially constructed conception. They maintained that disinhibition theory remains unproven. They posited however, that if there are alcohol expectancies, then they are culturally rooted and therefore can be changed. They concluded that public health interventions can modify these expectancies; "if alcohol-induced sexual disinhibition is ... a socially constructed phenomenon, then it is possible to imagine it being socially deconstructed as well" (p. 451).

\section{Self-efficacy Theory}

Self-efficacy, the central component of social cognitive theory, represents one's beliefs about individual capabilities to pursue certain courses of action (Bandura, 1986). Bandura further explains that observed behaviors are often not optimal even though people possess requisite knowledge because self-referent thought mediates between knowledge and behavior. Converting AIDS-related knowledge into anti-infective behavior is difficult because self-protective behavior may conflict with previously held beliefs, motives, and interpersonal pressures. The self-efficacy model is a triadic reciprocal model which includes behaviors, cognitions, and environmental influences which interact as determinants of each other (Bandura). Self-efficacy is concerned with 
self-beliefs about personal control over motivation, behavior, and social environment (Bandura, 1992). The model operates by influencing behavior choices, amounts of effort exerted in performing behaviors, and degrees of persistence exhibited in confronting obstacles (Bandura, 1986).

Attitudes and motives are components of individual cognitions which influence self-efficacy. Positive and negative outcome expectancies along with self-efficacy determine behavior (Bandura, 1986). Condom attitudes and expected outcomes of condom use are therefore important influences on behavior. O'Leary, Goodhart, Jemmott, and Boccher-Lattimore (1992) have shown that college students practicing riskier sex reported more negative expected outcomes from condom use, and lower perceived self-efficacy to perform safe sex. Attitudes of mistrust may be fostered by selfinefficacy which occurs due to the existence of system barriers. An inability to influence events and conditions in one's environment can give rise to self-inefficacy, futility, and anxiety. Bandura distinguished between internal sources of futility which stem from a personal belief of performance deficits, and external sources which stem from a prejudiced, or maltreating social environment. The distinction is important from an intervention perspective. Internalized futility can be approached by attempts to improve perceived self-efficacy. Futility stemming from a lack of outcomes calls for changing the environment to allow people to receive the benefits from the capabilities they already possess. Bandura places motives within social cognitive theory by defining motives as symbolic representations of expected outcomes. In this way motives act as behavior inducements (Bandura). Drinking motives form a part of the expected outcomes from the 
anticipated behavior of alcohol use with sex and influence such behavior.

Self-regulatory capability lies within self-efficacy theory and can be demonstrated by choices made in environmental conditions (Bandura, 1986). Self-regulation and selfefficacy as components in the self system will in part determine the particular social groups chosen for participation, and the types of risk behaviors undertaken. In addition, selfefficacy influences how well one negotiates social situations, and how well one can resist pressures toward risky behavior. Studies have shown that high levels of negotiation selfefficacy have been associated with higher rates of condom use (Catania et al., 1989; Jemmott et al., 1992; Lo Conte, O'Leary, \& Labouvie, 1993). Negotiation and personal change occur within a network of social influences which can support or undermine efforts to reduce personal sexual risk. This is due in part because self-efficacy will also be judged by the actions of others within a social network who are regarded as peers (Bandura, 1989). The influential role of a social network as an environmental factor has important implications for interventions. Where particular social groups are found to be predictors of risky sexual behaviors, individual self-efficacy of the group's members can be positively modified through an intervention targeted at the specific social group.

\section{Social Network Theory}

Within the social learning paradigm, social networks can be viewed as a mediator of social support. Most social network research centers around positive influences, that is, influences of network patterns upon such things as improved functioning, health protective behaviors, and resource utilization (Cleary, 1987; Hirsch, 1979; Mitchell \& Trickett, 1980). The concept however can also be useful to examine dysfunctional impacts such as 
influences toward mixing alcohol with risky sexual behavior.

Hirsch (1979) defines social networks as the current set of others with whom one has significant social interactions. Social networks can be described in terms of their dimensions, types of support, and determinants (Mitchell \& Trickett, 1980). The dimensions of social networks include (a) intensity, (b) stability, (c) multiplicity, (d) reciprocity, (e) frequency, and (f) homogeneity. The intensity of the network is a measure of the strength of the relationship between an individual and the other members of the network (Brim, 1974). Stability implies that the relationships have lasted over time (Shulman, 1975). Multiplicity relates to the number of functions that the network provides, which can be expressed as unidimensional or multidimensional (Sokolovsky, Cohen, Berger, \& Geiger, 1978). Reciprocity refers to the degree which affective and concrete aid is given and received by a member of the group (Shulman). Frequency represents the number of times a person has contact with other members of the group (Mitchell \& Trickett), and homogeneity refers to the extent which network members share common attributes (Brim).

The types of support provided by networks include (a) emotional (Caplan, 1974); (b) task oriented (Caplan); (c) attachment (Weiss, 1974); (d) advice and feedback (Tolsdorf, 1976); and (e) identity (Walker, MacBride, \& Vachon, 1977). Determinants of social networks, that is, the factors which affect the dimensions and the types of supports include individual factors and environmental factors. Holohoan and Wilcox (1978) found that friendship formation patterns in university residences differed as a function of both dormitory type and social competence. This suggests that the influence power of a social 
network is the interaction of the environment and of the self-efficacy of the individual member.

While it might be difficult to translate comprehensive social network concepts into criteria for interventions, the theory of social networks provides a conceptual framework for research. Such research can inform interventions in terms of the specific types of social networks to be targeted as well as the intensity of such interventions. It is important to know the extent to which social group participation has influenced risky sexual behavior if at all.

\section{Alcohol and Sexual Behavior}

In a survey of young adults aged 18 to 30 years old $(n=974)$ Graves $(1995)$ found that those who drank five or more drinks per sitting were more likely to have had multiple sexual partners in the past year $(p<.0001)$. Similarly, Graves found that consistent condom use decreased as levels of alcohol increased among men $(p<.05)$, but no differences were found among women. When Graves examined the co-occurrence of drinking alcohol and having intercourse both men and women reported a positive relationship between the amount of alcohol consumed and having $\operatorname{sex}(p<.001)$. However, Graves failed to find a relationship between condom use at the most recent sexual event and the amount or frequency of consuming alcohol. In other words, there seems to be a relationship between alcohol consumption and engaging in intercourse and condom use at a general level, but not with condom use at an event-specific level. These results are not contradictory but suggest that the relationship between alcohol consumption and risky sex is a complex association involving other variables. 
Robertson and Plant (1988) surveyed 220 young adults from Endinburgh, U.K. and found that the ages of first alcohol use and first sexual intercourse were correlated ( $p$ $<.01)$. Further analysis indicated that only $13 \%$ of males who drank alcohol at the event of first intercourse used contraception, while $57 \%$ of those who did not drink used contraception $(\mathrm{p}<.001)$. Among the females who used alcohol at first intercourse $24 \%$ had used contraception, while $68 \%$ used contraception among those who did not drink ( $p$ $<.001)$. These data indicate a link between alcohol consumption and the co-occurrence of risky sex at least at the event of first intercourse.

In a 1990 statewide survey in Massachusetts, Strunin and Hingson (1992) reported on the co-occurrence of sexual intercourse and alcohol use among 16 to 19 year olds $(\mathrm{n}=$ $1,152)$. The survey indicated that $66 \%$ of the adolescents surveyed had sexual intercourse in the past year. In addition, $82 \%$ reported drinking alcohol. Strunin and Hingson found that $64 \%$ of the sexually active youths had consumed alcohol before sex. In addition, they found that $17 \%$ of sexually active adolescents were less likely to use condoms after drinking $(\mathrm{p}<.05)$.

Butcher, Manning and O'Neil (1991) surveyed university students $(n=185)$ to determine risky sexual behavior. The researchers found that among this group of 17 to 24 year olds the frequency of condom use during intercourse decreased as the subjects became more advanced students. Twenty-nine percent of the freshman reported always using condoms and $18 \%$ reported never using condoms. However, the data for seniors indicated that only $7 \%$ always use condoms and $34 \%$ never use condoms. The study did not link condom use and alcohol consumption directly. However, having intercourse 
because of intoxication was measured as a risk behavior. The researchers found that this risk also increased with age. The findings of $30 \%$ of 18 year olds who indicated never having intercourse because of intoxication dropped to $19 \%$ among those over 21 years old.

In a San Francisco household survey $(\mathrm{n}=844)$ Leigh $(1990)$ sought to determine the relationship of substance use to risky sex among both homosexuals and heterosexuals. Even though Leigh found a strong relationship between risky sexual behavior categories and having sex under the influence of alcohol $(\mathrm{p}<.001)$, this relationship disappeared when the total amount of sexual activity was controlled. Leigh performed regression analysis using raw risk scores instead of risk categories as an outcome. The predictor variables were frequency of sex, sex with drinking, and sex with a drinking partner. Frequency of sex was the strongest predictor $(p<.001)$. The next most important variable was partner drinking which produced opposite effects in heterosexual and homosexual men. For heterosexuals, partner drinking was positively related to risk ( $p$ $<.01)$, and negatively related for homosexual men $(p<.05)$. The author discussed the difficulty in describing the interrelationships between alcohol use and sexual activity which are not straightforward. These relationships are complex and may include spurious correlations and multicollinearity problems within regression equations. These reviewed studies underscore the need to determine the effects of other third variables which may influence the correlations between risky sex and alcohol use.

\section{Condom Attitudes}

Many studies have examined the effects of AIDS knowledge upon risk behavior 
and have failed to find a significant relationship between AIDS knowledge and risk reduction behavior (see, e.g., Di Clemente, 1991; Di Clemente, Forest, Mickler, \& Principal Site Investigators, 1990; Mickler, 1993; Pendergrast, DuRant \& Gailland, 1992; Skurnick, Johnson, Quinones, Foster \& Louria, 1991). Knowledge about AIDS transmission and even knowledge of risk reduction strategies is insufficient by itself to change behavior. It is necessary to investigate other variables beyond knowledge which might influence behavior change. A number of studies have examined the influence of attitudes upon AIDS prevention strategies. Kegeles, Adler, and Irwin (1989) found positive condom attitudes were associated with intentions to use condoms. Conversely, they found negative condom beliefs acted as a barrier to condom-use intentions. Since behavior may not follow intentions, it is also important to examine the relationship between condom attitudes and condom use. Hingson, et al. (1990) performed a random telephone survey of 16 to 19 year olds $(n=1,773)$ in Massachusetts. They found that negative condom attitude predicted a reduced level of reported condom use among the adolescents.

Cole and Slocumb (1995) surveyed male university students $(n=227)$. They investigated five predictor variables of safe sex practices which included condom attitudes, two measures of health locus of control (internal vs. chance), self-esteem, and perceived susceptibility of AIDS. The researchers found that attitude toward condoms was the most powerful predictor of safe sex practices $(\mathrm{p}<.01)$.

Norris and Ford (1994) examined condom beliefs among low income, urban, African American and Hispanic men and women ages 15 to 24 years $(n=1,042)$. The 
researchers evaluated for mean differences in the frequencies of condom use against strength of condom beliefs. The findings indicated that of the 23 condom beliefs surveyed, 16 were significantly related to frequency of condom use $(p<.03)$.

Sheer and Cline (1994) proposed a conceptual model to explain college student sexual behavior. Condom attitude was found to be a significant $(p<.05)$ intervening variable secondary to risk taking and sexual motives, and the strongest predictor of risky sexual behavior. The authors concluded that condom attitude represents an important variable since modified attitudes may potentially affect behavior among those who are risk takers and those with strong sexual motives.

With a sample of university fraternity men $(n=89)$, Mink, Mareth, Russell, and Young (1991) analyzed correlates of condom use. The chi-square results indicated that negative condom beliefs were associated with less frequent condom use $(p<.001)$. The belief that a partner would reject using a condom was also associated with less condom use $(\mathrm{p}<.008)$.

This review of the literature supports the relationship between condom attitudes and condom use. Since none of the studies were experimental, causality has not been established. It is possible that changes in attitudes follow changes in behavior. In fact this is one of the results found in cognitive dissonance theory (Festinger, 1957). However, in terms of behavior-change strategies, condom attitudes have been found in the literature to be predictors of condom use. From this perspective, research investigating psychosocial variables related to risky sex behavior and alcohol use should include condom attitudes in the model, and can aid in the development of behavior change strategies. 


\section{General Risk Taking}

The purpose of including general risk taking as a variable in the model is to address the issue of whether a personal characteristic of general risk taking is associated with higher incidence of risky sexual behavior. Describing the person who engages in unsafe sex as a risk taker could lead to prevention efforts focused on risk taking aspects of sexual behavior. However, such an assumption may prove to be invalid as it may be that risk taking is not a common personal characteristic of the person who engages in unsafe sex. Practicing unsafe sex is a risk-taking behavior, however, it does not necessarily follow that such a person manifests a risk-taking personality profile. It may be that such behavior is context dependent. For example, the decision not to use a condom could represent a desire to maximize sexual satisfaction, demonstrate trust in one's partner, or represent a desire to maintain the relationship with the other person (Edgar, Hammond and Freinorth, 1989; Weinstein, 1989). These motives may not be related to a generalized risk taking profile.

Conversely, risk taking may indeed represent a relevant psychosocial factor of the person engaging in high-risk sex. Arnett (1991) investigated risk-taking behaviors among college graduates which included frequent high-speed driving, driving under the influence of alcohol, and sex without contraception for unmarried persons. Arnett related these behaviors to their consequences and found that the experience of negative consequences did not deter these types of behaviors. These results seem to implicate risk taking as an individual factor explaining risky behavior. Gillis, Meyer-Baulburg, and Exner reported at the 1992 International Conference on AIDS that risk taking increased the explained 
variance in their model of risky sexual behavior (Sheer \& Cline, 1994). It is therefore important to consider the relevance of risk taking in any AIDS risk reduction model.

General risk taking was examined by White and Johnson (1988) as a predictor of adolescent risky sexual activity. The researchers hypothesized that teens who were sexually active would be higher risk takers than those not sexually active, and that among those who were sexually active, the risk takers would have higher exposure to pregnancy risk than non-risk takers. The findings were inconclusive as to the associations between sexual activity, risk taking, and pregnancy exposure among the adolescent participants. Windle (1994) investigated the link between substance use, risky behaviors and victimization from a sample $(n=11,400)$ of eighth and tenth grade students. Victimization was defined as having experienced in the last 12 months something being taken from oneself, being threatened, attacked, or being forced to have sex. Windle posited that victimization was relevant as it may have contributed to repetition cycles involving substance use and risky behaviors thereby increasing vulnerability to HIV. The result from the multiple regression analyses indicated that the most significant predictor of victimization was risky behavior. In addition, risky behavior was also significantly correlated with substance use. While Windle's research was aimed at the predictor variables for victimization, it did establish a link between risky behaviors and substance use.

Graves (1995) explored the relationship of alcohol use and risky sexual behavior with a predictor model that included: (a) general risk-taking, (b) alcohol consumption, (c) number of sex partners, (d) concern about getting AIDS, and (e) attitudes toward sex. 
The study surveyed 974 respondents from a representative sample of young adults aged 18 to 30 years living in the contiguous United States. The results indicated that heavy drinking was linked to sexual activity in women. However, no support was found to indicate that alcohol use with sex leads to unsafe sex practices. Furthermore, Graves failed to find a relationship between measured risk-taking and risky sexual behavior.

Sheer and Cline (1994) tested a model to explain the sexual behavior among college students $(n=315)$ which included sensation seeking and sexual motives as antecedents. Intervening variables included condom attitudes. The findings from LISREL procedures indicated that sensation seeking (which included risk taking behaviors) had a significant $(p<.05)$ indirect effect on unprotected sex and condom use through the intervening variable of condom attitude.

While the above review indicated inconsistent results, general risk taking remains a relevant variable. General risk taking behaviors may fulfill needs of autonomy, mastery, and intimacy (Irwin \& Millstein, 1986). Weinstein (1989) posited while risk probabilities for individuals are usually unobtainable, individuals prone to risk taking tend to show optimistic bias greater than that of their peers. Another explanation offered by Weinstein for the observed differences in risk behaviors is that the variation reflects degrees of risk sensitivity. What follows then is that those who are risk aversive may practice HIV antiinfective behaviors, while those who are risk tolerant might not.

\section{Drinking Motives}

The reasons why people drink alcohol before or during sex can be one of the most important parameters to examine with respect to the co-occurrence of substance use and 
risky sex. Even though the purposes of alcohol consumption as defined by the user may be only one of several factors which influence drinking, Cox and Klinger (1988) described drinking motives as the "final common pathway" (p. 168). Cox and Klinger proposed a model which assessed the motivational structure of the drinker. An understanding of the underlying incentives of the drinker will provide valuable insight into intervention strategies regarding different degrees of effectiveness across individuals.

\section{Motivational Dimensions}

Cox and Klinger (1988) posited that motivation to drink is imbedded in the emotional effect that is desired. They described two pathways in which affective change can be achieved by drinking, a direct pathway and an indirect. The direct pathway represents the mood-altering chemical effects produced by alcohol within the individual, whereas the indirect pathway brings about an affective change by modulating one's social environment and thereby altering affective states. In other words, the indirect pathway is the use of alcohol as a social variable, for example, to celebrate, to do what is customary, but also to impress others, and to fit in.

Cooper, Russell, Skinner and Windle (1992) tested a three-dimensional model of drinking motives which represents a construction of the direct and indirect pathways. The direct pathway can be conceptualized as a motive to obtain a positive reinforcement or to avoid a negative reinforcement. Positive direct motives are termed enhancement motives and represent attempts to increase positive emotions. Motives to avoid negative emotions directly are called coping motives. Indirect motives can be used to both increase positive affective states as well as decrease negative affective states and are termed social motives 
(Cooper et al.).

Cooper et al. (1992) used confirmatory factor analysis to validate the existence of three distinct dimensions of drinking motives. The sample was a stratified probability sample $(n=1,206)$ representing equal number of Whites and Blacks across three educational levels, with a mean age of 43 years. Cooper et al. also used multiple regression analyses to assess the degree to which enhancement, coping and social motives could predict alcohol and drug use. The researchers found that enhancement motives predicted frequent heavy drinking in terms of use, but were less predictive of alcohol abuse than coping motives. Coping motives were predictive of frequent drinking but not heavy use. In addition, coping motives were associated with alcohol abuse symptoms of impaired social functioning, pathological patterns of abuse, and tolerance/withdrawal of alcohol. Social motives were predictive of drinking in social contexts, that is, with samesex friends, mixed-sex friends, and at parties, but not of alcohol abuse. When other drug use was examined, the researchers found that social motives were not predictive of other drug use, however, coping motives predicted use of depressant drugs, and enhancement motives predicted use of stimulant drugs and marijuana.

Motive effects were examined across White and Black racial groups. Social motives which appeared to be more normative did not vary. Coping motives were strongly related to drug use and alcohol problems among Blacks, and enhancement motives were related to drug use and alcohol problems among Whites.

In more recent research Cooper (1994) tested a four-factor conceptual model of drinking motives with a probability sample of adolescents $(n=2,052)$. In this model the 
social motive factor was divided into a positive component and a negative component. The positive social motive was called social motive and represented the desire to increase positive affect through the indirect pathway of modulating the social environment. The negative indirect motive was called conformity motive and represented negative affect which is desired to be minimized.

Cooper's findings (Cooper et al., 1992; Cooper, 1994) support a conceptual drinking motive model that is two-dimensional: direct/internal and indirect/external. Internal motives of enhancement and coping more strongly predicted alcohol abuse than the external motives. Cooper's research supports the drinking motive theory and indicates that the motivation perspective should be included in research seeking to explain alcohol use and other behaviors such as risky sex.

\section{Mistrust}

Mistrust of the medical profession, the government, or HIV/AIDS institutions can thwart the efforts and diminish the effectiveness of HIV/AIDS education and riskreduction programs. Individuals who lack confidence in the promoters of good health will be less compliant with health behavior and will be more likely to put themselves at high risk.

\section{Historical Perspective}

Some minorities believe that mainstream institutions in society cannot be trusted to treat all groups equally. These beliefs have their roots in history and can represent entrenched mistrust. For example, within the context of HIV/AIDS some AfricanAmericans believe in the genocide theory. This theory asserts that the HIV virus is man- 
made by Whites in an attempt to eliminate Blacks. Supported by funding from the Centers for Disease Control (CDC), the Southern Christian Leadership Conference (SCLC) conducted a survey of 1,056 Black church members in five cities (Thomas \& Quinn, 1991). With respect to the belief that AIDS is a manmade virus, only $22 \%$ responded in the negative, with $34 \%$ holding this belief and $44 \%$ were unsure. The belief that AIDS is a form of genocide was held by $35 \%$ with another $30 \%$ being unsure. Only $21 \%$ of respondents believed that the government was telling the truth about AIDS with $44 \%$ believing that the government is lying and $35 \%$ were unsure. These results provide an example that these views are not extreme, but are widely-held attitudes of mistrust among Blacks.

Thomas and Quinn (1991) assert that the legacy of the Tuskegee Syphilis Study, for which they provide a summary, helped to lay the foundation for pervasive mistrust among African Americans. This study fully described by Jones (1981) in the book Bad Blood, was conducted by the Public Health Service (PHS). The study began in 1932 and continued for 40 years in which treatment for syphilis was intentionally withheld from Blacks who had syphilis. The PHS failed to inform the participants of their disease and lack of treatment in order to study the effects of untreated syphilis by following the subjects to death and autopsy (Jones). Knowledge of this study was only made available to the general public in 1972 when a former PHS researcher broke the story to a news reporter which finally forced an end to the study. U.S. Senate subcommittee hearings on the study resulted in new laws regarding human experimentation. There were never any criminal charges filed even though the experiment violated existing health laws (Jones). 
There are three issues from the study which are relevant to currently held attitudes of mistrust regarding HIV. First, the Tuskegee Syphilis Study which began in 1932 did not end until 1972. This protracted period and relative recent publicity seemed to fuel mistrust, adding to the plausibility that the government is not trustworthy today. Second, comparisons are easily made to HIV from syphilis since both are sexually transmitted diseases. Third, the bitterness engendered by the study has provided fertile ground for HIV-related mistrust. For example, Dalton (1989), strongly expressed the "deep-seated suspicion and mistrust many of us feel whenever whites express a sudden interest in our well-being" (p. 211). The etiology of mistrust has its basis in historical mistreatment and abuse of minorities.

Gamble (1993) claims that the Tuskegee Syphilis Study is not the only case in which Blacks have been exploited in the name of medicine asserting that there is an entire legacy of mistrust. Gamble describes medical theories which were used to justify choosing Africans for slaves, such as having thicker skin and being less susceptible to diseases. Similar medical theories led to medical experimentation on Blacks resulting in extreme agony and pain such as induced heat stroke and vesico-vaginal surgery without anesthesia (Gamble).

\section{Underutilization of Services}

Nickerson, Helms and Terrell (1994) considered racial mistrust as an explanation for African American underutilization of some mental health facilities. Nickerson et al. studied Black university students' mistrust of Whites and reported that higher levels of mistrust were associated with more negative attitudes of seeking counseling help from 
Whites. Using multiple regression, four predictor variables were used. These included the Cultural Mistrust Inventory (CMI) (Terrell \& Terrell, 1981) to measure racial mistrust. Other predictor variables included opinions about mentally ill persons in terms of authoritarianism, restrictiveness, and etiology. The researchers found that cultural mistrust was the most powerful and only significant predictor of help seeking attitudes.

In another study of university students, Thompson, Neville, Weathers, Poston and Atkinson (1990) performed exploratory research toward the development of a Racism Reaction Scale. They found that African-American students are more likely than EuroAmerican students to agree with racism reaction statements and that this response is highest among those who exhibit racial mistrust as measured by two sub-scales of the CMI. The implication of the research is that racism reaction, which may appear as paranoia, is normative among those who score high on racial mistrust. The authors discuss the need for college counselors and university officials to become more familiar with racism reaction, its causes, and its manifestations in order to distinguish racism reaction from paranoia or other forms of pathology. The Thompson et al. study provided additional evidence of a link between racial mistrust and underutilization of counseling services provided by Euro-Americans.

\section{$\underline{\text { Racial Mistrust and Deviance }}$}

Racial mistrust and racial awareness were examined by Biafora, Taylor, Warheit, Zimmerman, and Vega, (1993b) to determine differences between African Americans and Black students from other national and cultural backgrounds. As a measure of racial mistrust, the researchers used sub-scales from the CMI. Their findings indicated that 
almost $30 \%$ of Black adolescents expressed mistrust of Whites generally, and of White teachers.

In a related study, Taylor, Biafora and Warheit (1994) examined the relationship between racial mistrust and a disposition to deviance among Black adolescents. Taylor et al. hypothesized that there may be a process whereby racial mistrust may go beyond an adaptive coping mechanism as implied in normative racism reaction, and become maladaptive for some individuals. This process may foster a willingness to engage in deviant behavior. The researchers found that there was a significant positive correlation between racial mistrust as measured by sub-scales of the CMI and a willingness to violate social norms and laws. In addition, when parental education was controlled using multiple regression, the importance of racial mistrust in predicting disposition to deviance was not affected. These findings indicated that perceptions of racial mistrust are maintained by Black adolescents and that this mistrust is related to attitudes toward deviance.

The question remains, however, whether this research can support the link between mistrust and behavior. This question was addressed by Biafora et al. (1993a) in a related study which examined mistrust and deviant behaviors among Black adolescents. They examined to what extent racial mistrust can predict deviant behaviors. In addition to racial mistrust as measured by sub-scales of the $\mathrm{CMI}$, other predictor variables included in the analyses were socioeconomic status, peer influences, familial influences, family structure, family cohesion, and religiosity. Two separate multiple regression models were used, one for minor deviant behaviors and one for major deviant behaviors. These behaviors ranged from breaking and entering a home to starting a fight. The results 
indicated that mistrust was significantly correlated with deviant behaviors. In addition, multiple regression results indicated that mistrust was the most powerful predictor of both minor and major deviant behaviors.

These studies indicated that racial mistrust may be an important variable to consider in examining noncompliant behaviors of Black adolescents. Even though the research did not address the etiology of mistrust, results did establish that perceptions of mistrust were held by Black adolescents, and that this mistrust was a significant predictor of deviant attitudes and deviant behaviors. These studies focused on Black adolescent subjects and measured racial mistrust utilizing sub-scales of the CMI. The CMI is specifically designed to measure racial mistrust of Whites among Blacks (Terrell \& Terrell, 1981). However, mistrust is not necessarily racially specific and does not necessarily have a specific direction toward deviance.

\section{Multi-Ethnic Mistrust}

Government or institutional mistrust is not limited to African-Americans; Hispanic communities may hold pervasive mistrust as well. Casas (1995) asserted that feelings of suspiciousness arise as a result of past experiences of Hispanic communities with government agencies and researchers representing mainstream United States society. Many times government agencies have failed to provide relevant and sufficient services, or in the event of an existing program, a negative evaluation may have been given by nonHispanics, resulting in the program's demise (Casas). Negative experiences also include the gathering of information by social scientists who fail to fulfill their promises to the Hispanic community (Casas). In some cases mistrust may be encouraged when data 
gathering efforts require the disclosure of personal and intimate information (Casas).

The Hispanic population does not represent a single group in the United States, but many subgroups which vary by national origin, racial lineage, and socioeconomic class (Padilla \& Salgado de Snyder, 1995). Even though these groups share the Spanish language and a family orientation, the cultures and histories differ. Institutional and government mistrust among Mexican-Americans is better understood within the framework of their history. As a result of the 1848 Treaty which ended the MexicanAmerican War, Mexican citizens were allowed to remain in the Southwest and become U. S. citizens. However, no provisions were made to integrate these new MexicanAmericans into society (McWilliams, 1990). According to McWilliams, they were denied access to mainstream institutions such as education, housing and employment, lost their land through land schemes, and were coerced into agricultural labor. It is this experience of termination with the parent country and subsequent cultural subordination against the will of indigenous people which sets the historical framework for the growth of mistrust for Mexican-Americans (Alvarez, 1985).

In order to examine parental mistrust toward AIDS among different ethnic groups, Dusenberg et al. (1994) conducted a multiethnic random telephone survey of Caucasian, African-American and Latino parents of school-age children. The researchers controlled for the effect of the respondents' level of education. The results indicated that AfricanAmericans (29\%) and Latinos (24\%) were more likely than Caucasians (9\%) to believe that AIDS was deliberately created to eliminate undesirable groups of people. The odds ratio (using Caucasian as the control group) for holding this belief was 4.16 and 3.41 for 
African Americans and Latinos, respectively. With respect to two questions of government or institutions withholding information about AIDS, $60 \%$ and $63 \%$ of African-Americans and $59 \%$ and $51 \%$ of Latinos believed that the medical community and the government respectively, were not disclosing all known information as compared to $38 \%$ of Caucasians who believed this. A related question was whether one believed that drug companies are withholding the cure for AIDS until the situation is more profitable. Twenty-eight percent of African-Americans, $30 \%$ of Latinos, and $23 \%$ of Caucasians agreed.

This study showed high levels of mistrust not only within the African-American community, but also within the Latino and Caucasian communities as well. Strong suspicions of the government and medical community were expressed. While only $9 \%$ of Caucasians believed in the AIDS genocide conjecture, $38 \%$ believed that more is known about AIDS than is being disclosed, and $23 \%$ of Caucasians surveyed believed that a cure is available, but is being withheld!

\section{Social Group Participation}

Social group participation, that is, membership or participation in fraternities, sororities, clubs, or other organizations, can be viewed as a type of social network. Within the social learning paradigm, social networks can be potential sources of influence upon drinking and sexual behavior. The college student literature regarding the relationships between fraternity, sorority, or organization membership, sexual behavior, and alcohol use reveals research concentrated on aggression, and sexual abuse (Boeringer, Shehan \& Akers, 1991; Frinter \& Rubinson, 1993; Koss \& Gaines, 1993; Stombler, 
1994). However, there are some studies which have investigated the relationships between social group participation and condom attitudes or nonaggressive risky sexual behavior within the theory of social networks. These studies support the further investigation of a model of social group participation as an antecedent variable to alcohol use and sexual behavior (Treboux \& Busch-Rossnagel, 1990; Wechsler et al., 1995; Whitbeck \& Hoyt, 1991).

In an attempt to construct a causal model of social network influence, Treboux and Busch-Rossnagel (1990) investigated antecedents to sexual behavior and contraceptive use among high school students $(n=361)$. They conceptualized social network influence as having four elements: (a) discussion with parents, (b) parental approval, (c) discussion with friends, and (d) approval of friends. The context of the discussions and approvals regarding sexual behaviors were relative to the different levels of commitment in relationships.

The findings of the study indicated that a significant source of sexual behavior influence is a social network. However, with respect to contraceptive use, the findings were inconclusive. While this research was based upon data from adolescents, it may well be that social network influences remain an important predictor variable for late adolescents and young adults of sexual behavior and of condom attitudes.

Wechsler, et al. (1995) investigated the correlates of college student binge drinking $(n=17,592)$. These correlates included variables of interest to the present research, namely status in school which included fraternity residence, risky behaviors which included multiple sex partners within a month, and hours per day spent in specified activities which 
included participation in student organizations. The logistic regression provided the odds ratios that a binge drinker was associated with the correlates as compared to a person who was not a binge drinker.

Results indicated that those students who had two or more sex partners within a month were 1.66 times more likely to binge drink than those having fewer than two sex partners in a month. Students who lived at a fraternity/sorority residence were 4.08 times more likely to be a binge drinker than those living in other residences. However, the binge drinking odds ratio was not significant for those who did not participate in student organizations as compared to those students who did. The study confirmed the indirect relationship of sex behavior to fraternity membership through binge drinking, and therefore supports the inclusion of fraternity and sorority memberships in a risky sexual behavior model.

Whitbeck and Hoyt (1991) investigated the types of college students' residence as it relates to various dating variables. These variables included alcohol use on dates, dating frequency, attitudes of premarital sexual permissiveness and other related variables. Using a telephone sample of 394 students from a large university, the sample included dormitory residents, fraternity/sorority residents, and off-campus residents.

The results indicated that those who lived in dormitories and off-campus housing were twice as likely than those who lived in fraternity/sorority residences to be not dating. Fraternity and off-campus male residents were twice as likely than dormitory male residences to report that they always used alcohol on dates. For females, sorority residents were almost $50 \%$ more likely than off-campus residents, and more than twice as 
likely as dormitory residents to report always using alcohol on dates. With respect to the highest levels of sexual permissiveness, fraternity men were approximately $50 \%$ more likely than either dormitory or off-campus residents to hold this attitude. However, for women, off-campus residents were twice as likely than either dormitory or sorority residents to hold the highest sexual permissiveness attitude. While the research of Whitbeck and Hoyt (1991) is limited by the conclusions which can be drawn from chisquare analysis, it does indicate the importance of including fraternity/sorority membership in a model of college student sexual and drinking behaviors.

\section{Implications of the Literature Review}

The purpose of this study was to test the relative influence of the five psychosocial variables of (a) negative condom attitudes, (b) general risk taking, (c) drinking motives, (d) mistrust, and (e) social group participation upon the co-occurrence of alcohol use and risky sex among university students. Conclusions drawn from the theoretical and empirical literature reviewed support the research model. There is ample evidence that alcohol use is associated with less condom usage at the general level. However, this implied direct influence has been criticized. An alternative explanation is that alcohol has an indirect effect upon HIV risk behaviors through other psychosocial processes. In addition, most studies have not utilized event analysis to determine whether risky sex occurred during the same event in which alcohol was consumed. There is a paucity of data which indicated a psychosocial profile upon which alcohol may interact, resulting in risky sexual behaviors at the event level. The importance of establishing a more precise profile of variables which lead to higher susceptibility to engage in risky sex and exposure to HIV 
infection has been expressed in the literature. Donaldson et al. (1996) concluded prevention science will be improved if researchers continue to identify unique and interaction effects. It is the identification of such interactions and effects across multiple populations which will lead to more successful interventions. In the absence of an AIDS vaccine or cure, primary prevention is critical. Effective prevention programs necessitate knowing the activities, the factors, and the subgroups of those who are at risk.

\section{Research Hypotheses}

This study was concerned with whether and how (a) negative condom attitudes, (b) general risk taking, (c) drinking motives, (d) mistrust, and (e) fraternity/sorority membership are related to risky sex with alcohol. The following six research hypotheses were posited for testing in this study.

\section{Hypothesis 1}

I hypothesized that individuals from a university student sample are more likely to engage in risky sex behaviors only when drinking, than only when not drinking or when drinking or not.

\section{Hypothesis 2}

I hypothesized that individuals from a university student sample who engage in sex without a condom only when drinking, compared to those who engage in sex without a condom only when not drinking or whether drinking or not, and to those who do not engage in sex without a condom, will have (a) stronger negative condom attitudes, (b) greater general risk taking, (c) stronger drinking motives, (d) stronger beliefs of mistrust, and (e) fraternity/sorority membership. 


\section{Hypothesis 3}

I hypothesized that individuals from a university student sample who engage in sex with people not known very well only when drinking, compared to those who engage in sex with people not known very well only when not drinking or whether drinking or not, and to those who do not engage in sex with people not known very well, will have (a) stronger negative condom attitudes, (b) greater general risk taking, (c) stronger drinking motives, (d) stronger beliefs of mistrust, and (e) fraternity/sorority membership.

\section{Hypothesis 4}

I hypothesized that individuals from a university student sample who engage in sex with injecting drug users (IDUs) only when drinking, compared to those who engage in sex with injecting drug users (IDUs) only when not drinking or whether drinking or not, and to those who do not engage in sex with injecting drug users (IDUs), will have (a) stronger negative condom attitudes, (b) greater general risk taking, (c) stronger drinking motives, (d) stronger beliefs of mistrust, and (e) fraternity/sorority membership.

\section{Hypothesis 5}

I hypothesized that individuals from a university student sample who engage in sex with people without knowing whether they had a STD only when drinking, compared to those who engage in sex with people without knowing whether they had a STD only when not drinking or whether drinking or not, and to those who do not engage in sex with people without knowing whether they had a STD, will have (a) stronger negative condom attitudes, (b) greater general risk taking, (c) stronger drinking motives, (d) stronger beliefs of mistrust, and (e) fraternity/sorority membership. 
Hypothesis 6

I hypothesized that individuals from a university student sample who engage in sex with using drugs only when drinking, compared to those who engage in sex with using drugs only when not drinking or whether drinking or not, and to those who do not engage in sex with using drugs, will have (a) stronger negative condom attitudes, (b) greater general risk taking, (c) stronger drinking motives, (d) stronger beliefs of mistrust, and (e) fraternity/sorority membership. 


\section{Chapter III}

\section{Methodology}

Chapter III elucidates the methodology used in this survey study. The chapter includes a discussion of the research design, subjects, data collection, instrumentation, and data analysis.

\section{Research Design}

This research was a cross-sectional, retrospective, survey design. Survey research represents the primary means of obtaining social science data ( Rubin \& Babbie, 1997). Cross-sectional designs, being non-experimental, do not establish the casual relationships among the variables. However, correlational relationships can be examined from such data (Rubin \& Babbie). The survey design accumulated retrospective data, and therefore contained an inherent reliability weakness, that is, the memory recall of the subjects. However, this method is widely used in the research of co-occurring alcohol use and sexual behavior (Senf \& Price, 1994; Strunin \& Hingson, 1992). The instrumentation section further discusses issues of reliability and validity of the survey instrument.

\section{Subjects}

The source of the subjects was a purposive sample. Non-probability samples are commonly used when there are no lists of individuals with the desired attributes from which a random sample can be drawn (Rubin \& Babbie, 1997). Subjects for the study were recruited from undergraduate students attending Florida International University (FIU) from October 1995 through April 1996. The use of college students in alcohol and sexual behavioral research is typical (see, e.g., Butcher et al., 1991; Cole \& Slocumb, 
1995; Wechsler et al., 1995). Students were sought from both the University Park and the North Miami campuses to maximize the diversity of the sample. Classes chosen for participation represented a variety of disciplines.

The study included only those subjects who answered positively to the survey screening question "In the past 6 months, have you ever had sex after you had been drinking alcohol?" (See Appendix). Participation in the study was voluntary, and all participants were instructed to complete the survey instrument regardless of the answer to the above qualifying question. This procedure was used in order to avoid a response bias and to maintain privacy and confidentiality. Since only a proportion of those agreeing to participate qualified, the total number of instruments completed was larger than the study sample. There were 599 instruments administered, and 574 were completed which represented a response rate of $96 \%$. Of the total completed surveys, the qualified sample consisted of 222 subjects.

Power functions were calculated in order to determine the statistical power of the proposed analyses. Statistical power is defined as the ability or probability that a statistical test will yield significant results when the null hypothesis is false (Cohen, 1988). Power is dependent on the three elements of significance level, sample size, and effect size (ES), and represents the probability of correctly rejecting the null hypothesis. In order to test the association of risky sex behaviors to the three alcohol-use categories, a chi-square test was used. A power analysis for a chi-square test with two degrees of freedom, a medium ES (.30), a significance level of .05 , and a sample size of 222 yields a power of .98 (Cohen). This means that the probability of correctly rejecting the null hypothesis is .98 
and the probability of incorrectly accepting a false null hypothesis is .02 . In order to determine the classification into three alcohol-use and non-use categories with respect to the collection of nine predictor variables, discriminant analysis was used. Discriminant analysis is a method of multivariate analysis, and therefore a power analysis based on multiple regression was performed. Based on a medium ES (.30), a significance of .05 , a sample of 222 subjects, and nine independent variables, a power of .99 was determined (Cohen).

\section{Data Collection}

This research was part of a larger study which was supported in part by a NIAAA grant to Lilly M. Langer, M.P.H., Ph.D., Principal Investigator (PI) and Associate Professor of Sociology at FIU. An application for approval of research involving human subjects was completed by the PI and approved by the University Research Council (URC) of FIU. Various class instructors were contacted by the PI, faculty research colleagues of the PI, and the author, and were informed of the research. When instructors agreed to participate, the survey instrument was administered in their classes. First, students were informed that participation was voluntary and anonymous, and that participation was not part of their course requirement. They were also informed of the importance of the research. Informed consents and survey instruments were distributed to all students, at which time those who participated completed the forms. The informed consents were collected separately. The survey took approximately 1 hour to complete. Since the survey instrument was pre-coded, the data were entered directly into the computer. When the direct data entry method is used, it is important to edit all survey 
documents prior to data entry (Rubin \& Babbie, 1997). Document editing was performed on all surveys by the grant research assistant prior to computer processing. This procedure included reading the survey questions to insure that all questions had been answered or that proper missing data codes were recorded. This procedure was used to decrease the possibility of data entry errors. Edited surveys were then given to a professional data processing company for data entry. After all data were entered in the computer, the next step was cleaning the data, which is an essential procedure in order to verify that data coding has been done properly (Neuman, 1997). All survey data were cleaned by the grant research assistant and student volunteers. This process included verifying the coding of the computer output back to the original survey instrument for $100 \%$ of the sample.

\section{Instrumentation}

The survey instrument included many questions beyond the scope of this study since the instrument was designed for more comprehensive research objectives. The total number of questions included in the instrument numbered 187 and covered 36 pages (See Appendix). Information relevant to this study included basic demographic data and the variables of interest. Basic demographic data included age, sex, marital status, education, and racial/ethnic group identification.

\section{Measured Variables}

Risky sexual behaviors. Risky sexual behaviors were measured by the responses to five items which inquired whether the listed behaviors had been done by the respondent. The five items were (a) sex without a condom, (b) sex with people not known very well, 
(c) sex with injecting drug users (IDUs), (d) sex with people without knowing whether they had a STD, and (e) sex with using drugs. Responses were categorical and asked the participant if the behaviors occurred (a) only when drinking, (b) only when not drinking, (c) when drinking or not, or (d) not at all.

Negative condom attitudes. Condom attitudes were measured by these five items: (a) telling your partner you want to use a condom suggests that one of you has been unfaithful, (b) telling your partner you want to use a condom suggests that one of you has a STD, (c) having to stop sex to put on a condom takes the fun out of sex, (d) as a result of suggesting to use a condom your partner may not want to have sex with you again, and (e) as a result of suggesting to use a condom your partner might get angry and hurt you. Responses were measured on a four-point scale from very true (1), to not true at all (4).

General risk taking. The propensity toward general risk taking was measured by the responses to five items which inquired how much the respondent would like to engage in the behavior. These five items included (a) parachute jumping, (b) driving or riding on a motorcycle, (c) being a race car driver, (d) riding in a car with a person who likes to speed, and (e) flying or riding in a helicopter. The item had a four-point response from a lot (1), to not at all (4).

Drinking motives. Motives for drinking alcohol before or during sex were measured by 18 items in three domains: enhancement, coping, and social motives. Responses were measured on a four-point scale from very true (1), to not true at all (4), and asked participants how true each statement was in describing reasons why they drank alcohol before or during sex. For example, An enhancement motive statement was "to get 
relaxed/feel good;" a coping motive statement was "to be able to have sex with someone you really don't care for very much;" a social motive statement was "to drink with your partner."

Mistrust. Mistrust was measured by one item which asked the respondents how true they thought it was that an AIDS vaccine had been approved but the government had not distributed it to the general public. Responses were measured on a four-point scale from very true (1), to not true at all (4).

Social group participation. Social group participation was measured by two items. The first was divided into three response categories and asked whether the participant was in a fraternity or sorority. Response categories were (a) yes to a fraternity, (b) yes to a sorority, and (c) no to a fraternity or a sorority. The second item asked if the respondents participated in any clubs/organizations which were not considered fraternities or sororities with a yes or no response.

\section{Validity and Reliability}

The mainstays of measurements of alcohol use and sexual behaviors are self-report methods ( Blumstein et al., 1990; Catania, Gibson, Chitwood \& Coates, 1990). The issues of validity and reliability of self-report measures of sensitive behaviors are widely discussed in the literature (Leigh \& Stall, 1993; Weatherby et al., 1994; Wish \& Mieczkowski, 1994). Validity of self-reports of sensitive behaviors can be assessed by correlation to criteria such as urinalysis, blood tests, or arrest records in certain types of research. However, most sex behavior survey research is based on data with unknown validity (Catania et al.; Leigh \& Stall). Sex behavior research obviously presents difficulty 
for establishing criterion validity. It is not feasible to either observe or test subjects for the occurrence of risky sex behavior.

Two crucial issues concerning self-report surveys are those of social desirability and privacy. The social desirability theory as described by Harrell (1985) posited that the more highly stigmatized and negatively sanctioned a behavior, the stronger the tendency to deny having engaged in it. In other words, either under-reporting or over-reporting will occur as a function of the perceived acceptability of the correct response. Privacy can also affect the validity of self-reports of sensitive behaviors. Gfroerer (1985) studied the influence of privacy on self-reported drug use by adolescents and found that the degree of privacy affected the validity of the data. Self-report methods also obtain retrospective data, and are therefore subject to recall error. Bailey, Flewelling, and Rachal (1992) examined self-reports of alcohol and drug use among adolescents in a longitudinal study. Based on the total sample which exceeded 5,500 participants, consistency rates over time were $83 \%$ and $96 \%$ for alcohol and marijuana use, respectively. However, these rates dropped to $75 \%$ and $83 \%$, respectively, when based on self-reported users only.

The alcohol use consistency rates both for the total sample and for users-only was lower than for marijuana. Bailey et al. (1992) asserted that these results support the "deviant" substances hypothesis which states that the more deviant a substance, the more easily it is remembered. Alcohol is the most widely used drug among high school students and used legally for those over 21 years of age. Therefore, alcohol is considered less deviant than marijuana. This theory implies that more deviant or risky behaviors will be less susceptible to recall error. 
In their discussion of validity, Johnson and O'Malley (1985), authors of the national student survey on drug use since 1975, stated that adoption of a set of four procedures is essential to achieve high validity in self reports. These procedures include (a) communicating legitimate reasons for the research, (b) providing suitable privacy, (c) protection of confidentiality, and (d) convincing respondents that the researchers can be trusted. While retrospective, self-report data have the inherent limitations discussed, the recommended procedures have been addressed in this study as described in this chapter.

A method of assessing the validity of self-report data is the use of an honest report question at the end of the instrument. Zimmerman and Langer (1995) found moderate levels of reliability $(\underline{\mathrm{r}}=.45, \underline{\mathrm{p}}<.001)$ in an honesty measure over time utilizing a sample of high school students $(n=1,886)$. The authors concluded that the honesty question may have been more useful in assessing the validity of over-reporting and suggested that the honesty report be combined with other techniques to increase accuracy of sensitive selfreported behaviors. Tubman and Langer (1995) reported using participant honesty in a study of sexual behavior and alcohol use among high-risk adolescents and young adults. The authors found that $95 \%$ of the participants reported being either completely or very honest in the survey answers. The instrument used in this study employs the same honesty self-report technique. The final question asked the respondents if there were any questions that made them so uncomfortable that they were unable to answer honestly. The item had a five-point response from all (1) to none of the questions (5). The wording of this item is aimed at separating the instrument from the person, allowing the participant to blame a dishonest answer on the survey. By reasoning that the survey question caused 
the discomfort which led to a dishonest answer, the participant may be more likely to answer the honesty question honestly. Results indicated that $93.2 \%$ of the respondents stated that they answered all or almost all of the questions honestly.

\section{Data Analysis}

All data was processed using the computer program SPSS 7.0 for Windows. The data were analyzed to determine the descriptive statistics of the sample and the inferential statistics used to test the research hypotheses. Prior to data analysis, all measured variable scales were tested for internal consistency using Cronbach's Alpha.

\section{Hypothesis 1}

I hypothesized that individuals from a university student sample are more likely to engage in risky sex behaviors only when drinking, than only when not drinking or when drinking or not. The chi-square test was used to test the observed frequencies of each of five risky sex behaviors, (a) sex without a condom, (b) sex with people not known very well, (c) sex with injecting drug users (IDUs), (d) sex with people without knowing whether they had a STD, and (e) sex with using drugs. Chi-square is the appropriate test to examine the association between two categorical variables (SPSS, Inc., 1996; Weinbach \& Grinnell, 1995).

\section{Hypothesis 2}

I hypothesized that individuals from a university student sample who engage in sex without a condom only when drinking, compared to those who engage in sex without a condom only when not drinking or whether drinking or not, and to those who do not engage in sex without a condom, will have (a) stronger negative condom attitudes, (b) 
greater general risk taking, (c) stronger drinking motives, (d) stronger beliefs of mistrust, and (e) fraternity/sorority membership.

\section{Hypothesis 3}

I hypothesized that individuals from a university student sample who engage in sex with people not known very well only when drinking, compared to those who engage in sex with people not known very well only when not drinking or whether drinking or not, and to those who do not engage in sex with people not known very well, will have (a) stronger negative condom attitudes, (b) greater general risk taking, (c) stronger drinking motives, (d) stronger beliefs of mistrust, and (e) fraternity/sorority membership. Hypothesis 4

I hypothesized that individuals from a university student sample who engage in sex with injecting drug users (IDUs) only when drinking, compared to those who engage in sex with injecting drug users (IDUs) only when not drinking or whether drinking or not, and to those who do not engage in sex with injecting drug users (IDUs), will have (a) stronger negative condom attitudes, (b) greater general risk taking, (c) stronger drinking motives, (d) stronger beliefs of mistrust, and (e) fraternity/sorority membership.

\section{Hypothesis 5}

I hypothesized that individuals from a university student sample who engage in sex with people without knowing whether they had a STD only when drinking, compared to those who engage in sex with people without knowing whether they had a STD only when not drinking or whether drinking or not, and to those who do not engage in sex with people without knowing whether they had a STD, will have (a) stronger negative 
condom attitudes, (b) greater general risk taking, (c) stronger drinking motives, (d) stronger beliefs of mistrust, and (e) fraternity/sorority membership.

\section{Hypothesis 6}

I hypothesized that individuals from a university student sample who engage in sex with using drugs only when drinking, compared to those who engage in sex with using drugs only when not drinking or whether drinking or not, and to those who do not engage in sex with using drugs, will have (a) stronger negative condom attitudes, (b) greater general risk taking, (c) stronger drinking motives, (d) stronger beliefs of mistrust, and (e) fraternity/sorority membership.

The analysis, utilized four separate dimensions of drinking motives of selfenhancement, partner-enhancement, coping, and social motives. In addition, gender was added as an independent variable after the sample was analyzed for differences between the female and male groups on the dependent variables. Therefore, a total of nine predictor variables were used. The statistical method used was discriminant analysis. This is the appropriate technique to use when, based on a collection of variables, classification into mutually exclusive categories is desired ( Norusis \& SPSS Inc., 1994; Klecka, 1980). The dependent variable was represented by the five risky sex behaviors and therefore five separate analyses were performed. 


\section{Chapter IV}

\section{Results}

The results of the study are presented in Chapter IV. Demographic data for the sample are presented first. This is followed by a discussion of the independent variables and encompasses the development of the scales used in the study. Included are descriptive statistics of the items and tests of scale reliability using Cronbach's Alpha $(\alpha)$. A summary discussion of all independent variables follows including t-tests for mean differences between the female and male groups of the sample, and a bivariate correlation matrix. Dependent variables are then discussed. The chapter concludes with the results of the analyses performed for hypotheses testing.

\section{Subjects}

Of the 222 subjects, the ages ranged from 18 to 54 years, with a mean age of 23.4 years $(\mathrm{SD}=5.44)$. Additional demographic characteristics of the sample are presented in Table 1 . Women represented $75.2 \%$ of the sample. Currently married respondents represented only $9.5 \%(n=21)$ of the sample. Of those, women represented $81 \%$. The remaining respondents indicated that they were never married $(84.5 \%)$, or were divorced, separated, or widowed $(6 \%)$. Of these, women represented $74 \%$. In terms of highest education levels achieved, the majority of the subjects indicated that their highest level was some college $(\mathrm{n}=153,69.2 \%)$, while the remainder was almost equally split between those who had obtained a bachelor's degree (16.3\%), and those who had completed high school or received a GED (14.5\%). Of those who had some college and a bachelor's degree, women represented $78 \%$ and $75 \%$ respectively. Women represented $62 \%$ of the 
Table 1

Demographic Characteristics of the Sample

Characteristic

Female (\%)

Male (\%)

Total (\%)

Sex

Female

167

(75.2)

Male

55

Marital Status

Never Married

$137 \quad(62.0)$

$50 \quad(22.5)$

$187 \quad(84.5)$

Married

$17(7.7)$

$4 \quad(1.8)$

$21 \quad(9.5)$

Divorced

$10(4.5)$

$1 \quad(.5)$

$11 \quad(5.0)$

Separated/Widowed

$2(1.0)$

$0 \quad(.0)$

$2(1.0)$

Highest Education Level

Some College

$119 \quad(53.8)$

$34 \quad(15.4)$

$153 \quad(69.2)$

Bachelor Degree

$27 \quad(12.2)$

$9 \quad(4.1)$

$36 \quad(16.3)$

High School/GED

$20 \quad(9.0)$

$12 \quad(5.4)$

$32 \quad(14.5)$

\section{Race/Ethnicity}

Hispanic

$96 \quad(53.8)$

$34(15.4)$

$137 \quad(62.0)$

White

$51(23.1)$

$9 \quad(4.1)$

$60 \quad(27.1)$

Black/African American

$10 \quad(4.5)$

$2(.9)$

$12 \quad(5.4)$

Other

$4 \quad(1.8)$

$1(.5)$

$5 \quad(2.3)$

Asian/Pacific Islander

2 (.9)

2 (.9)

$4 \quad(1.8)$

Haitian

3 (1.4)

$0 \quad(.0)$

3 (1.4) 
high school/GED group. The racial/ethnic composition of the sample was primarily Hispanic $(n=137,62.0 \%)$, and White non-Hispanic $(n=60,27.1 \%)$. Of the Hispanic and White non-Hispanic groups, women represented $70 \%$ and $85 \%$, respectively. Black/African Americans represented 5.4\% $(n=12)$ of the sample, which included 10 women. The remainder of the sample was represented by Asian/Pacific Islander, Haitian, and Other $(n=12,5.5 \%)$, and these included 9 women.

\section{Independent Variables}

As a measure of reliability of the scales included in the study, the author obtained the reliability coefficient Cronbach's Alpha $(\alpha)$ for each scale. These scales included negative condom attitudes, general risk taking, self-enhancement drinking motives, partner-enhancement drinking motives, and coping drinking motives.

\section{$\underline{\text { Negative Condom Attitudes }}$}

Respondents' attitudes toward the use of condoms were measured by five items:

(a) Unfaithful: "if you tell your partner you want to use a condom, it suggests that one of you has been unfaithful," (b) Has STD: "if you tell your partner you want to use a condom, it suggests that one of you has a sexually transmitted disease," (c) No Fun: "having to stop sex to put on a condom takes the fun out of sex," (d) Rejection: "if you suggest using a condom your partner may not want to have sex with you again," and (e) Hurt: "if you suggest using a condom, your partner might get angry and hurt you." Responses were measured on a four-point scale from very true (1), to not true at all (4). Shown on Table 2 are the descriptive statistics of the items. Four of the five means were above 3.5 which indicated that respondents did not strongly agree with negative beliefs. 
Table 2

\section{Condom Attitudes Descriptive Statistics}

\begin{tabular}{lccc} 
Item & $\mathbf{n}$ & Mean & SD \\
Unfaithful & 213 & 3.57 & .73 \\
Has STD & 211 & 3.69 & .63 \\
No Fun & 213 & 2.92 & .96 \\
Rejection & 212 & 3.73 & .60 \\
Hurt & 212 & 3.81 & .53 \\
\hline
\end{tabular}

Note. Item responses ranged from 1 to 4 , and lower scores indicated stronger negative condom attitudes. 
Cronbach's $\alpha$ for the scale was .67. Carmines and Zeller (1979) opined that the minimum $\alpha$ should be .80 for widely used instruments, however, Nunnally (1978) viewed .70 adequate for predictor tests used in the early stages of research. The author decided to use the scale with the study sample even though its use adds to the limitations of the study.

\section{General Risk Taking}

The propensity toward general risk taking was measured by the responses to five items which inquired how much the respondent would like to engage in the behavior.

These five items included (a) Parachute: "parachute jumping," (b) Motorcycle: "driving or riding on a motorcycle," (c) Race Car: "being a race car driver," (d) Speed: "riding in a car with a person who likes to speed," and (e) Helicopter: "flying or riding in a helicopter." The items were measured on a four-point scale from a lot (1), to not at all (4). Presented on Table 3 are the descriptive statistics of the items. The means ranged from 2.1 to 3.1 indicating moderate levels of general risk taking by the respondents.

Cronbach's $\alpha$ for the scale was .78. This $\alpha$ coefficient was deemed adequate for use in this study.

\section{Drinking Motives}

Drinking motives were measured by 18 items. Drinking motive theory (Cooper et al., 1992; Cox \& Klinger, 1988) has posited that there are multiple dimensions of drinking motives. The research outcomes of Cooper et al. and Cooper (1994) have suggested the existence of three or four factors to explain drinking motives. However, the number of factors which would account for the observed association of the drinking motive items within this data set was unknown. The author used exploratory factor analysis to identify 


\section{Table 3}

\section{General Risk Taking Descriptive Statistics}

$\begin{array}{lccc}\text { Item } & \mathbf{n} & \text { Mean } & \text { SD } \\ \text { Parachute } & 213 & 2.53 & 1.14 \\ \text { Motorcycle } & 212 & 2.35 & 1.12 \\ \text { Race Car } & 213 & 2.88 & 1.09 \\ \text { Speed } & 213 & 3.12 & .91 \\ \text { Helicopter } & 213 & 2.15 & 1.09\end{array}$

Note. Item responses ranged from 1 to 4 , and lower scores indicated greater general risk taking. 
the factors which explained the relationships among the drinking motive variables

(Norusis, 1994). A zero-order correlation matrix for the 18 drinking motive items was computed which confirmed the inter-relationships of the indicators. All items had large correlations with at least one other item except Drink with Partner: "to drink with your partner." The largest correlations found between Drink and other items were .195, and .186 with Not Responsible: "do whatever you want to do without being responsible," and Do: "do what friends do," respectively.

The Kaiser-Meyer-Olkin (KMO) measure of sampling adequacy was computed as an index of whether factor analysis was appropriate for the observed sample. This index is a measure of the magnitudes of the correlations. A high KMO ( 875$)$ was found which indicated that the factor analysis could proceed. A test for sphericity using Bartlett's method was computed and resulted in a statistic of $1710.86(p<.0001)$. Therefore the null hypothesis of an identity matrix was rejected, further indicating the existence of interitem associations.

The principal components method extracted four factors which explained $64.9 \%$ of the total variance among the 18 drinking motive items (Table 4). A scree plot was developed and confirmed the sufficiency of using four factors (Figure 1). An examination of the communality values indicated that the four factors explained more than $50 \%$ of the total variance of each of the 18 items. Varimax rotation was used, and the rotated factor matrix was sorted and blanked such that only factor loadings of at least .40 were examined to facilitate interpretation (Table 5). The lower bound for meaningful loadings recommended by Kachigan (1991) is from .3 to .5 . The midpoint was chosen as the 


\section{Table 4}

Drinking Motives Factor Analysis Extracted Factors

Percent of Cumulative

Factor

Eigenvalue

7.276

40.4

2

2.035

1.341

1.037
40.4

Variance

11.3

7.5

5.8

\section{Percent}

3

4
51.7

59.2

64.9 
Figure 1

Drinking Motives Factor Analysis Scree Plot

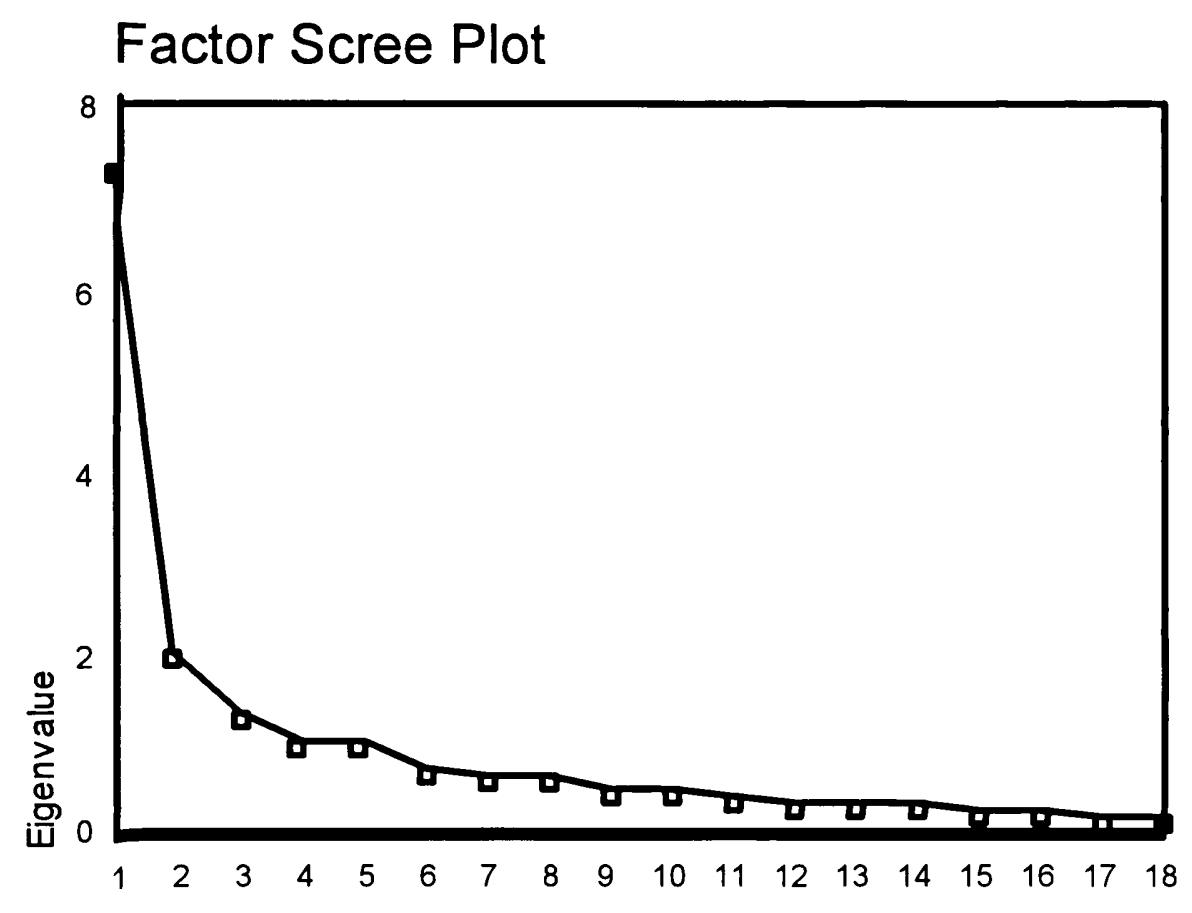

Factor Number 
Table 5

Drinking Motives Factor Loadings Rotated Factor Matrix

\begin{tabular}{|c|c|c|c|c|}
\hline Item & Factor 1 & Factor 2 & Factor 3 & Factor 4 \\
\hline Enjoy & .851 & & & \\
\hline Mood & .831 & & & \\
\hline Feel & .736 & & & \\
\hline Perform & .695 & & & \\
\hline Comfort & .618 & & .524 & \\
\hline Closer & .573 & & .459 & \\
\hline Worry STD & & .810 & & \\
\hline Guilt & & .728 & & \\
\hline Happy & & .699 & & \\
\hline Not Responsible & & .664 & & \\
\hline Do & & .599 & & \\
\hline Funny & & & .804 & \\
\hline Know & & & .706 & \\
\hline Open & .459 & & .632 & \\
\hline No Caring & & .507 & .577 & \\
\hline Impress & & .454 & .555 & \\
\hline Drink with Partner & & & & .676 \\
\hline Forget Life Worries & & .418 & .410 & -.423 \\
\hline
\end{tabular}


lower bound in this study to avoid any potential bias from either low loadings or from the elimination of items due to high inclusion criterion. The results indicated that there were four constructs of drinking motives which were labeled self-enhancement for factor 1 , coping for factor 2, partner-enhancement for factor 3, and social drinking for factor 4. The social drinking motive was a unique factor with only one item loading, "to drink with your partner." The item of wanting to drink to "forget worries about life" loaded between .41 and .42 on three factors. In other words, this item did not contribute significantly to any factor because of its low loading, and was difficult to interpret due to its almost equal multiple loadings. For these reasons, the item was dropped from the analyses.

Description of the results of the four factors follows.

Self-enhancement drinking motives. The self-enhancement dimension of drinking motives was measured by six items. Responses were measured on a four-point scale from very true (1), to not true at all (4). These reasons for drinking were: (a) Feel: "to get relaxed/feel good," (b) Mood: "to get in the mood for sex,", (c) Enjoy: "to enjoy sex more," (d) Perform: "to be able to perform sex/climax," (e) Comfort: "to be more comfortable with your partner," and (f) Closer: "to feel closer to your partner." Shown on Table 6 are the descriptive statistics of the items. Five of the six means were above 3.0 indicating that the respondents did not report high levels of self-enhancement as a reason to drink alcohol with sex. Cronbach's $\alpha$ for the scale was 87 .

Partner-enhancement drinking motives. The partner-enhancement dimension of drinking motives was measured by five items. Responses were measured on a four-point scale from very true (1), to not true at all (4). These reasons for drinking were: (a) No 
Table 6

Self-enhancement Drinking Motives Descriptive Statistics

$\begin{array}{lccc}\text { Item } & \mathbf{n} & \text { Mean } & \text { SD } \\ \text { Feel } & 206 & 2.44 & 1.13 \\ \text { Mood } & 205 & 3.02 & 1.03 \\ \text { Enjoy } & 205 & 3.16 & 1.00 \\ \text { Perform } & 205 & 3.51 & .81 \\ \text { Comfort } & 202 & 3.17 & .94 \\ \text { Closer } & 202 & 3.45 & .84\end{array}$

Note. Item responses ranged from 1 to 4 , and lower scores indicated stronger selfenhancement drinking motives. 
Caring: "to be able to have sex with someone you really don't care for very much," (b) Impress: "to impress your partner," (c) Open: "to be able to express your feelings," (d) Funny: "to be funnier or wittier," and (e) Know: "to be able to get to know your partner better." Presented on Table 7 are the descriptive statistics of the items. All of the means were above 3.4 indicating that the respondents did not report high levels of partnerenhancement as a reason to drink alcohol with sex. Cronbach's $\alpha$ for the scale was .80 .

Coping drinking motives. Motives for drinking alcohol before or during sex which corresponded to the coping dimension of drinking motives were measured by five items. Responses were on a four-point scale from very true (1), to not true at all (4). These reasons for drinking were: (a) Not Responsible: "to be able to do whatever you want to do without being responsible," (b) Worry STD: "to forget about your worries about getting a sexually transmitted disease," (c) Guilt: "to get rid of guilt you have about having sex," (d) Do: "to be able to do what your friends do," and (e) Happy: "to make your partner happy even though you didn't want to drink." Presented on Table 8 are the descriptive statistics of the items. All of the means were above 3.6 indicating that the respondents did not report high levels of coping as a reason to drink alcohol with sex. Cronbach's $\alpha$ for the scale was 80 .

Social Drinking Motive. Social drinking motive was a unique factor extracted by the factor analysis which was represented by the item, "wanting to drink with one's sex partner." Responses were measured on a four-point scale from very true (1), to not true at all (4). The mean response was $2.93(n=201, S D=1.07)$. 


\section{Table 7}

\section{Partner-enhancement Drinking Motives Descriptive Statistics}

\begin{tabular}{lccc} 
Item & $\mathbf{n}$ & Mean & SD \\
No Caring & 197 & 3.49 & .95 \\
Impress & 201 & 3.79 & .57 \\
Open & 201 & 3.42 & .87 \\
Funny & 202 & 3.44 & .81 \\
Know & 198 & 3.71 & .61 \\
\hline
\end{tabular}

Note. Item responses ranged from 1 to 4 , and lower scores indicated stronger partnerenhancement drinking motives. 


\section{Table 8}

\section{Coping Drinking Motives Descriptive Statistics}

\begin{tabular}{lccc} 
Item & $\mathbf{n}$ & Mean & SD \\
Not Responsible & 200 & 3.63 & .76 \\
Worry STD & 199 & 3.84 & .51 \\
Guilt & 200 & 3.73 & .66 \\
Do & 200 & 3.87 & .44 \\
Happy & 200 & 3.78 & .60 \\
\hline
\end{tabular}

Note. Item responses ranged from 1 to 4 , and lower scores indicated stronger coping drinking motives. 


\section{$\underline{\text { Mistrust }}$}

Mistrust was measured by one item which asked the respondents how true they thought that "a vaccine to protect people from the AIDS virus has already been approved but the government has not distributed it for use by the general public." Responses were measured on a four-point scale from very true (1), to not true at all (4). The mean response was $3.5(\mathrm{n}=158, \mathrm{SD}=.79)$.

\section{Social Group Participation}

Social group participation was measured by two items. The first was divided into three response categories and asked whether the participant was in a fraternity or sorority. Response categories were (a) "yes, I am in a fraternity," (b) "yes, I am in a sorority," and (c) "no, I am not in a fraternity or a sorority." This variable was recoded into the dichotomous responses (a) yes, I am in a fraternity or sorority, and (b) no, I am not in a fraternity or a sorority." The responses included 179 no answers and 18 yes answers $(n=$ 197). The second item asked respondents "do you participate in any clubs/organizations that are not a fraternity or a sorority?" Responses were either yes or no, and included 127 no answers and 69 yes answers $(n=196)$. There was low correlation between the items, $\underline{r}$ $(196)=.17, p<.05$. This result indicated that the two items were not substantively associated. The question on fraternity or sorority participation is a narrower construction of group participation than the variable of any other clubs/organizations, as the specific type of club/organization is unknown. For these reasons the item on other clubs/organization was dropped from the analyses. 
Independent Variables Summary

The descriptive statistics for the independent variable scales are presented on Table 9. Since females represented $75 \%$ of the sample, results of t-tests for mean differences on these scales between the female and male groups of the sample are also presented on Table 9. The respondents generally did not report strong attributes for negative condom attitudes, or drinking motives. Item means for these variables ranged from 3.13 to 3.77 with a possible range of 1 to 4 . The item mean for general risk taking was 2.61 suggesting moderate levels of general risk taking by the respondents. Significant differences between the female and male groups were found on all of the scales except self-enhancement drinking motives. The mean for females on condom attitudes was 18.0 compared to 17.0 for males indicating stronger negative attitudes were held by males. Greater general risk taking was exhibited by males $(M=11.2)$ than females $(M=13.6)$. Stronger drinking motives were held by males on both partner-enhancement and coping motives. The mean for males was 16.6 compared to 18.3 for females for the former, and 17.8 for males compared to 19.2 for females for the latter. For the additional variables of social drinking motive and mistrust, differences between female and male groups were not found. Analysis of Fraternity/Sorority participation indicated that $72 \%$ of the respondents who indicated that they did belong to a fraternity or sorority were females.

A bivariate correlation matrix indicating Pearson's correlation coefficients among the independent variables was computed and is presented on Table 10. There were 16 significant correlations found among the nine variables, however, 11 of these were low correlations, with three moderate and two high correlations. Significant but low 
Table 9

Independent Variable Scales Descriptive Statistics

and Results of t-tests of Mean Differences between Females and Males

Total Sample

Variable

Negative Condom Attitudes Scale

General Risk Taking Scale

Self-enhancement

Drinking Motives Scale

Partner-enhancement

Drinking Motives Scale

Coping Drinking Motives Scale

Variable

Negative Condom Attitudes Scale

General Risk Taking Scale

Self-enhancement

Drinking Motives Scale

Partner-enhancement

Drinking Motives Scale

Coping Drinking Motives Scale n

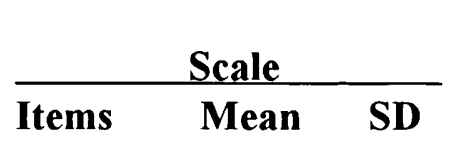

$207 \quad 5$

$17.7 \quad 2.27$

3.55

2125

13.0

3.92

2.61

Per

Item

Mean

2016

$18.7 \quad 4.52$

3.13

1915

$17.8 \quad 2.88$

3.57

$195 \quad 5$

$18.9 \quad 2.25$

3.77
Males
Females

n Mean SD

159

18.

160

13.6

150

19.0

142

146
$18.3 \quad 2.61$

49

16.6

$\begin{array}{lll}3.28 & -3.47 & .001\end{array}$

$\begin{array}{lll}19.2 & 1.67 & 49\end{array}$

17.8

$\begin{array}{lll}3.24 & -3.96 \quad 000\end{array}$

Note. Item responses ranged from 1 to 4 , and lower scores indicated less favorable attributes. 
Table 10

Independent Variables Correlation Matrix

Self Partner

Condom Risk Enhance Enhance Coping Social Frat/

Variable Attitudes Taking Motives Motives Motives Motive Mistrust Sorority Gender

Condom

Attitudes

Risk

Taking $\quad .077$

Self

Enhance

Motives $\quad .294^{* *}-.066$

Partner

Enhance

Motives $\quad .380^{* *} \quad .147^{*} \quad .613^{* *}$

Coping

Motives $\quad .374^{* *} \quad .068 \quad .451^{* *} \quad .590^{* *}$

Social

Motive

.133

.114

$.173 *$

$.234 * * \quad .216^{* *}$

Mistrust

.005

.119

.075

.058

.083

.022

Frat/

Sorority

$$
.034 \quad-.089
$$

.024

$.188^{*}$

$.161^{*}$

.140

$-.054 \quad-$

Gende

$.189^{* *}$

$.265^{* *}$

.074

$.245^{* *} \quad .274^{* *}$

.103

$-.039 \quad .025$

${ }^{*} \mathrm{p}<.05 . \quad{ }^{* *} \mathrm{p}<.01$. 
correlations were found between condom attitudes and self-enhancement drinking motives $(\underline{r}=.294, \underline{p}<.01)$, between condom attitudes and gender $(\underline{r}=.189, \underline{p}<.01)$, between general risk taking and partner-enhancement drinking motives $(\underline{r}=.147, \mathfrak{p}<.05)$, between general risk taking and gender $(\underline{r}=.265, \underline{p}<.01)$, between self-enhancement drinking motives and social drinking motive $(\underline{r}=.173, \underline{p}<.05)$, between partnerenhancement drinking motives and social drinking motive $(\underline{r}=.234, \underline{p}<.01)$, between partner-enhancement drinking motives and fraternity/sorority membership $(\underline{r}=.188, \mathfrak{p}<$ $.05)$, between partner-enhancement drinking motive and gender $(\underline{r}=.245, \underline{p}<.01)$, between coping drinking motives and social drinking motive $(\underline{r}=.216, \underline{p}<.01)$, between coping and fraternity/sorority membership $(\underline{r}=.161, \underline{p}<.05)$, and between coping drinking motives and gender $(\underline{r}=.274, \underline{p}<.01)$. Significant and moderate correlations were found between condom attitudes and partner-enhancement drinking motives $(\underline{r}=$ $.380, \mathfrak{p}<.01)$, between condom attitudes and coping drinking motives $(\underline{r}=.374, \underline{p}<.01)$, and between self-enhancement drinking motives and coping drinking motives $(\underline{r}=.451, \underline{p}<$ .005). Two high associations were found between self-enhancement drinking motives and partner-enhancement drinking motives $(r=.613, \underline{p}<.01)$, and between partnerenhancement drinking motives and coping motives $(\underline{r}=.590, \underline{p}<.01)$.

\section{Dependent Variables}

Reported on Table 11 are the percentage distributions of the five risky sex behaviors among four groups. These groups included the three alcohol use contexts of (a) only when drinking, (b) only when not drinking, and (c) either context, and a fourth group which indicated that the behavior was something that the respondents had never done. 


\section{Table 11}

\section{Risky Sex Behaviors Among University Students}

\section{Percentage Distribution}

\begin{tabular}{|c|c|c|c|c|c|}
\hline Risky Sex Behavior & $\mathbf{n}$ & $\begin{array}{l}\text { Only when } \\
\text { drinking }\end{array}$ & $\begin{array}{l}\text { Only when } \\
\text { not drinking }\end{array}$ & $\begin{array}{l}\text { Either } \\
\text { context }\end{array}$ & $\begin{array}{l}\text { Not at } \\
\text { all }\end{array}$ \\
\hline Sex without a condom & 201 & 2.0 & 6.0 & 67.1 & 24.9 \\
\hline Partner not well known & 205 & 19.0 & 2.9 & 21.0 & 57.1 \\
\hline Sex with an IDU & 202 & 1.0 & 0.0 & 2.0 & 97.0 \\
\hline STD status not known & 201 & 4.0 & 2.5 & 20.4 & 73.1 \\
\hline Sex while using drugs & 200 & 2.0 & 1.0 & 23.5 & 73.5 \\
\hline
\end{tabular}


For three of the risky sex behaviors, many indicated that they never engaged in these behaviors as follows: (a) sex with an IDU, 97\%, (b) sex with a partner of unknown STD status, $73 \%$, and (c) sex while using drugs, $73 \%$. Those that stated that they never engaged in sex with a partner not known very well represented $57 \%$ of the respondents, whereas only $25 \%$ of the respondents indicated that they never had sex without a condom.

Among the alcohol use contexts, $67 \%$ of the respondents indicated that they had sex without a condom either when drinking or when not drinking. However, those having sex with a partner not known very well $(43 \%)$, reported that having sex with a partner not known well occurred almost equally when drinking (19\%), and when drinking or not (21\%). Among those that reported having sex with a partner of unknown STD status $(27 \%)$, one-fifth indicated that having sex with a partner of unknown STD status occurred in either alcohol context.

\section{Research Hypotheses}

Prior to testing the research hypotheses, the differences between males and females on the dependent variables were tested using a series of chi-square tests. The results, shown on Table 12, indicated that there were significant differences on two of the five dependent variables. Therefore, gender was added as a predictor variable in the discriminant analyses to test the research hypotheses. Similar chi-square tests were performed to test for differences among ethnic groups. For these tests, two groups were contrasted, "foreign" and "non-foreign." The "foreign" group included Hispanic, Asian, and Haitian respondents ("Foreign" in this context does not necessarily indicate that the respondents were foreign-born). These "Foreign" groups are traditionally male-dominated 
Table 12

\section{Gender Differences on Dependent Variables}

Behavior

Sex without a condom

Partner not well known ${ }^{\mathrm{b}}$

Sex with an IDU

STD status not known

Sex while using drugs

$\begin{array}{llcl}\text { Gender } & \begin{array}{l}\text { Only When } \\ \text { Drinking (\%) }\end{array} & \begin{array}{c}\text { Regardless } \\ \text { of Drinking (\%) }\end{array} & \begin{array}{c}\text { Not } \\ \text { at All (\%) }\end{array}\end{array}$

$\begin{array}{ll}\text { Female } & 2(1.4) \\ \text { Male } & 2(3.6)\end{array}$

$112(76.7)$

$35(63.6)$

$22(14.6)$

$27(50.0)$

$1(.7)$

$3(5.7)$

$30(20.1)$

$16(30.8)$

$31(20.8)$

$18(35.3)$
$32(21.9)$

$18(32.7)$

$101(66.9)$

$16(29.6)$

$147(98.6)$

$49(92.4)$

$112(75.2)$

$35(67.3)$

$116(77.9)$

$31(60.8)$

Note. Amounts represent observed frequencies.

${ }^{\mathrm{a}} \chi^{2}(2, \mathrm{~N}=201)=3.84$, p n.s.

${ }^{\mathrm{b}} \chi^{2}(2, \mathrm{~N}=205)=30.63, \mathrm{p}<.0001$.

${ }^{c} \chi^{2}(2, N=202)=5.65$, p n.s.

${ }^{\mathrm{d}} \chi^{2}(2, \mathrm{~N}=201)=2.98, \mathrm{p}$ n.s.

${ }^{\mathrm{e}} \chi^{2}(2, \mathrm{~N}=200)=6.02, \mathrm{p}<.05$. 
in terms of couple relationships, therefore, the dependent variables could differ by ethnicity. The "non-foreign" group included Black non-Hispanic, White non-Hispanic, and other respondents. The results, shown on Table 13, indicated that there were no significant differences.

\section{Hypothesis 1:}

Individuals from a university student sample are more likely to engage in risky sex behaviors only when drinking than only when not drinking or when drinking or not. This hypothesis was not accepted. Testing of this hypothesis was done by using chi-square tests. The cases of interest were those in which the respondents indicated they did in fact engage in the risky sex behavior. Therefore, cases selected for the chi-square analyses excluded those cases that represented no manifestation of the behavior. This resulted in reduced sample sizes as follows: (a) sex without a condom $(n=151)$, (b) partner not known well $(\mathrm{n}=88)$, (c) sex with an IDU $(\mathrm{n}=6)$, (d) sex with a partner of unknown STD status $(n=54)$, and (e) sex while using drugs $(n=53)$. The assumptions for chi-square analysis include the condition that no more than $20 \%$ of the cells have expected frequencies less than five. Since the total frequency of having sex with an IDU was only six, the minimum expected frequency assumption was violated. Therefore, the results for engaging in sex with an IDU only when drinking, only when not drinking, or whether drinking or not are inconclusive. The five chi-square tests for each risky sex behavior are shown on Table 14. The results are discussed below for each one except sex with an IDU because of the assumption violation previously stated. 
Table 13

\section{Racial/Ethnic Differences on Dependent Variables}

\begin{tabular}{|c|c|c|c|c|}
\hline Behavior & $\begin{array}{c}\text { Race/ } \\
\text { Ethnicity }\end{array}$ & $\begin{array}{l}\text { Only When } \\
\text { Drinking (\%) }\end{array}$ & $\begin{array}{c}\text { Regardless } \\
\text { of Drinking (\%) }\end{array}$ & $\begin{array}{c}\text { Not } \\
\text { at All (\%) }\end{array}$ \\
\hline \multirow[t]{2}{*}{ Sex without a condom ${ }^{a}$} & Foreign & $4(3.0)$ & $97(73.5)$ & $31(23.5)$ \\
\hline & Non-foreign & $0(.0)$ & $50(73.5)$ & $18(26.5)$ \\
\hline \multirow[t]{2}{*}{ Partner not well known ${ }^{b}$} & Foreign & $23(16.9)$ & $32(23.5)$ & $81(59.6)$ \\
\hline & Non-foreign & $16(23.5)$ & $17(25.0)$ & $35(51.5)$ \\
\hline \multirow[t]{2}{*}{ Sex with an $\mathrm{IDU}^{\mathrm{c}}$} & Foreign & $1(.7)$ & $3(2.2)$ & $131(97.1)$ \\
\hline & Non-foreign & $1(1.5)$ & $1(1.5)$ & $64(97.0)$ \\
\hline \multirow[t]{2}{*}{ STD status not known ${ }^{d}$} & Foreign & $4(3.1)$ & $25(19.1)$ & $102(77.8)$ \\
\hline & Non-foreign & $4(5.8)$ & $21(30.4)$ & $44(63.8)$ \\
\hline \multirow[t]{2}{*}{ Sex while using drugs ${ }^{e}$} & Foreign & $4(3.1)$ & $32(24.4)$ & $95(72.5)$ \\
\hline & Non-foreign & $0 \quad(.0)$ & $17(25.0)$ & $51(75.0)$ \\
\hline
\end{tabular}

Note. Amounts represent observed frequencies.

$$
\begin{aligned}
& { }^{\mathrm{a}} \chi^{2}(2, \mathrm{~N}=200)=2.22, \mathfrak{p} \text { n.s. } \\
& { }^{\mathrm{b}} \chi^{2}(2, \mathrm{~N}=204)=1.60, \mathfrak{p} \text { n.s. } \\
& { }^{\mathrm{c}} \chi^{2}(2, \mathrm{~N}=201)=.38, \text { p n.s. } \\
& { }^{\mathrm{d}} \chi^{2}(2, \mathrm{~N}=200)=4.61, \mathfrak{p} \text { n.s. } \\
& { }^{\mathrm{e}} \chi^{2}(2, \mathrm{~N}=199)=2.12, \mathrm{p} \text { n.s. }
\end{aligned}
$$




\section{Table 14}

Risky Sex Behaviors Among University Students in Discrete Alcohol Use Contexts

Risky Sex Behavior

Sex without a condom ${ }^{\mathrm{a}}$

Partner not well known

Sex with an IDU ${ }^{c}$

STD status not known ${ }^{d}$

Sex while using drugs ${ }^{\mathrm{e}}$

\section{Only When}

Drinking (\%)

$4(2.6)$

$39(44.3)$

$2(33.3)$

$8(14.8)$

$4(7.5)$
Only When

Not Drinking (\%)

$12(8.0)$

$6(6.8)$

$0 \quad(.0)$

$5(9.3)$

$2(3.8)$
Either

Context (\%)

$135(89.4)$

$43(48.9)$

$4(66.7)$

$41(75.9)$

47 (88.7)

Note. Amounts represent observed frequencies.

${ }^{\mathrm{a}} \chi^{2}(2, \mathrm{~N}=151)=214.26, \mathrm{p}<.000$.

${ }^{\mathrm{b}} \chi^{2}(2, \mathrm{~N}=88)=28.11, \mathrm{p}<.000$.

${ }^{c} \chi^{2}(1, N=6)=.67, p$ n.s.

${ }^{\mathrm{d}} \chi^{2}(2, \mathrm{~N}=54)=44.33, \mathfrak{p}<.000$.

${ }^{\mathrm{e}} \chi^{2}(2, \mathrm{~N}=53)=73.17, \mathrm{p}<.000$. 
Sex without a condom. As indicated on Table 14, the observed percentages of sex without a condom when drinking or not was $89 \%(n=135)$, only when not drinking was $8 \%(n=12)$, and only when drinking, represented $3 \%(n=4)$. Even though the chisquare results were significant, the analysis failed to indicate that individuals are more likely to engage in sex without a condom only when drinking than only when not drinking or when drinking or not. In other words, those who engage in sex without a condom will likely do so regardless of drinking.

Partner not well known. The observed percentages of having sex with a partner not well known when drinking or not was $49 \%(n=43)$, only when drinking $44 \%(n=$ $39)$, and only when not drinking $7 \%(n=6)$. The chi-square results were significant. However, the analysis failed to indicate that individuals are more likely to engage in sex with a partner not well known only when drinking than only when not drinking or when drinking or not. In other words, from the group of those who engage in casual sex, the likelihood of doing so only when drinking is no different than the likelihood of doing so regardless of drinking.

Partner STD status unknown. The observed percentage of having sex with a partner without knowing whether they had a STD when drinking or not was $76 \%$ ( $\mathrm{n}=$ $41)$, and the combined percentage for the other two categories was $24 \%(n=13)$. The chi-square results were significant. However, the analysis failed to indicate that individuals are more likely to engage in sex with a partner without knowing whether they had a STD only when drinking than only when not drinking or when drinking or not. In other words, those who engage in sex without knowing the STD status of their partner, 
will likely do so regardless of drinking.

Sex while using drugs. The observed percentage of having sex while using drugs when drinking or not was $89 \%(n=47)$, and the combined percentage for the other two categories was $11 \%(n=6)$. The chi-square results were significant, however the analysis failed to indicate that individuals are more likely to engage in sex while using drugs only when drinking than only when not drinking or when drinking or not. In other words, those who engaged in sex while using drugs, will likely do so regardless of drinking. Hypothesis 2:

Individuals from a university student sample who engage in sex without a condom only when drinking, compared to those who engage in sex without a condom only when not drinking or whether drinking or not, and to those who do not engage in sex without a condom, will have (a) stronger negative condom attitudes, (b) greater general risk taking, (c) stronger drinking motives, (d) stronger beliefs of mistrust, and (e) fraternity/sorority membership. This hypothesis was not accepted. The hypothesis was tested using discriminant analysis. In addition, the means of each independent variable for each category of risky sex behavior were examined to determine whether the directions of the relationships were as hypothesized. The responses to each outcome were recoded in order to combine the response categories of only when not drinking and whether drinking or not. This new category was termed regardless of drinking. Since there are three categories to which cases can be classified, there were two discriminant functions derived for each analysis. The various discriminant analysis statistics are provided on Table 15 . The substantive utility of the discriminant function as a predictor model can be determined 
Table 15

Sex Without a Condom Discriminant Analysis

Canonical Discriminant Functions

$\begin{array}{ccccc}\text { Function } & \text { Eigenvalue } & \text { \% Variance } & \begin{array}{c}\text { Cumulative } \\ \%\end{array} & \begin{array}{c}\text { Canonical } \\ \text { Correlation }\end{array} \\ 1 & .186 & 74.2 & 74.2 & .396 \\ 2 & .065 & 25.8 & 100.0 & .246\end{array}$

Discrimination Indices

Function

Removed

0

1
Wilks'

$\lambda$

.792

.939

6.14

22.84

Structure Coefficients

Variable

Condom Attitudes

Risk taking

Self-enhancement motives

Partner-enhancement motives

Coping drinking motives

Social drinking motive

Mistrust

Fraternity/Sorority

Gender
Function 1

$-.184$

.020

.241

.641

.210

.362

.381

$-.056$

$-.178$
18

8

df

p

.197

.631

Function 2

.069

.627

$-.414$

.152

.254

.161

$-.298$

.194

$-.175$ 
by the eigenvalue interpretation, the canonical correlation, and the lambda analysis (Klecka, 1980). Eigenvalues represent the ratio of between-groups to within groups sum of squares. The low eigenvalues of .186 and .065 for the sex without a condom analysis indicated that both functions may not be good functions. The canonical correlation between the discriminant scores and the groups for the two functions indicated moderate and low associations, $\underline{\mathrm{r}}=.40 ; \underline{\mathrm{r}}=.25$, respectively. Wilks' lambda $(\lambda)$ represents the proportion of the total variance not explained by the discriminant model, and therefore small values indicate a better model. For this model, $\lambda=.792 ; \lambda=.939$ for the two functions indicated high percentages of unexplained variances. The $\lambda$ statistics were transformed to $\chi^{2}$ values which were not significant. Labeling the function involves identifying the important constructs for distinguishing among the groups. Labeling is performed by ascertaining the commonalities among the variables with the highest absolute structure coefficients. Rather than use standardized coefficients, structure coefficients are recommended when there is bivariate correlation between the independent variables (Klecka). Table 10 indicated correlations among the predictors, therefore structure coefficients were used. Function one is labeled partner-enhancement drinking motive since it is the only high coefficient. Function two is labeled general risk taking, however the analyses indicated that this was a weak predictor model.

An additional purpose of discriminant analysis is to classify groups based on predictor variables. The results of the classification are shown on Table 16. Cases correctly classified were $56.2 \%$. In evaluating the percentage of cases classified correctly, a comparison to prior probabilities classification is important. The prior probability is the 
Table 16

Sex Without a Condom Classification Results

\section{Actual Group}

Group 1: Only when drinking

Group 2: Regardless of drinking

Group 3: Not at all
Predicted Group Membership (\%)

n

1

2

3

2

$1(50.0)$

$1(50.0)$

0(

$.0)$

75

$8(10.7) \quad 39(52.0)$

$28(37.3)$

28

$1(3.6)$

$8(28.6)$

19 (67.9)

Percent of grouped cases correctly classified : $56.2 \%$ 
likelihood that a case belongs to a particular group when no information is available about the case. The actual sample used in the study is an estimate of the prior probability. Using the largest group in terms of frequency distribution, regardless of drinking, the observed classification rate was $71 \%$. Therefore, prediction based on the model was actually worse than that based on probability.

The distribution of means for each of the predictors across the risky sex categories was examined (Table 17). Those respondents who reported engaging in sex without a condom only when drinking expressed stronger drinking motives on all four dimensions of drinking motives, and stronger beliefs of mistrust. This directional relationship was not exhibited on condom attitudes nor on general risk taking. The frequency distributions shown in percentages of those respondents belonging to a fraternity/sorority membership did not indicate higher rates for those in the only when drinking category. The chi-square results on this variable were not significant nor interpretable since more than $20 \%$ of the cells had fewer than five cases.

The analyses provided mixed results with respect to support of the research hypothesis for the risky sex behavior of sex without a condom. The correct classification rate was not high. A statistically significant function was not derived, however, a partnerenhancement drinking motive predictor model was extracted with a moderate correlation. The relevance of partner-enhancement drinking motive was confirmed by the mean distribution analysis. In other words, those who had less favorable partner-enhancement drinking motives tended to engage in sex without a condom. 
Table 17

Sex Without a Condom Mean and Frequency Distributions

\begin{tabular}{|c|c|c|c|}
\hline Predictor & $\begin{array}{l}\text { Only When } \\
\text { Drinking (SD) }\end{array}$ & $\begin{array}{c}\text { Regardless } \\
\text { of Drinking (SD) }\end{array}$ & $\begin{array}{c}\text { Not } \\
\text { At All (SD) }\end{array}$ \\
\hline Condom Attitudes & $17.5(3.8)$ & $17.6(2.3)$ & $18.0(2.3)$ \\
\hline Risk taking & $13.8(4.6)$ & $12.5(3.6)$ & $13.6(4.3)$ \\
\hline $\begin{array}{l}\text { Self-enhancement } \\
\text { drinking motives }\end{array}$ & $14.8(3.8)$ & $18.9(4.4)$ & $18.8(4.6)$ \\
\hline $\begin{array}{l}\text { Partner-enhancement } \\
\text { drinking motives }\end{array}$ & $14.0(2.4)$ & $17.8(2.9)$ & $18.2(2.9)$ \\
\hline Coping drinking motives & $17.5(3.0)$ & $18.8(2.1)$ & $19.0(2.7)$ \\
\hline Social drinking motive & $2.0(.0)$ & $2.9(1.1)$ & $3.1(1.1)$ \\
\hline Mistrust & $3.0(.8)$ & $3.6(.8)$ & $3.6(.9)$ \\
\hline Fraternity/Sorority (\% Yes) & .0 & 5.6 & 6.0 \\
\hline
\end{tabular}

Note. Lower scores indicated less favorable attributes. 


\section{Hypothesis 3:}

Individuals from a university student sample who engage in sex with people not known very well only when drinking, compared to those who engage in sex with people not known very well only when not drinking or whether drinking or not, and to those who do not engage in sex with people not known very well, will have (a) stronger negative condom attitudes, (b) greater general risk taking, (c) stronger drinking motives, (d) stronger beliefs of mistrust, and (e) fraternity/sorority membership. This hypothesis was accepted. The various discriminant analysis statistics are described on Table 18. The eigenvalue for function one was moderate at .526 and low for function two at .162 . The function one canonical correlation indicated a high association between the discriminant scores and the groups, $\underline{r}=.59$, while function two was moderate, $\underline{r}=.37$. The proportion of total variance not explained by function one was $\lambda=.56$, and was transformed to a significant $\chi^{2}(18, \mathrm{n}=108)=57.82, \mathrm{p}<.00001$. For function two, $\lambda=.86 ; \chi^{2}(8, \mathrm{n}=$ $108)=15.15, \mathfrak{p}=.0563$. These results indicated that it is unlikely that the means of discriminant function one are equal among the three groups. Function two was nearly significant on this test. The important constructs for function one were gender and negative condom attitudes. Significant gender differences were found $\chi^{2}(2, N=205)=$ $30.63, \mathrm{p}<.0001$. Higher proportions of males than females engaged in sex with a partner not well known for both the only when drinking and the regardless of drinking categories. For function two the important construct was social drinking motive. The classification results are displayed in Table 19. Cases correctly classified were $67.6 \%$. The prior probability based on the largest group, not at all, was $60 \%$. 
Table 18

Sex With People Not Known Well Discriminant Analysis

Canonical Discriminant Functions

$\begin{array}{ccccc}\text { Function } & \text { Eigenvalue } & \text { \% Variance } & \begin{array}{c}\text { Cumulative } \\ \%\end{array} & \begin{array}{c}\text { Canonical } \\ \text { Correlation }\end{array} \\ 1 & .526 & 76.5 & 76.5 & .587 \\ 2 & .162 & 23.5 & 100.0 & .373\end{array}$

Discrimination Indices

$\begin{array}{ccccc}\begin{array}{c}\text { Function } \\ \text { Removed }\end{array} & \begin{array}{c}\text { Wilks' } \\ \lambda\end{array} & \chi^{2} & \text { df } & \text { p } \\ 0 & .564 & 57.82 & 18 & .0000 \\ 1 & .861 & 15.15 & 8 & .0563\end{array}$

Structure Coefficients

Variable

Condom Attitudes

Risk taking

Self-enhancement motives

Partner-enhancement motives

Coping drinking motives

Social drinking motive

Mistrust

Fraternity/Sorority

Gender
Function 1

.667

.257

.331

.542

.410

.303

.026

.069

.690
Function 2

.068

.022

.332

$-.110$

.560

$-.204$

.178

$-.488$ 
Table 19

\section{Sex With People Not Known Well Classification Results}

\section{Actual Group}

Group 1: Only when drinking

Group 2: Regardless of drinking

Group 3: Not at all n

21

22

65
Predicted Group Membership (\%) 1

2

$12(57.1) \quad 5(23.8) \quad 4(19.0)$

$4(18.2) \quad 15(68.2) \quad 3(13.6)$

$10(15.4) \quad 9(13.8) \quad 46(70.8)$

Percent of grouped cases correctly classified : $67.6 \%$ 
The means for the independent variables for each group are shown on Table 20.

Those respondents who reported engaging in sex with people not known well only when drinking expressed stronger self-enhancement, partner-enhancement, and social drinking motives. This directional relationship was not exhibited on the other predictor variables. The frequency distributions shown in percentages of those respondents belonging to a fraternity/sorority did not indicate higher rates for those in the only when drinking category. The chi-square results on this variable were not significant nor interpretable since more than $20 \%$ of the cells had fewer than five cases.

The analyses did support the research hypothesis for the risky sex behavior of sex with people not known well. A statistically significant function was derived with high correlation, and a good eigenvalue which strongly supports the hypothesis. Also, good correct classification rates were found. However, the complexity of the relationships was underscored by the lack of confirmation of the mean distribution test for condom attitudes. In other words, those who had less favorable partner-enhancement drinking motives will more likely engage in casual sex only when drinking.

Hypothesis 4:

Individuals from a university student sample who engage in sex with injecting drug users (IDUs) only when drinking, compared to those who engage in sex with injecting drug users (IDUs) only when not drinking or whether drinking or not, and to those who do not engage in sex with injecting drug users (IDUs), will have (a) stronger negative condom attitudes, (b) greater general risk taking, (c) stronger drinking motives, (d) stronger beliefs of mistrust, and (e) fraternity/sorority membership. This hypothesis was 
Table 20

Sex With People Not Known Well Mean and Frequency Distribution

Predictor

Condom Attitudes

Risk taking

Self-enhancement drinking motives

Partner-enhancement drinking motives

Coping drinking motives

Social drinking motive

Mistrust

Fraternity/Sorority (\% Yes)
Only When

Drinking (SD)
Regardless

of Drinking (SD)
Not

At All (SD)

$18.4(1.9)$

$13.4(3.5)$

$12.1(4.4)$

$12.0(3.9)$

$18.0(4.3)$

$19.5(4.4)$

$17.2(4.8)$

$16.3(3.0)$

$17.0(3.2)$

$18.8(2.3)$

$18.2(1.9)$

$18.1(2.9)$

$19.3(2.0)$

$2.5(1.2)$

$2.8(1.0)$

$3.1(1.0)$

$3.6(.5)$

$3.5(.8)$

$3.5(.8)$

2.2

1.7

5.5

Note. Lower scores indicated less favorable attributes. 
not accepted. Since there was an imbalance in the distribution of observed cases, discriminant analysis could not be used. There were no cases in the only when drinking group, and only two cases in the regardless of drinking group. However, the means distribution for observed variables are shown on Table 21. Self-enhancement drinking motive is evidenced stronger in the only when drinking group than the other two groups. However, this directional relationship was not indicated on any other predictors. The frequency distributions shown in percentages of those respondents belonging to a fraternity/sorority did not indicate higher rates for those in the only when drinking category. The chi-square results on this variable were not significant nor interpretable since more than $20 \%$ of the cells had fewer than five cases. The data failed to support the research hypothesis for sex with an IV drug user due to insufficient cases among the different groups.

Hypothesis 5:

Individuals from a university student sample who engage in sex with people without knowing whether they had a STD only when drinking, compared to those who engage in sex with people without knowing whether they had a STD only when not drinking or whether drinking or not, and to those who do not engage in sex with people without knowing whether they had a STD, will have (a) stronger negative condom attitudes, (b) greater general risk taking, (c) stronger drinking motives, (d) stronger beliefs of mistrust, and (e) fraternity/sorority membership. This hypothesis was not accepted. The various discriminant analysis statistics are described on Table 22. The eigenvalues for sex not knowing if partner had STD were low for both functions $(.109 \& .047)$ which 


\section{Table 21}

Sex With IV Drug User Mean and Frequency Distribution

Predictor

Condom Attitudes

Risk taking

Self-enhancement drinking motives

Partner-enhancement drinking motives

Coping drinking motives

Social drinking motive ${ }^{a}$

Mistrust $^{a}$

Fraternity/Sorority (\% Yes)
Only When

Drinking (SD)

$16.0(2.8)$

$11.0(7.1)$

$15.2(1.4)$

$19.0(4.1)$

$14.0(2.8)$

$16.5(2.1)$

Regardless

$13.7(4.5)$

$8.5(4.7)$

$14.8(4.3)$

$15.5(5.7)$ of Drinking (SD)
$12.9(3.7)$

$18.9(4.5)$

$18.0(2.8)$

Not

At All (SD)

$17.8(2.2)$

$18.9(2.1)$

Note. Lower scores indicated less favorable attributes.

${ }^{\text {a }}$ Too few cases to evaluate 
Table 22

Sex Not Knowing if Partner Had STD Discriminant Analysis

Canonical Discriminant Functions

$\begin{array}{ccccc}\text { Function } & \text { Eigenvalue } & \begin{array}{c}\text { \% Variance } \\ \text { Cumulative } \\ \text { \% }\end{array} & \begin{array}{c}\text { Canonical } \\ \text { Correlation }\end{array} \\ 1 & .109 & 70.0 & 70.0 & .314 \\ 2 & .047 & 30.0 & 100.0 & .212\end{array}$

Discrimination Indices

$\begin{array}{ccccc}\begin{array}{c}\text { Function } \\ \text { Removed }\end{array} & \begin{array}{c}\text { Wilks' } \\ \lambda\end{array} & \chi^{2} & \text { df } & \text { p } \\ 0 & .861 & 14.9 & 18 & .667 \\ 1 & .955 & 4.6 & 8 & .802 \\ & & & \\ & & & \\ & & & \end{array}$

Variable

Condom Attitudes

Risk taking

Self-enhancement motives

Partner-enhancement motives

Coping drinking motives

Social drinking motive

Mistrust

Fraternity/Sorority

Gender
Function 1

.469

.394

.358

.626

.520

.460

.095

$-.272$

.650
Function 2

.581

$-.326$

.535

.511

.068

$-.066$

$-.018$

.501

$-.059$ 
indicated that both functions may not be good functions. The canonical correlations indicated low associations between the discriminant scores and the groups, $\underline{r}=.314 ; \underline{r}=$ 212. The two functions resulted in $\lambda=.861 ; \lambda=.955$, indicating high percentages of unexplained variances. The $\lambda$ statistics were transformed to $\chi^{2}$ which were not significant. The important constructs for function one were gender and partnerenhancement drinking motives. Higher proportions of females than males engaged in sex with a partner of unknown STD status in the only when drinking group. However, the gender differences were not found to be significant. The classification results are displayed in Table 23 . Cases correctly classified were $54.2 \%$. The prior probability was $73 \%$. Thus, the model performed worse than classification based on prior probability. The means for the independent variables for each group are shown on Table 24. Those respondents who reported engaging in sex with a partner without knowing the partner's STD status expressed stronger negative condom attitudes, stronger self- and partner-enhancement drinking motives, and stronger coping drinking motives. This directional relationship was not exhibited on any of the other predictor variables. The frequency distributions shown in percentages of those respondents belonging to a fraternity/sorority did not indicate higher rates for those in the only when drinking category. The chi-square results on this variable were not significant nor interpretable since more than $20 \%$ of the cells had fewer than five cases. The results of the discriminant analyses did not support the hypothesis that those who engage in sex without knowing their partner's STD status only when drinking would be predicted by the model. This conclusion is based on the lack of a significant model, low correlations, low eigenvalues, 


\section{Table 23}

\section{Sex Not Knowing if Partner Had STD Classification Results}

\section{Actual Group}

Group 1: Only when drinking

Group 2: Regardless of drinking

Group 3: Not at all

\begin{abstract}
n
\end{abstract}
4

25

78
Predicted Group Membership (\%) 1

2

3

$3(75.0) \quad 0(.0) \quad 1(25.0)$

$6(24.0) \quad 11(44.0) \quad 8(32.0)$

$14(17.9) \quad 20(25.6) \quad 44(56.4)$

Percent of grouped cases correctly classified : $54.2 \%$ 


\section{Table 24}

Sex Not Knowing if Partner Had STD Mean and Frequency Distribution

\begin{tabular}{lccr} 
Predictor & $\begin{array}{c}\text { Only When } \\
\text { Drinking (SD) }\end{array}$ & $\begin{array}{c}\text { Regardless } \\
\text { of Drinking (SD) }\end{array}$ & $\begin{array}{c}\text { Not } \\
\text { At All (SD) }\end{array}$ \\
Condom Attitudes & $16.2(2.9)$ & $17.1(2.5)$ & $17.9(2.2)$ \\
Risk taking & $14.5(4.5)$ & $12.5(3.9)$ & $12.9(3.8)$ \\
$\begin{array}{l}\text { Self-enhancement } \\
\text { drinking motives }\end{array}$ & $16.6(6.1)$ & $18.2(4.1)$ & $19.0(4.6)$ \\
$\begin{array}{l}\text { Partner-enhancement } \\
\text { drinking motives }\end{array}$ & $16.1(3.1)$ & $17.4(2.7)$ & $18.1(2.9)$ \\
$\begin{array}{l}\text { Coping drinking motives } \\
\text { Social drinking motive }\end{array}$ & $17.8(2.4)$ & $18.3(2.6)$ & $19.0(2.2)$ \\
Mistrust & $3.0(1.1)$ & $2.6(1.0)$ & $3.0(1.1)$ \\
Fraternity/Sorority (\% Yes) & .6 & $3.6(.8)$ & $3.5(.8)$ \\
\hline
\end{tabular}

Note. Lower scores indicated less favorable attributes. 
and only a modest correct classification rate. In other words, the model of psychosocial variables used failed to predict the sexual risky behavior of sex without knowing a partner's a STD status within the different drinking events.

\section{Hypothesis 6:}

Individuals from a university student sample who engage in sex with using drugs only when drinking, compared to those who engage in sex with using drugs only when not drinking or whether drinking or not, and to those who do not engage in sex with using drugs, will have (a) stronger negative condom attitudes, (b) greater general risk taking, (c) stronger drinking motives, (d) stronger beliefs of mistrust, and (e) fraternity/sorority membership. This hypothesis was not accepted. Since there was an imbalance in the distribution of observed cases, discriminant analysis could not be used to test the research hypothesis. There were no cases in the only when drinking group. However, the means distribution for observed variables are shown on Table 25. Enhancement and social drinking motives are evidenced stronger in the only when drinking group. This directional relationship was not indicated on any other predictors. The frequency distributions shown in percentages of those respondents belonging to a fraternity/sorority did not indicate higher rates for those in the only when drinking category. The data failed to support the research hypothesis. In other words, the model of psychosocial variables used failed to predict the sexual risky behavior of sex without knowing a partner's a STD status within the different drinking events. 
Table 25

Sex with Using Drugs Mean and Frequency Distribution

Predictor

Condom Attitudes

Risk taking

Self-enhancement drinking motives

Partner-enhancement drinking motives

Coping drinking motives

Social drinking motive

Mistrust

Fraternity/Sorority (\% Yes)
Only When

Drinking (SD)

$16.7(3.2)$

$12.7(3.0)$

$14.5(5.3)$

$14.5(3.0)$

$18.7(1.1)$

$2.2(1.2)$

$3.7(.6)$

.0
Regardless of Drinking (SD)

$17.4(2.3)$

$10.8(3.4)$

$18.9(3.9)$

$17.4(2.6)$

$18.5(2.1)$

$2.8(1.0)$

$3.5(.9)$

2.2
Not

At All (SD)

$17.9(2.2)$

$13.5(3.8)$

$18.8(4.7)$

$18.1(2.9)$

$18.9(2.3)$

$3.0(1.1)$

$3.5(.8)$

6.7

Note. Lower scores indicated less favorable attributes. 


\section{Chapter V \\ Discussion}

Chapter V includes a discussion of the study's findings. First, the findings with respect to the association of alcohol to risky sex behavior are discussed. This is followed by a discussion of the psychosocial variables hypothesized to be associated with alcohol and risky sex behavior. This chapter also contains the limitations of the study, implications for social work research, and implications social work practice and policy.

The purpose of this study was to examine factors which might influence the cooccurrence of alcohol consumption and risky sex behavior among university students leading to increased risk of HIV infection. This study tested five theory- and researchbased psychosocial variables which were hypothesized to influence university students to engage in risky sex with alcohol consumption. These included negative condom attitudes, general risk taking, drinking motives, mistrust, and fraternity/sorority participation.

\section{Association of Alcohol and Risky Sex Behavior}

The findings of the study failed to support hypothesis number one that risky sex behavior is more likely to occur within alcohol use contexts among university students. The existing literature includes correlational evidence of alcohol use with risky sex at the general level, and has led to an implied direct effect of alcohol upon risky sexual behavior. However, the mixed findings of these studies has led researchers like Leigh and Stall (1993) to assert that this association has been an artifact in the research. To improve the validity of outcomes, event analysis has been used to determine whether the times when individuals were drinking were the same times when risky sex was performed (e.g., 
Graves, 1995; Langer \& Tubman, in press; Tubman \& Langer, 1995). While the results of event analysis research have been inconsistent (Graves), the initial findings of this event analysis study add to the growing body of research which calls into question the direct association of alcohol use and risky sex behavior.

Alcohol disinhibition theory has attempted to explain the alcohol/risky sex link by ascribing to alcohol a particular disabling potential which acts upon alcohol users (Crowe \& George, 1989; Steele \& Josephs, 1990). This construction is well imbedded in the literature despite the lack of causation research confirming such a premise (Leigh \& Stall, 1993). Reinarman and Leigh (1987) maintained that alcohol disinhibition is a social construction that can be deconstructed. This study replicates and extends the findings of others (Graves, 1995; Langer \& Tubman, in press; Tubman \& Langer, 1995) to a sample of university students. Such results lend evidence to the need for modification of the fundamental theoretical conceptualization of the direct role that alcohol plays in risky sex behavior.

The hypothesis, which was not supported, was that students are more likely to engage in sexual risk when drinking. The observed sexual risk behaviors were distributed among the drinking/non-drinking contexts, and therefore, an alcohol effect was not observed. One explanation for these results is that relevant data within the category of when drinking or not was not measured. Though not supported by the testing of this first hypothesis, alcohol may have had an effect on those respondents who reported risky sex in the category of when drinking or not. For a given participant, the distribution of frequencies of risky sex with alcohol and risky sex without alcohol is not known. 
Psychosocial Variables Associated with Alcohol and Risky Sex

Of the five risky sexual behaviors examined, (hypotheses two through six) only one, sex with persons not known well, was significantly explained by the predictive model. Additionally, constructs were identified in relation to sex without a condom, and sex with persons not known well.

Partner-enhancement drinking motives emerged as the major distinguishing construct for sex without a condom. Enhancement drinking motives have been shown to be a predictor of frequent heavy alcohol use and of stimulant drug and marijuana use (Cooper et al., 1992). Using factor analysis, this study found two separate enhancement factors, self-enhancement, and partner-enhancement by measuring drinking motives linked to sexual behavior. The findings of this study suggested that those university students who drank with sex for reasons which are partner-focused tended to engage in sex without using a condom to a greater extent than those for whom partner enhancement was a weaker drinking motive. This result is consistent with the findings of Langer and Tubman (in press) that a composite drinking motive scale predicted risky sex behavior among high risk adolescents.

Gender was found to be an important discriminant factor in the casual sex model. Higher proportions of males engaged in this type of sexual risk under any drinking/nondrinking context. This result was opposite the findings for sex without a condom, which indicated that a higher proportion of females than males engaged in the sex risk of not using a condom whether drinking or not (Table 12). Even though males had stronger negative condom attitudes (Table 9), this may not necessarily lead to a lower rate of 
condom usage among male university students compared to females. However, the manifestation of negative condom beliefs as a predictor of sexual risk for males, is demonstrated in the observed alternative sexual risk behavior of casual sex. One potential explanation is that an additional variable adds to the complexity of the relationships such as sexual motives. Sheer and Cline (1994) found that sexual pleasure seeking motives were antecedent to condom use and numbers of sex partners.

The study tested the association of psychosocial variables with five different risky sexual behaviors within drinking contexts. The hypotheses for four of these behaviors were not supported. There are several potential reasons why support was not found in the study. Alcohol may not exert an effect on risky sexual behavior regardless of the measurement of any psychosocial variable. The findings from the test of the first hypothesis indicated that risky sexual behavior occurs in all drinking/non-drinking contexts. If alcohol has no effect, then no psychosocial variable will result in prediction of risky sexual behavior within alcohol use contexts.

There are alternative explanations for these results which did not support the assertion that alcohol affects behavior through the psychosocial variables tested. One explanation is that relevant mediating variables were excluded from the model. Selfefficacy theory guided the inclusion of motives as a variable in the model, and therefore drinking motives were included. However, it might also be necessary to measure sexual motives and include these in a predictor model of sexual behavior and drinking. Alcohol may exert differential effects on those with different sexual motives as well as those with different drinking motives. 
Another alternative explanation for the findings is that there may exist relevant social contexts in addition to the drinking contexts which affect alcohol consumption, sexual behavior, or both. Only alcohol contexts were included in the model. An example of a social context not examined is sexual partner relationship dimensions. Relationships can be measured on a level of commitment, frequency of dating, and whether monogamous or non-monogamous. These different types of relationships with sexual partners may significantly add to the explanation of alcohol and risky sex.

An additional explanation for the findings relates to the method chosen to measure the drinking contexts. Within the whether drinking or not category, the study did not differentiate how often the sex behavior occurred when drinking, compared to when not drinking. Also, the amount of alcohol consumed at the occurrence of sexual risk behaviors was not measured. Had these differences been measured, psychosocial variable prediction may have been successful. By not determining these data, cases which may have been distinguished by the model were classified together with other cases in the whether drinking or not group.

While not supported by the results, the author feels it necessary to reach beyond the data to discuss what may be going on, and to discuss important underlying findings. Seventy-five percent of the sample engaged in sex without a condom, $43 \%$ in casual sex, and $27 \%$ in sex with a partner of unknown STD status, or sex while using drugs. The finding that participants were just as likely to engage in casual sex only when drinking as whether drinking or not implies that alcohol is relevant even though not measured by the study. In addition, for all risky behaviors, none of the frequencies of only when not 
drinking were more than $10 \%$. This finding also implicates alcohol as an inclusive element in the risky sex model.

The author, going beyond the data, believes that among these university students substantive numbers are influenced by alcohol to engage in risky sex than would otherwise do so had alcohol not been consumed. Utilizing the constructs of drinking motives and gender may improve the prediction of such students. The author believes further, that if the study had measured the frequency of sex with alcohol and the amount of alcohol within the group of whether drinking or not, that results would have supported the hypotheses.

\section{Limitations of the Study}

\section{$\underline{\text { Research Design }}$}

The cross-sectional design of the study limits any conclusions of causation and direction of the relationships found among the variables. The sample of university students was a purposive sample, and being non-random cannot be generalized to the population of all university students. The study sample of students may have a bias that was not measured. However, the study's response rate of $96 \%$ is an indicator of a representative sample of those university students who were asked to participate in the study.

A more severe limitation of the sample exits due to the gender and ethnicity distributions of the sample. Seventy-five percent of the subjects were female, and $62 \%$ were Hispanic (of those who were Hispanic, $70 \%$ were female). Due to these distributions of the sample, the results are not generalizable to other university students throughout the country. Also, generalizability is limited when extended to all late 
adolescents and young adults, or to adolescents and young adults of the same age who are not university students.

\section{Measurement and Analysis}

The study utilized retrospective, self-report data. The validity of retrospective data are subject to accurate recall of the respondents. However, Bailey et al. (1992) have posited that as the deviance of substances used by an individual increases, the recall accuracy of such use will increase. This deviant substance theory suggests that those sensitive behaviors more deviant are subject to more accurate recall. Self-report data of sensitive behaviors are also subject to social desirability. In order to address this issue of response truthfulness, the instrument employed a self-report honesty validity check.

A limitation of the findings exists due to having conducted multiple analyses within the data set using the alpha level of .05. Multiple analyses of the same data will increase the probability of making a Type I error. Generally, for a given number of tests, the significance of the results should be evaluated against the alpha level divided by the number of tests (Pedhazur \& Schmelkin, 1991), for example, as is done in post hoc comparisons using the Bonferroni test (SPSS, Inc. 1996). Therefore, the one significant finding may in fact be due to chance, since no adjustment to the alpha level was made.

\section{Implication for Social Work Research}

The study examined drinking motives, but did not measure sexual motives. Future research should include sexual motives. Sexual motives may represent an additional variable which may influence the relationship between alcohol and risky sex. Dimensions of sexual motives might include pleasure seeking, relationship maintenance, and coping 
motives. These motives may operate independently or in conjunction with drinking motives to influence the co-occurrence of alcohol and risky sex.

The study examined relationships between psychosocial variables and risky sex within alcohol use contexts. Future research needs to expand the social contexts beyond drinking contexts. The sexual partner relationship dimension is a social context which should be examined since this dimension may have an correlation with sexual risk behavior. The relationship context could include measures of dating frequency, levels of commitment, and whether the relationship is monogamous or non-monogamous.

Additional dimensions might include if a partner was someone with whom one is in love, or a marital engagement partner (Treboux \& Busch-Rossnagel, 1990).

Future research should include additional variables in the predictor model. These variables might include phenomenological constructs such as cognitions, feelings, and emotive states experienced at the decision point of whether to engage or not engage in risky sex. Also, different degrees of self-awareness and levels of mindfulness may be associated with more or less sexual risk with or without alcohol consumption.

This study was designed to determine the occurrence of risky sex within mutually exclusive alcohol use/non-use contexts. Future research should include an assessment of the amount of alcohol consumed at the occurrence of the identified behavior. Psychosocial variable predictor models would be improved by controlling for alcohol consumption amounts. In addition, future research should identify the frequencies of the risky sex behaviors occurring within each alcohol use/non-use contexts. This design would circumvent the problem of including varying magnitudes of drinking and varying 
frequencies of risky sex within the whether drinking or not category.

Findings of the study indicated that among university students, $75 \%$ engaged in sex without a condom, and $43 \%$ had sex with a partner not known very well. Of those students who engaged in these behaviors, less than $3 \%$ reported sex without a condom only when drinking, as compared to $44 \%$ who reported having casual sex only when drinking. These high levels of sexual risk behaviors, and complexity of the relationships among the variables support the need for more HIV/AIDS prevention research. Results of the study indicated that within alcohol-use contexts, partner-enhancement drinking motives and gender were related to sex without a condom and casual sex, respectively. The study sample included those students who responded that they had used alcohol before sex during the prior 6 months. Future research needs to examine these and other hypothesized relationships in a broader university student sample. The study indicated that the variables investigated represent a complexity of direct and indirect relationships. These results suggest that research should continue to define additional psychosocial models which can explain the underlying relationships of risky sexual behaviors in both alcohol use contexts as well as non-alcohol use contexts.

\section{Implications for Social Work Practice}

The lack of support for the direct association of alcohol and risky sex has general implications for social workers involved in prevention efforts. While researchers may be apprized of recent alcohol/sex behavior findings, the communities responsible for making local decisions on prevention messages also need to be made aware of research findings which may compromise imbedded assumptions. The presumption that alcohol is directly 
associated with risky sex results in messages that urge abstinence from alcohol when engaging in sex (see, e.g., Jones, 1996). These attempts assume that the outcome will be safer sex. However, such messages promote behavior change without giving consideration to the more complex nature of human behavior and alcohol consumption. The prevention effort may fail to change either alcohol consumption or risky sex behavior. A more effective message will attempt to address the salient conditions surrounding the co-occurrence of drinking and sex behavior.

This study identified partner enhancement drinking motives as an important construct related to reduced levels of condom use within alcohol drinking events among university students. This finding has important implications for HIV/AIDS prevention strategies by refining the type of risky sex behavior (sex without a condom), and linking this to a sub-type of enhancement drinking motive, i.e., a motive which is partner focused. This knowledge can be applied in primary, secondary, or tertiary prevention levels. By addressing the specific drinking motives which underlie the risky sex behavior, practitioners may improve the likelihood of effecting behavior change. This can occur in prevention programs in universities, and in psycho-education interventions in treatment facilities, clinics, and communities.

An application of this finding to an intervention might include the advocacy of new substituted lower risk behaviors to meet the expectancies of enhancement drinking motives rather than advocating directly for condom use or alcohol abstinence. Bandura (1989) has posited that a more difficult task is to extinguish behaviors that are reinforced, than to substitute safer forms of behaviors which serve similar functions. The goal 
becomes to replace alcohol consumption with alternative behaviors which satisfy partner enhancement motives. This approach represents a new conceptualization. Various models of HIV risk reduction have addressed the substitution of the target behaviors directly (risky sex or alcohol use) or have utilized cognitive approaches to decrease target behaviors (Catania, Kegeles, \& Coates, 1990; Kelly, 1995). A more effective approach may be to substitute the behaviors which underlie the motives of the target behavior which would in turn lead to change in the target.

This might be accomplished by incorporating into practice the constructs which were found to underlie partner drinking motives such as, to be able to express one's feelings, to be funny or witty, and to get to know a partner better. By adding this method to existing intervention models, overall effectiveness may be increased. Existing behavior change models provide opportunities to increase self efficacy by improved communication skills, identification of barriers to initiating condom use, and assertiveness training. Specifically including partner enhancement factors as a precursor to risky sex may improve outcomes. It is also important to design the most effective primary prevention campaigns which convey risk reducing messages. These messages can include those which exhibit partner enhancement without alcohol in a context of safer sex.

The study found that among university students, males were more likely than females to engage in casual sex within alcohol drinking events. There is a need to develop gender-specific prevention campaign messages which address the issue of how well a potential sex partner is known. Current prevention interventions address the issue of multiple sex partners; however, these strategies often are directed to males and females 
generally (e.g., Kelly, 1995). These messages, however, should be gender specific. Male targeted messages could portray men discussing normative behavior as not having sex with others not known well especially in drinking contexts. Messages targeted for females might emphasize condom use as a social normative behavior.

The study found high frequency levels on four of the five measured risky sex behaviors. AIDS is the leading cause of death among those between 25 and 44 years of age, and the rates of AIDS cases are increasing within the adolescent and young adult populations. The fact that there is no vaccine for HIV, nor a cure for AIDS, raises the importance of behavior change strategies to reduce risk of HIV transmission. While the results from this study are not numerous, they do provide additional knowledge for more effective prevention strategies.

\section{Implications for Social Policy}

The results of this study suggests that HIV/AIDS prevention needs to move beyond education strategies and include psychosocial conceptualizations. There is potential to apply new knowledge in both AIDS prevention and sex education models. The CDC's current prevention efforts center on public service announcements promoting sexual abstinence and the correct use of condoms, combined with support to communities in AIDS prevention strategies (DHHS, 1996a). The policy of limiting the CDC's role can be changed to a more aggressive policy in which the $\mathrm{CDC}$ can initiate campaigns for community use. With the benefit of federal support, creative campaigns can be produced which portray research-based psychosocial contexts while advocating safer sex. The findings discussed in this study have potential for such community marketing campaigns. 
The complex behavioral associations found in this study suggest that prevention policies of the Ryan White CARE Act be modified. Currently, only public and non-profit agencies who provide primary health care services to persons with HIV/AIDS can access funds for prevention. There is a need to design and produce complex prevention strategies that require creative resources which may be beyond these community providers. Ryan White grants should be accessible to non-profit organizations which are currently involved in prevention of health risk behaviors. Many of theses organizations have established campaigns to prevent the abuse of alcohol, tobacco, and other drugs (ATOD), and risky sex behavior among adolescents and young adults (SAMHSA, 1997). By expanding the funding beyond health care providers, a broader and more comprehensive resource pool would result.

High-risk sexual behavior prevention policy initiatives also stem from the Adolescent Family Life Act of 1981 which funds projects that provide abstinence-focused education to prevent pregnancy and HIV/STD infection (DHHS, 1996c). Research findings from this and other research indicate that this policy should be changed. To limit prevention efforts to abstinence messages is similar to the "just say no" campaigns which were narrowly focused and reached only those at minimal risk. Sexual behavior with or without alcohol represents complex human behavior which demands reality-based risk reduction messages.

DHHS has established the Office of AIDS Research (OAR) to coordinate all NIH HIV/AIDS research. The prevention research includes areas of biomedical, behavioral, and social interventions (DHHS, 1996d). DHHS includes the Substance Abuse and Mental 
Health Services Administration (SAMHSA) which also funds HIV/AIDS prevention programs through the NIH. It is important to continue the policy of funding prevention programs and prevention research until more is understood about the relationships involved in risky sex behaviors, alcohol use, and other psychosocial influences. 


\section{References}

Alvarez, R. (1985). The psycho-historical and socioeconomic development of the Chicano community in the United States. In R.O. De La Garza, F.D. Bean, C.M. Bonjean, R. Romeo, \& R. Alvarez (Eds.). The Mexican American experience: An interdisciplinary anthology. Austin, TX: University of Texas Press.

Arnett, J. (1991). Still crazy after all these years: Reckless behavior among young adults aged 23-27. Personality and Individual Differences, 12 (12), 1305-1313.

Bailey, S. L., Flewelling, R. L., \& Rachal, V. (1992). The characterization of inconsistencies in self-reports of alcohol and marijuana use in a longitudinal study of adolescents. Journal of Studies on Alcohol, 53, 636-647.

Bandura, A. (1986). Social foundations of thought and action: A social cognitive theory. Englewood Cliffs, NJ: Prentice Hall.

Bandura, A. (1989). Perceived self-efficacy in the exercise of control over AIDS infection. In V.M. Mays, G.W. Albee, \& S.F. Schneider (Eds.). Primary Prevention of AIDS: Psychological approaches. Thousand Oaks, CA: Sage.

Bandura, A. (1992). A social cognitive approach to the exercise of control over AIDS infection. In R.J. Di Clemente (Ed.) Adolescents and AIDS: A generation in jeopardy. Thousand Oaks, CA: Sage.

Becker, M.H., \& Joseph, J.G. (1988). AIDS and behavioral change to reduce risk: A review. American Journal of Public Health, 78 , (4), 394-410.

Biafora, F.A., Warheit, G.J., Zimmerman, R.S., Gil, A.G., Apospori, E., Taylor, D., \& Vega, W.A. (1993a). Racial mistrust and deviant behavior among ethnically 
diverse black adolescent boys. Journal of Applied Social Psychology, 23 (11) 891-910.

Biafora, F.A., Taylor, D.L., Warheit, G.J. Zimmerman, R.S., \& Vega, W.A. (1993b). Cultural mistrust and racial awareness among ethnically diverse Black adolescent boys. Journal of Black Psychology 19 (3), 266-281.

Blumstein, P. W., Dawes, R. M., Lindenbaum, S., Rudkin-Miniot, L., Sorenson, J.K., Turner, C. F., \& Wiley, J. A. (1990). Methodological issues in AIDS surveys. In H. G. Miller, C. F. Turner, \& L. E. Moses (Eds.). AIDS: The second decade (pp.359-472). Washington D.C.: National Academy Press.

Boeringer, S.B., Shelran, C.L., \& Alsers, R.L. (1991). Social contexts and social learning in sexual coercion and aggression: Assessing the contribution of fraternity membership. Family Relations, 40, 58-64.

Brim, J. A. (1974). Social networks correlates of avowed happiness. Journal of Nervous and Mental Diseases, $158,432-439$.

Butcher, A.H., Manning, T., \& O'Neal, E.C. (1991). HIV-related sexual behaviors of college students. Journal of American College Health, 40 115-118.

Catania, J. A., Kegeles, S. M., \& Coates, T. J. (1990). Towards an understanding of risk behavior: An AIDS Reduction Model (ARRM). Health Education Quarterly, 17 (1), 53-72.

Caplan, G. (1974). Support systems and community mental health. New York: Behavioral Publication.

Carmines, E. G. \& Zeller, R. A. (1979). Reliability and validity assessment. Thousand Oaks, CA: Sage. 
Casas, J.M. (1995). A culturally sensitive model for evaluating alcohol and other drug abuse prevention programs: A Hispanic perspective. In M.A. Orlandi (Ed.). Cultural competence for evaluators (CSAP Cultural Competence Series Vol. 1. DHHS Publication No. SMA 95-3006, pp. 75-116). Washington, DC.: U.S. Government Printing Office.

Catania, J.A., Dolcini, M.M., Coates, T.J., Kegeles, S.M., Greenblatt, R.M., Puckett, S., Corman, M., \& Miller, J. (1989). Predictors of condom use and multiple partnered sex among sexually active adolescent women: Implications for AIDS-related health interventions. The Journal of Sex Research, 26 (4), 514-524.

Catania, J. A., Gibson, D. R., Chitwood, D. D., \& Coates, T. J. (1990). Methodological problems in AIDS behavioral research: Influences on measurement error and participation bias in studies of sexual behavior. Psychological Bulletin, 108 (3), 339362.

Catania, J. A., Kegeles, S. M., \& Coates, T. J. (1990). Towards an understanding of risk behavior: An AIDS risk reduction model (ARRM). Health Education Quarterly, 17, 53-72.

Centers for Disease Control and Prevention. (1990). Estimates of HIV prevalence and projected AIDS cases: Summary workshop, October 31-November 1, 1989. Morbidity and Mortality Weekly Report (MMWR), 39 (7), 110-119.

Centers for Disease Control and Prevention. (1995). First 500,000 AIDS casesUnited States, 1995. Morbidity and Mortality Weekly Report (MMWR), 44 (46), 849853. 
Centers for Disease Control and Prevention (1996a). World AIDS Day.

Morbidity and Mortality Weekly Report (MMWR), 45, (46), 1005.

Centers for Disease Control and Prevention. (1996b). HIV/AIDS Surveillance

$\underline{\text { Report, } 8}$ (1), 1-34.

Cleary, P.D. (1987). Why people take precautions against health risk. In N.D.

Weinstein (Ed.) Taking care: Understanding and encouraging self-protective behavior.

New York: Cambridge University Press.

Cohen, J. (1988). Statistical power analysis for the behavioral sciences. Hillsdale,

NJ: Lawrence Erlbaum Associates.

Cole, F.L., \& Slocumb, E.M. (1995). Factors influencing safer sexual behaviors in heterosexual late adolescent and young adult collegiate males. Image: Journal of Nursing Scholarship, 27 (3), 217-223.

Cooper, M.L. (1994). Motivations for alcohol use among adolescents:

Development and validation of a four-factor model. Psychological Assessment, 6 (2), 117-128.

Cooper, M.L., Russell, M., Skinner, J.B., \& Windle, M. (1992). Development and validation of a three dimensional measure of drinking motives. Psychological Assessment, $4(2), 123-132$.

Cooper, M.L., Skinner, J.B.,\& George, W.H. (1990). Alcohol use and sexual risktaking among adolescents: Methodological approaches for addressing causal issues. In D. Seminara, R.R. Watson, \& A. Pawlowski (Eds.). Alcohol immunomodulation, and AIDS pp. 11-19). New York: LISS. 
Cox, W.M., \& Klinger, E. (1988). A motivational model of alcohol use. Journal of Abnormal Psychology, 97 (2), 168-180.

Crowe, L.C., \& George, W.H. (1989). Alcohol and human sexuality: Review and integration. Psychological Bulletin, 105 (3), 374-386.

Dalton, H.L. (1989). AIDS in blackface. Doedalus: Journal of the American Academy of Arts \& Sciences, 118, (3), 205-227.

Department of Health and Human Services (1996a). Clinton administration record on HIV/AIDS (Fact Sheet October 11, 1996) [On-line]. Available http:// www.os.dhhs.gov/cgi-bin.

Department of Health and Human Services (1996b). The Ryan White Comprehensive AIDS Resources Emergency (CARE) Act (Fact Sheet May 20, 1996) [On-line]. Available http://www.os.dhhs.gov/cgi-bin.

Department of Health and Human Services (1996c). Preventing teenage pregnancy (Fact Sheet October 4, 1996) [On-line]. Available http://www.os.dhhs.gov/cgi-bin.

Department of health and Human Services (1996d). Major report on AIDS research at NIH (Release, March 14, 1996) [On-line]. Available http://www.os.dhhs.gov/cgi-bin.

DiClemente, R.J. (1991). Predictors of HIV-preventive sexual behavior in a highrisk adolescent population: The influence of perceived peer norms and sexual communications on incarcerated adolescents' consistent use of condoms. Journal of Adolescent Health, 12, 385-390. 
DiClemente, R.J., Forrest, K.A., Mickler, S., \& Principal Site Investigators (1990). College students' knowledge and attitude about AIDS and changes in HIV preventative behaviors. AIDS Education and Prevention, 2 (3), 201-212.

Donaldson, S.I., Sussman, S., MacKinnon, D.P., Severson, H.H., Glynn, T., Murray, D.M., \& Stone, E.J. (1996). Drug abuse prevention programming: Do we know what works? American Behavioral Scientist, 39, (7), 868-883.

Dusenbury, L., Diaz, T., Epstein, J.A., Botvin, C.J., \& Caton, M. (1994).

Attitudes toward AIDS and AIDS education among multi-ethnic parents of school aged children in New York City. AIDS Education and Prevention 6. (3), 237-248.

Edgar, T., Hammond, S.L., \& Freimuth, V.S. (1989). The role of mass media and interpersonal communication in promoting AIDS-related behavioral change. AIDS \& Public Policy Journal, 4 (1), 3-9.

Ell, K. (1996). Social work and health care practice and policy: A psychosocial research agenda. Social Work 41, 583-592.

Festinger, L. (1957). A theory of cognitive dissonance. Stanford, CA: Stanford University Press.

Fisher, J.D., \& Misovich, S.J. (1990). Evolution of college students' AIDS-related behavioral responses, attitudes, knowledge, and fear. AIDS Educational and Prevention, 2(4), 322-337.

Frinter, M.P., \& Rubenson, L. (1993). Acquaintance rape: The influence of alcohol, fraternity membership, and sports team membership. Journal of Sex Education and Therapy, 19 (4), 272-284. 
Gamble, V.N. (1993). A legacy of distrust: African Americans and medical research. American Journal of Preventive Medicine, 9 (6, Suppl), 35-38.

George, W.H. \& Norris, J. (1991). Alcohol, disinhibition, sexual arousal, and deviant sexual behavior. Alcohol Health \& Research World, 15 (2), 133-138.

Gfroerer, J. (1985). Influence of privacy on self-reported drug use by youths. In B. A. Rouse, N. J. Kozel, \& L. G. Richards (Eds.). Self-report methods of estimating drug use: Meeting current challenges to validity (pp. 22-30). NIDA Research Monograph No. 57 (DHHS Publication No. (ADM) 84-1402. Washington D.C.: U.S. Government Printing Office.

Graves, K.L. (1995). Risky sexual behavior and alcohol use among young adults: Results from a national survey. American Journal of health Promotion, 10 (1), 27-36. Harrell, A. V. (1985). Validation of self-report: The research record. In B. A. Rouse, N. J. Kozel, \& L. G. Richards (Eds.). Self-report methods of estimating drug use: Meeting current challenges to validity (pp. 12-21). NIDA Research Monograph No. 57 (DHHS Publication No. (ADM) 84-1402. Washington D.C.: U.S. Government Printing Office.

Hepworth, D.H.., Rooney, R.H., \& Larsen, J.A. (1997). Direct social work practice (5th ed.). New York: Brooks/Cole.

Hingson, R.W., Strunin, L., Berlin, B.M., \& Heeren, T. (1990). Beliefs about AIDS, use of alcohol and drugs, and unprotected sex among Massachusetts adolescents. American Journal of Public Health, 80 (3), 295-299.

Hirsch, B.J. (1979). Psychological dimensions of social networks: A multi- 
method analysis. American Journal of Community Psychology, 7 (3), 263-277.

Holahan, C.J., \& Wilcox, B.L. (1978). Residential satisfaction and friendship formation in high- and low-rise student housing: An interactional analysis. Educational Psychology, 70 (2), 237-241.

Irwin, C. E., \& Millstein, S. G. (1986). Biopsychosocial correlates of risk-taking behaviors during adolescence. Journal of Adolescent Health Care, 7, 82S-96S.

Jemmott, J. B. III, Jemmott, S., Spears, H., Hewitt, N., \& Cruz-Collins, M. (1992). Self-efficacy, hedonistic expectancies, and condom-use intentions among innercity black adolescent women: A social-cognitive approach to AIDS risk behavior. Journal of Adolescent Health, 13, 512-519.

Johnson, L. D., \& O’Malley, P. M. (1985). Issues of validity and population coverage in student surveys of drug use. In B. A. Rouse, N. J. Kozel, \& L. G. Richards (Eds.). Self-report methods of estimating drug use: Meeting current challenges to validity (pp. 31-54). NIDA Research Monograph No. 57 (DHHS Publication No. (ADM) 841402. Washington D.C.: U.S. Government Printing Office.

Jones, J.H. (1981). Bad blood: The Tuskegee syphilis experiment. New York: The Free Press.

Jones, L. (1996). HIV/AIDS: What to do about it. New York: Brooks Cole.

Karon, J.M., Rosenberg, P.S., McQuillan, G., Khare, M., Gwisen, M., \& Petersen, L.R. (1996). Prevalence of HIV infection in the United States, 1984 to 1992. JAMA, $\underline{276}(2), 126-131$.

Kegeles, S.M., Adler, N.E. \& Irwin, C.E. JR. (1989). Adolescents and condoms: 
Associations of beliefs with intentions to use. American Journal of Diseases in Children, $\underline{143}, 911-915$.

Kelly, J. A. (1995). Changing HIV risk behavior: Practical strategies. New York: Guilford.

Klecka, W. R. (1980). Discriminant analysis. Thousand Oaks, CA: Sage.

Koss, M.P., \& Gaines, J.A. (1993). The prediction of sexual aggression by alcohol use, athletic participation, and fraternity affiliation. Journal of Interpersonal Violence, 8 (3), 94-108.

Langer, L. M. \& Tubman, J. G. (in press). Psychological and contextual factors associated with risky sexual behaviors among substance abusing adolescents. American Journal of Orthopsychiatry.

Leigh, B.C. (1990). The relationship of substance use during sex to high-risk sexual behavior. The Journal of Sex Research, 27 (2), 199-213.

Leigh, B.C., \& Morrison, D.M. (1991). Alcohol consumption and sexual risktaking in adolescents. Alcohol Health \& Research World, 15 (1), 58-63.

Leigh, B. C., \& Stall, R. (1993). Substance use and risky sexual behavior for exposure to HIV: Issues in methodology, interpretation, and prevention. American Psychologist, 48 (10), 1035-1045.

Levitor, L.C., Valdiserri, R.O., Lyter, D.W., Callahan, C.M., Kingsley, L.A. Huggins, J., \& Reinaldo, C.R. (1990). Preventing HIV infection in gay and bisexual men: Experimental Evaluation of attitude change from two risk reduction interventions. AIDS Education and Prevention, 2 (2), 95-108. 
LoConte, J. S., O’Leary, A., \& Labouvie, E. (1993). Applying social-cognitive theory to the unsafe sexual behavior of inner city African Americans. Annals of Behavioral Medicine, S15, 102.

McWilliams, C. (1990). North from Mexico. New York: Greenwood Press.

Mickler, S.E. (1993). Perceptions of vulnerability: Impact on AIDS-preventive behavior among college adolescents. AIDS Education and Prevention, 5 (1), 43-53.

Mink, E.M., Mareth, L., Russell, J., \& Young, M. (1991). Correlates of condom use among fraternity men. Psychological Reports, 68, 225-258.

Mitchell, R.E., \& Trickett, E.J. (1980). Task force report: Social networks as mediators of social support. Community Mental Health Journal, 16, (1), 27-44.

Neuman, W. L. (1997). Social research methods: Qualitative and quantitative approaches ( $3^{\text {rd }}$ ed.). Boston: Allyn and Bacon.

Nickerson, K.J., Helms, J.E., \& Terrell, F. (1994). Cultural mistrust, opinions about mental illness, and black students' attitudes toward seeking psychological help from white counselors. Journal of Counseling Psychology, 41 (3), 378-385.

Norris, A.E., \& Ford, (1994). Condom beliefs in urban, low income, African American and Hispanic youth. Health Education Quarterly, 21, (1), 39-53.

Norusis, M. J. \& SPSS Inc. (1994). SPSS professional statistics 6.1. Chicago: SPSS Inc.

Nunnally, J. C. (1978). Psychometric theory (2 $2^{\text {nd }}$ ed.).New York: McGraw-Hill. O’Leary, A., Goodhart, F., Jemmott, L.S. \& Boccher-Lattimore, D. (1992). Predictors of safer sex on the college campus: A social cognitive theory analysis. Journal 
of American College Health, 40, 254-263.

Padilla, A.M., \& Salgado de Snyder, V.N. (1995). Hispanics: What the culturally informed educator needs to know. In M.A. Orlandi (Ed.). Cultural Competence for Evaluators (CSAP Cultural Competence Series Vol. 1. DHHS Publication No. SMA 953006, pp 117-146). Washington, D.C. U.S. Government Printing Office.

Pedhazur, E. J., \& Schmelkin,L. P. (1991). Measurement, design, and analysis: An integrated approach. Hillsdale, NJ: Lawrence Erlbaum.

Pendergrast, R.A., DuRant, R.H., \& Gaillard, G.L. (1992). Attitudinal and behavioral correlates of condom use in urban adolescent males. Journal of Adolescent Health, 13, 133-139.

Reamer, F.G. (1993). AIDS and social work: The ethics and civil liberties agenda. Social Work, 38, 412-419.

Reinarman, C., \& Leigh, B.C. (1987). Culture, cognition, and disinhibition: Notes on sexuality and alcohol in the age of AIDS. Contemporary Drug Problems, Fall, 435460.

Robertson, J.A., \& Plant, M.A. (1988). Alcohol, sex and risks of HIV infection. Drug and Alcohol Dependence, 22, 75-78.

Rubin, A., \& Babbie, E. (1997). Research methods for social work ( ${ }^{\text {rd }}$ ed.). Pacific Grove, CA: Brooks/Cole.

Ryan, C.C. (1987). Statement of the challenge. In C.G. Leukefeld, \& M. Fimbres (Eds.) Responding to AIDS: Psychosocial initiatives. Washington, DC.: NASW Press. Saunders, D.N. (1995). Substance abuse: Federal, state, and local policies. In 
R.L. Edwards, et al. (Eds.), Encyclopedia of Social Work, (19th ed., Vol 3, pp.2338-

2347). Washington, D.C.: NASW Press.

Senf, J.H., and Price, C.Q. (1994). Young adults, alcohol and condom use: What is the connection? Journal of Adolescent health, 15 238-244.

Sheer, V.C., \& Cline, R.J. (1994). The development and validation of a model explaining sexual behavior among college students. Human Communication Research, 21 (2), 280-304.

Shulman, N. (1975). Life-cycle variations in patterns of close relationships. Journal of Marriage and the Family, 37, 813-821.

Skidmore, R.A., Thackeray, M.G., \& Farley, O.W. (1997). Introduction to social work (7th ed.). Boston: Allyn and Bacon.

Skurnick, J.H., Johnson, R.L., Quinones, M.A., Foster, J.D., \& Louria, D.B. (1991). New Jersey high school students' knowledge, attitudes, and behavior regarding AIDS. AIDS Education and Prevention, 3 (1), 21-30.

Sokolovsky, J., Cohen, C., Berger, D., \& Geiger, J. (1978). Personal networks of ex-mental patients in a Manhattan SRO hotel._Human Organization, 37 5-15.

SPSS Inc. (1996). SPSS base 7.0 for Windows user's guide. Chicago: Author.

Steele, C.M. \& Josephs, R.A. (1990). Alcohol myopia: Its prized and dangerous effects. American Psychologist, 45 (8), 921-933.

Stombler, M. (1994). "Buddies" or "Slutties": The collective sexual reputation of fraternity little sisters. Gender \& Society, 8(3), 297-323.

Strunin, L., \& Hingson, R. (1992). Alcohol, drugs, and adolescent sexual 
behavior. The International Journal of the Addictions. 27 (2), 129-146.

Substance Abuse and Mental Health Services Administration [SAMHSA] (1996). Preliminary estimates from the 1995 national household survey on drug abuse (Advance Report No._18) [On-line]. Available http://www.samhsa.gov.

Substance Abuse and Mental Health Services Administration [SAMHSA] (1997). The prevention pipeline, 10 (1).

Taylor, D.L., Biafora, F.A., \& Warheit, G.J. (1994). Racial mistrust and disposition to deviance among African American, Haitian, and other Caribbean island adolescent boys. Law and Human Behavior, 18 (3), 291-303.

Terrell, F., \& Terrell, S. (1981). An inventory to measure cultural mistrust among blacks. The Western Journal of Black Studies, 5 (3), 180-185.

Thomas, S.B. \& Quinn, S.C. (1991). The Tuskegee syphilis study, 1932 to 1972 : Implications for HIV education and AIDS risk education programs in the Black community. American Journal of Public health, 81 (11), 1498-1505.

Thompson, C.C., Neville, H., Weathers, P.L., Poston, W.C., \& Atkinson, D.R. (1990). Cultural mistrust and racism reaction among African-American students. Journal of College Student Development, 31, 162-168.

Treboux, D., \& Busch-Rossnagel (1990). Social network influences on adolescent sexual attitudes and behaviors. Journal of Adolescent Research., 5 (2), 175-189.

Tubman, J. G., \& Langer, L. M. (1995). “About last night:” The social ecology of sexual behavior relative to alcohol use among adolescents and young adults in substance abuse treatment. Journal of Substance Abuse, 7 (4), 449-461. 
Videka-Sherman, L. \& Viggiani, P. (1996). The impact of federal policy changes on children: Research needs for the future, Social Work, 41 594-600.

Walker, K. N., MacBride, A., \& Vachon, M. L. S. (1977). Social support networks and the crisis of bereavement. Social Science and Medicine, $11,335-42$.

Weatherby, N. L., Needle, R., Ceseri, H., Booth, R., McCoy, C. B., Watters, J. K., Williams, M., \& Chitwood, D. D. (1994). Validity of self-reported drug use among injection drug users and crack cocaine users recruited through street outreach. Evaluation and Program Planning, 17 (4), 347-355.

Wechsler, H., Dowdall, G.W., Davenport, A., \& Costillo, S. (1995). Correlates of college student binge drinking. American Journal of Public Health, 85 (7), 921-926.

Weinbach, R. W. \& Grinnell, R. M. (1995). Statistics for social workers (3 ${ }^{\text {rd }}$ ed.). White Plains, N.Y.: Longman.

Weinstein, N.D. (1989). Perceptions of personal susceptibility to harm. In V.M. Mays, G.W. Albee, \& S.F. Schneider (Eds.). Primary prevention of AIDS: Psychological approaches. Thousand Oaks, CA: Sage.

Weiss, R. S. (1974). The provisions of social relationships. In Z. Rubin (Ed.). Doing unto others. Englewood Cliffs, N.J.: Prentice-Hall.

Whitbeck, L.B., \& Hoyt, D.R. (1991). Campus prestige and dating behaviors. College Student Journal, 25, 457-469.

White, H.R., \& Johnson, V. (1988). Risk taking as a predictor of adolescent sexual activity and use of contraception. Journal of Adolescent Research, 3, 317-331.

Windle, M. (1994). Substance use, risky behaviors, and victimization among a 
U.S. national adolescent sample. Addiction, 89, 175-182.

Wish, E. D., \& Mieczkowski, T. (1994). Comment on Weatherby et al. Evaluation and Program Planning, 17 (4), 429-430.

Yarber, W.L. (1992). While we stood by...the limiting of sexual information to our youth. Journal of Health Education, $23,326-335$.

Zimmerman, R. S., \& Langer, L. M. (1995). Improving estimates of prevalence rates of sensitive behaviors: The randomized lists technique and consideration of selfreports honesty. The Journal of Sex Research, 32 (2), 107-117. 


\section{Appendix}

\section{HEALTH BEHAVIOR SURVEY INFORMED CONSENT}

Sexually transmitted diseases are major health problems in America today. The National Institute of Health with the help of FIU is doing a survey to find better ways to help people to avoid these diseases.

We will be surveying students to learn about what they think and how they feel about sex and alcohol. The survey contains questions about your recent sexual behavior, substance use, and how you make health behavior decisions.

It will take approximately one hour to complete the questionnaire. The questionnaire will not have your name on it, or any other information that anyone could use to identify you as the person giving the answers. Even this consent form will be kept separate from your survey form, so no one could identify you as the person giving the answers.

By participating in this survey, the information you give us may help in deciding how we can best lower the risk of sexually transmitted diseases for people your age. The possible drawback to helping with this survey is answering difficult personal questions about your sex life and alcohol and drug use.

I would like your help but it is totally up to you. It's okay to say no. Saying no will not affect you as a student here at FIU. You can change your mind about being in the survey any time and you do not have to answer any questions you don't want to answer.

Will you agree to be in this survey?

\section{CONSENT}

. I have read this form and all my questions about this survey have been answered.

- I freely agree to be in this survey and answer the questions I feel I can answer.

- I understand that my answers are confidential to the extent permitted by law and that no one will know which answers I gave personally.

- I also understand that this form will be kept separate from the form containing my answers. I have also been given a copy of this form.

(Name)

(Interviewer Name please type/print)

(Date)

If you have any questions about the survey or about your rights as a participant at a later time you may contact the Principal Investigator, Dr. Lilly M. Langer at (305) 348-2247. 
NIAAA PHASE 2 HEALTH BEHAVIOR CLINIC SURVEY INSTRUMENT

NA $=$ Not Applicable

DK $=$ Don't Know

Please answer the following questions about your background.

1. How old are you? years old

2. What is your sex?

$\begin{array}{ll}1 & \text { Male } \\ 2 & \text { Female }\end{array}$

3. Are you now. .

$\begin{array}{ll}1 & \text { Married } \\ 2 & \text { Divorced } \\ 3 & \text { Separated } \\ 4 & \text { Widowed, or } \\ 5 & \text { Single/never married } \\ 8 & \text { Refused }\end{array}$

4. With whom do you now live? (CIRCLE ALL THAT APPLY)

$\begin{array}{llll}1 & \text { alone } & 5 & \text { shelter/homeless } \\ 2 & \text { with spouse or other } & 6 & \text { institutional setting } \\ \text { sex partner (lover) } & & \\ 3 & \text { with friends/roommates } & 7 & \text { Other: } \\ 4 & \text { with family } & 8 & \text { Refused }\end{array}$

5. What is the highest grade in school that you completed?
1 Eighth grade or less
4 Some college/tech.school
2 Some high school, but less
5 College graduation than high school graduation (4 yr. bachelor's degree)
3 High school diploma/GED
$8 \quad$ Refused

6. Are you Hispanic? (IF NOT SURE, USE FOLLOWING PROBE: Were you or one of your parents born in a spanish-speaking country?)

$\begin{array}{llll}1 & \text { Yes } & 8 & \text { Refused } \\ 2 & \text { No } & 9 & \text { DK/NA }\end{array}$

7. Were any of your grandparents born in a spanish country?

$\begin{array}{crr}\text { YES } & \text { NO } & \text { DK } \\ 1 & 2 & 8\end{array}$

8. What is the country of your birth?

9. How long have you lived in the U.S.?

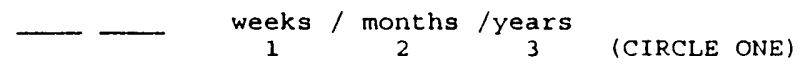

10. What is the country of your mother's birth?

11. How long has your mother lived in the U.S.?

$$
\text { years } 8 \mathrm{NA} / \mathrm{DK}
$$


11.0 How old was your mother when her first child was born?

years

12. What is the country of your father's birth?

13. How long has your father lived in the U.S.?

$$
\text { years } 8 \mathrm{NA} / \mathrm{DK}
$$

14. Most people think of themselves as belonging to a racial/ethnic group. What racial/ethnic group would you say you belong to?

$\begin{array}{ll}1 & \text { American Indian or Alaskan Native } \\ 2 & \text { Asian/Pacific Islander } \\ 3 & \text { Black or African American } \\ 4 & \text { White } \\ 5 & \text { Haitian } \\ 6 & \text { Hispanic } \\ 7 & \text { DK } \\ 9 & \text { Refused } \\ 10 & \text { Other }\end{array}$

Throughout this survey, there are some questions that deal with your attitudes and beliefs about sex and some of the things you might have done. There are no right or wrong answers. (For survey purposes, sex is defined as: if you gave or received oral sex (mouth to penis or mouth to vagina), anal sex (penis in rectum or butt-fucking), or intercourse/vaginal sex.]

15. How would you rate your physical health? would you say...

$\begin{array}{llll}1 & \text { Excellent } & 3 & \text { Fair } \\ 2 & \text { Good } & 4 & \text { Poor }\end{array}$

16.0 In the past 6 months, have you ever had sex after you had been drinking alcohol?

$\left.\begin{array}{c|ll}\text { YES } \\ 1\end{array} \quad \begin{array}{lll}\text { NO } & \text { DK } & \text { NA } \\ 2 & 7 & 8\end{array}\right] \longrightarrow \begin{aligned} & \text { ASK PROCTOR FOR } \\ & \text { FURTHER INSTRUCTIONS }\end{aligned}$

18. Have you been treated for a sexually transmitted disease at some time in the past?

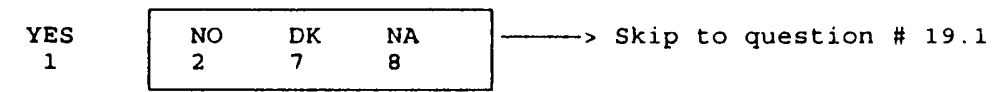

18.1 (IF YES) How many times in your life have you been treated for a STD?

$$
\text { times } \quad 77 \mathrm{DK} \quad 88 \mathrm{NA}
$$

The following questions concern your family. For each, please circle the number corresponding to whether you agree, sort of agree, sort of disagree, or disagree a lot.

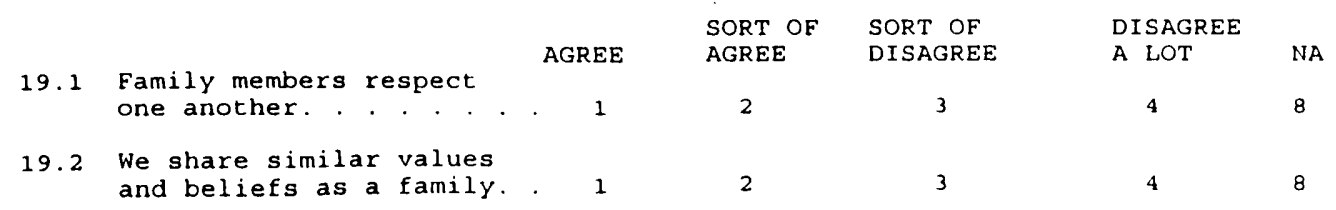




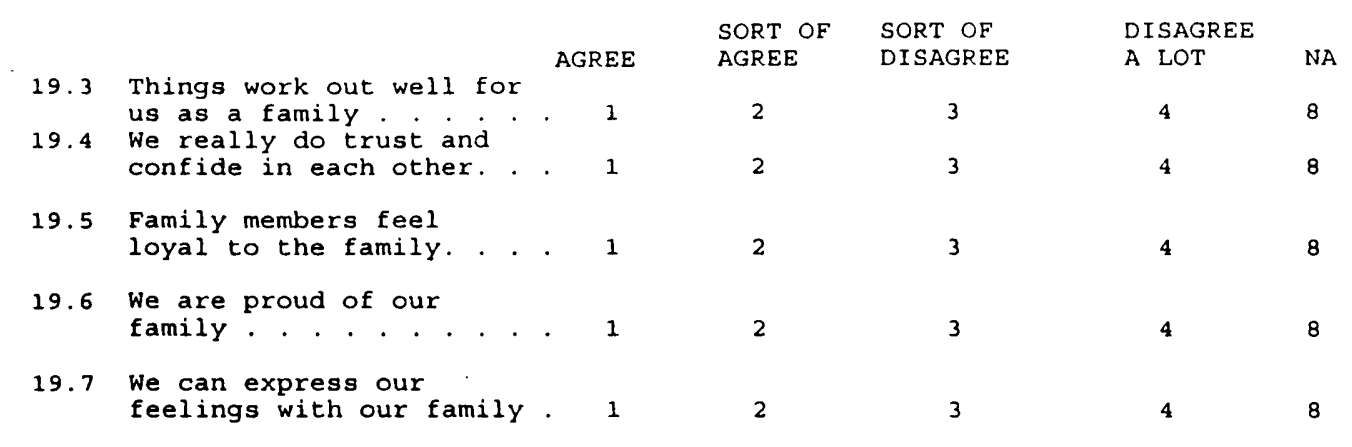

For the next three questions about your family, please circle the number corresponding to whether this is something that is never true for you, once in a while true for you, sometimes true for you, often true for you or always true for you.

would you say...

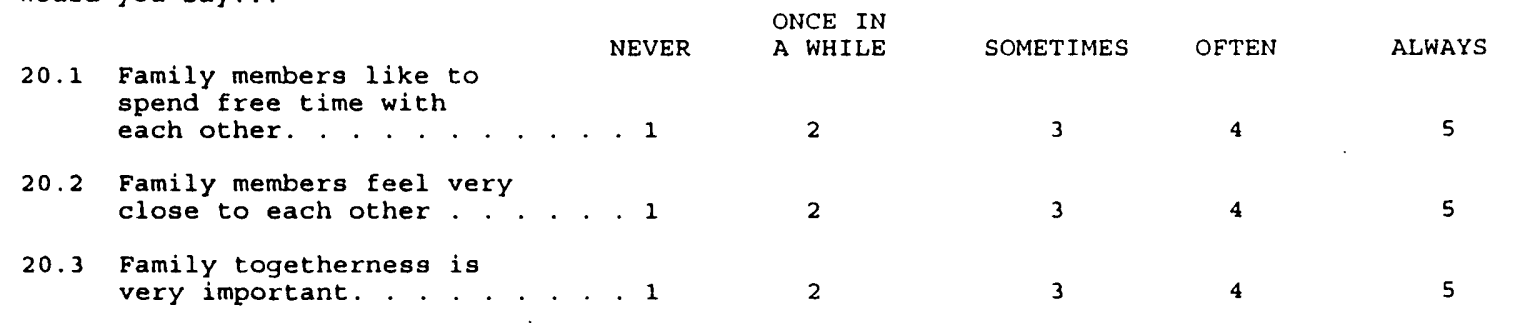

The following questions deal with your decision-making strategies. Please circle how often you usually do each of the following things when you make important decisions.

When you decide to do something...

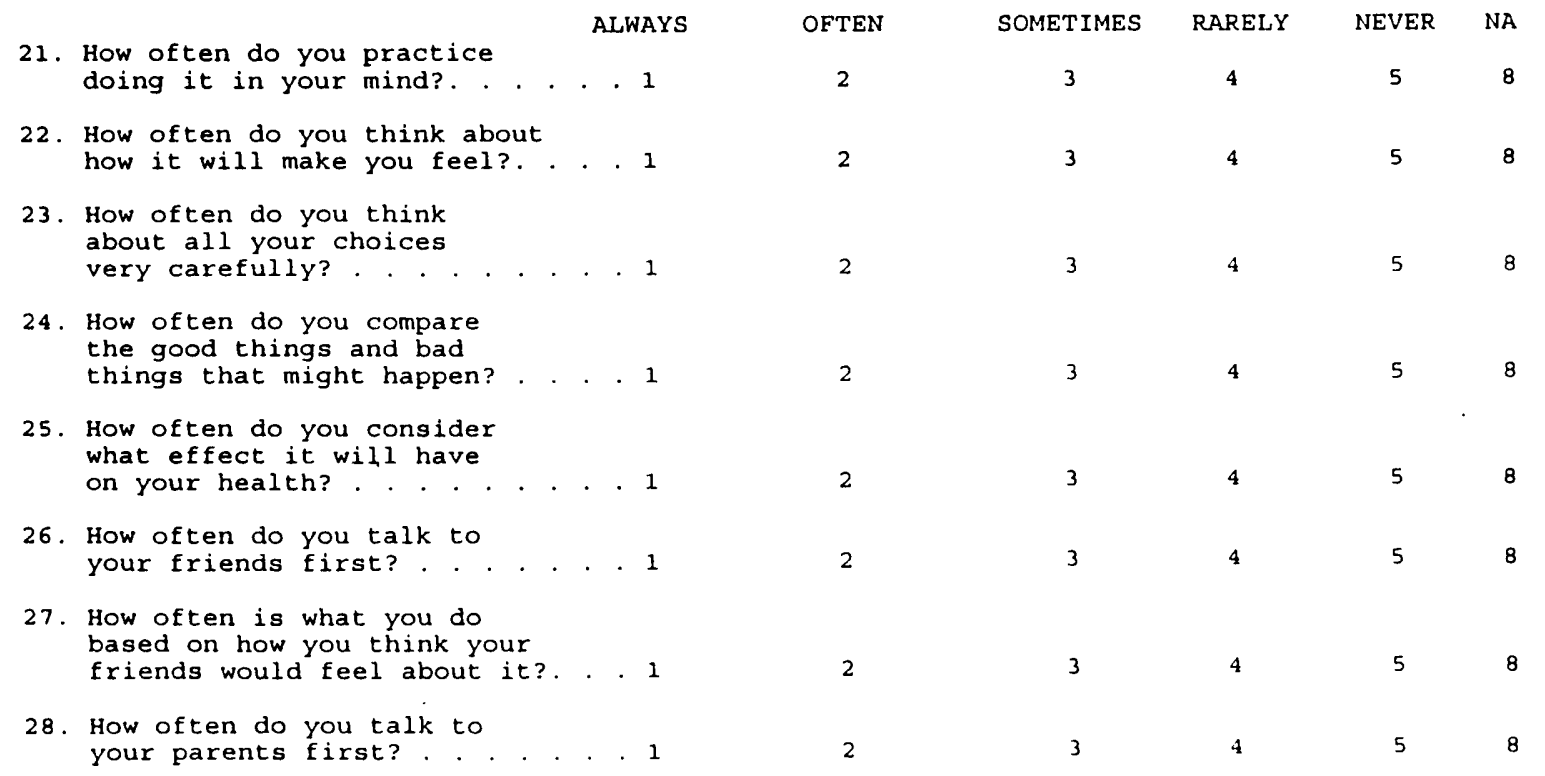


29. How often is what you do

30.1 How often do you do what your parents think is right for you. . 1

31. How often do you do only what your heart tells you?. . . . . . 1

32. How often do you do only what your heart tells you even if you know you are making a mistake?. . 1

32.0 When your friends make decisions, how often do you approve of what they do?. . . . . . . . . . . 1

How often do you do what you

think will make other people

happy even if it may

make you unhappy?.

what you have been told by

your parents or teachers? . . . . 1

35.0 Not counting traffic violations.

how often is what you do

against the law? . . . . . . . .

whether you have the knowledge,

skills or experience to do it?. . I

40.0 For whatever reasons, how often do you do what your friends do? . 1

2

2

$\begin{array}{lll}4 & 5 & 8 \\ 4 & 5 & 8 \\ 4 & 5 & 8 \\ 4 & 5 & 8 \\ 4 & & 8 \\ 4 & 5 & 8\end{array}$

4

8

8

5

8

8

8

8

8

8

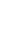


42. How important do you think it is for you to have a good time no matter what lt takes?

Would you say...

\begin{tabular}{|c|c|c|c|}
\hline NOT & A LITTLE & & VERY \\
\hline MPORTANT & IMPORTANT & IMPORTANT & IMPORTANT \\
\hline 1 & 2 & 3 & 4 \\
\hline
\end{tabular}

The following questions are about your attitudes and beliefs about sex and some of the things you might have done. There are no right or wrong answers.

43. How old were you the very first time you had any kind of sex with another person or they had sex with you?

$$
\text { years } \quad 77 \text { DK }
$$

44. How many sex partners have you had in your life?

$$
\longrightarrow
$$

45.0 Some people prefer sexual partners who are of the same sex as themselves, some prefer members of the opposite sex, and others enjoy having sex with both men and women. what do you prefer the sex of your partner to be?

$\begin{array}{lllll}\text { Male } & \text { Female } & \text { Both } & \text { DK } & \text { NA } \\ 1 & 2 & 3 & 7 & 8\end{array}$

46. How old do you think most of your male friends were when they had sex for the first time?

$$
\text { years } \quad 77 \text { DK }
$$

47. How old do you think most of your female friends were when they had sex for the first time?

$$
\text { years } \quad 77 \text { DK }
$$

48. If your best friends thought you were a virgin, how would you feel? would you say that you would be...

VERY UPSET

1
A LITTLE UPSET 2
NOT UPSET 3
HAPPY OR PLEASED

4

49. Have you ever been pregnant [or gotten someone pregnant]?

$\begin{array}{crll}\text { YES } & \text { NO } & \text { (Skip to } 49.4 \text { ) } & \text { DK } \\ 1 & 2 & & 7\end{array}$

49.1 (IF YES) How many times?

49.2 Was this something that you wanted to happen?

$\begin{array}{cllr}\text { YES } & \text { DK } & \text { NO } & \text { NA } \\ 1 & 2 & 3 & 8\end{array}$

49.3 How did the pregnancy finish?
1. birth
2. abortion
3. miscarriage
4. still birth
5. currently pregnant
6 . other
8 NA

How many times? 
49.4 How much do you want to get pregnant [get someone pregnant] at this time?
A LOT
A LITTLE
2
NOT SURE/DK
3
NOT AT ALL
4
NA

$\begin{array}{llllll}1 & 2 & 3 & 4 & 8\end{array}$

50.0 The following questions are about the sex partners you have had in the past 6 months. How many people have you had any kind of sex with, or had sex with you, in the past 6 months?

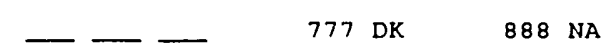

51. How many of these were men?
52. How many of these were women? $-1-888$ NA

52.0 In the past year, how many of your sex partners have been of the same sex as you?

777 DK

53. Did you have a main sex partner in the past 6 months? This would be a regular partner, like a husband/wife or boyfriend/girlfriend or someone you see a lot.

$$
\begin{aligned}
& 1 \text { Yes [GO TO } \# 53.1 \text { ] } \\
& 2 \text { No [GO TO \#54] }
\end{aligned}
$$

53.1 How long has this person been your main sex partner?

$$
\begin{gathered}
\text { weeks / months / years } \\
1 \text { (circle one) }
\end{gathered}
$$

53.2 Is your main sex partner male or female?

$\begin{array}{lcr}\text { MALE } & \text { FEMALE } & \text { NA } \\ 1 & 2 & 8\end{array}$

54.0 How many other sex partners did you have (other than your main sex partner) in the last 6 months?

$$
-777 \mathrm{DK} \quad 888 \mathrm{NA}
$$

In the past 6 months when you had sex, how often did you do the following things with your main sex partner. (IF NO MAIN SEX PARTNER, SKIP TO \#57)

MAIN PARTNER:

$\begin{array}{rlllll}\text { EVERY } & \text { MOST OF } & \text { SOME OF } & & \\ \text { TIME } & \text { THE TIME } & \text { THE TIME } & \text { RARELY } & \text { NEVER } & \text { NA }\end{array}$

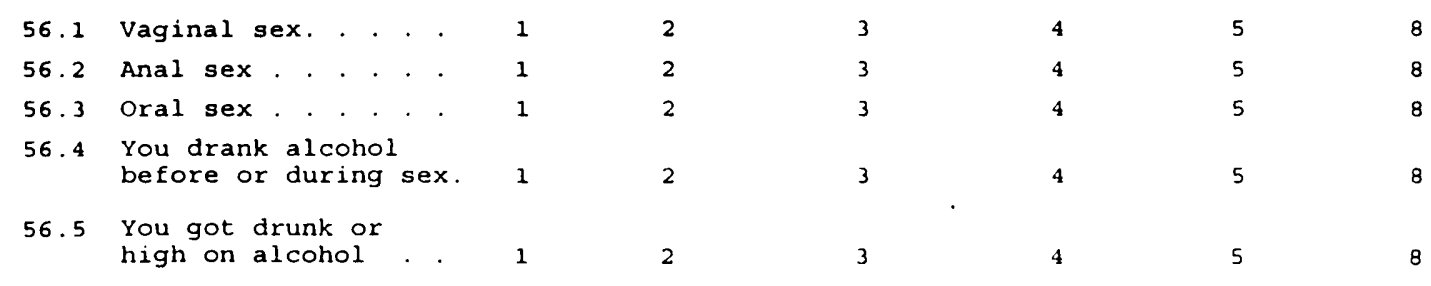


MAIN PARTNER:

\section{EVERY MOST OF SOME OF}

TIME THE TIME THE TIME

RARELY NEVER NA

56.6 Your partner got drunk or high

on alcohol..... 12

THE TIME RARELY NEVER

56.7 You got high on drugs

56.8 Your partner got

high on drugs. . . . 1

56.9 You decided not

to drink because

it might increase

your risk for HIV.

1

56.10 You wanted a

condom to be used.

56.11 How often was a

condom used. . . . . 1

2

3

4

5

8

56.12 You decided not to have

sex because you or

your partner were high

on alcohol or drugs. .

2

3

4

8

56.13 You wanted to tell

your partner you

wouldn't have sex

without a condom. . .

2

3

4

8

56.14 Told your partner

you wouldn't have

sex without a condom . 1

2

3

4

8

56.15 You felt sexually

attracted to

this person. . . . . . 1

2

3

4

8

56.16 You enjoyed having

sex with this person.

2

3

4

8

56.17 How often do you have sex with your main sex partner?

$-\begin{array}{ccccccc}\text { day/ week/ month/ year } & \text { DK } & \text { NA } \\ 1 & 2 & 3 & 4 & 777 & 888\end{array}$

57. In the past 6 months when you had sex, how often did you do the following things with your other sex partner: (IF NO OTHER SEX PARTNER, SKIP TO \#58)

$\begin{array}{cll}\text { EVERY } & \text { MOST OF } & \text { SOME OF } \\ \text { TIME } & \text { THE TIME } & \text { THE TIME }\end{array}$

RARELY

NEVER

NA

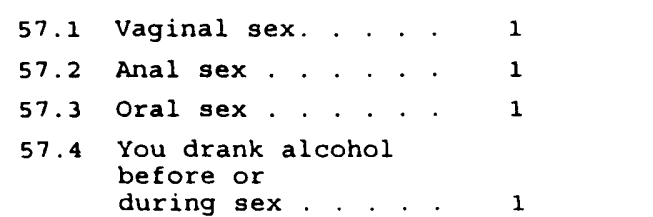

57.5 You got drunk or high on alcohol

2
2
2

3
3
3

4

4

4

4

5

8

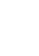

3

4

5

8 
OTHER PARTNER :

EVERY MOST OF SOME OF

TIME THE TIME THE TIME RARELY NEVER NA

57.6 Your partner got drunk or high on alcohol . 1123

57.7 You got high on drugs $1 \quad 3$

57.8 Your partner got high on drugs. . . . 112

your risk for HIV. . 112

23

4

(2)
57.9 You decided not
to drink because
it might increase
57.9 You decided not
to drink because
it might increase
57.9 You decided not
to drink because
it might increase

57.10 You wanted a condom to be used. . 1

2

4

8

57.11 How often was a condom used.

57.12 You decided not to have sex because you or your partner were high on alcohol or drugs. . 1

57.13 You wanted to tell your partner you wouldn't have sex without

a condom....... . 1 57.14 Told your partner
you wouldn't have sex without a condom. 1

57.15 You felt sexually attracted to this person. . . . . . 1

57.16 You enjoyed having sex with this person. 1

57.17 Because you were afraid of getting the AIDS virus, you told your partner there were certain things you just won't do. . . 1

57.18 How often have you had sex with this other sex partner?

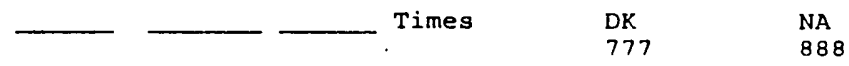

The next few questions are about your partners in the past year.

58. During the past year, have you had sex with someone you know, or you think, uses or used needles to shoot drugs or steroids into their veins or under their skin?

$\begin{array}{ll}1 & \text { Yes } \\ 2 & \text { No } \\ 7 & \text { Not sure/ DK } \\ 9 & \text { Refused }\end{array}$


59. During the past year have you had sex with someone you know or think is a prostitute?

1 Yes

2 No
7 Not sure/DK

9 Refused

8 NA

60. (FOR FEMALES ONLY) In the past year, have you had sex with a man who you know or think also has had sex with other men?

$\begin{array}{llll}1 & \text { Yes } & 9 & \text { Refused } \\ 2 & \text { No } & 8 & \text { NA } \\ 7 & \text { Not sure/ DK } & & \end{array}$

The next few questions are about your experience with substance use such as cigarettes, alcohol and other drugs. Remember you can be honest when you answer questions like these because all of your responses are anonymous. No one will ever be able to match your answers with your name.

61. On an average day, about how many cigarettes do you smoke?

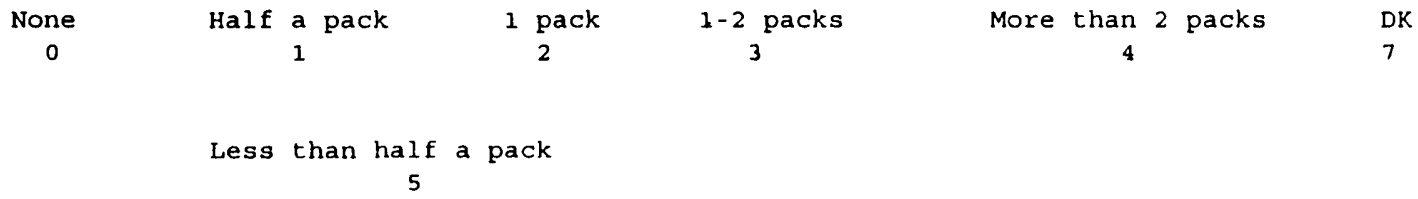

None

0

Half a pack

1

1 pack

2

1-2 packs

3

More than 2 packs

4

DK

7

Less than half a pack

5

62. Not counting small tastes for religious purposes, how old were you when you first began drinking alcohol?

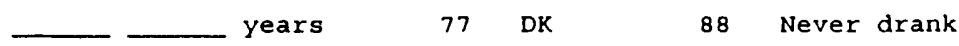

63. How old were you the first time you got drunk?

years

77 DK

88 Never got drunk

64. How long has it been since your last drink of beer, wine or hard liquor?

\begin{tabular}{|lll|l}
1 & more than a year ago & 7 DK \\
2 & $7-12$ months ago & $\rightarrow$ ASK PROCTOR FOR \\
FURTHER INSTRUCTIONS
\end{tabular}

$\left|\begin{array}{lll}3 & 3-6 & \text { months ago } \\ 4 & 1-2 & \text { months ago }\end{array}\right| \longrightarrow$ SKIP TO \#68

5 Within the past 30 days

6. Within the past week 
65. During the past 30 days, how often did you drink beer?

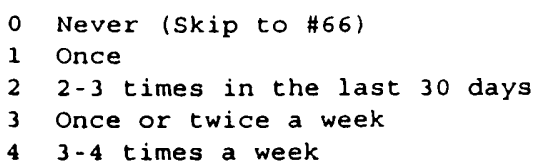

5 Nearly every day

6 Every day

7 DK

8 NA

65.1 Would you say that your beer drinking during the past 30 days was unusually high, about average for the last 12 months, or unusually low?

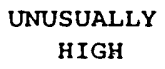

AVERAGE
UNUSUALLY
LOW

1
DK

7
NA

8

65.2 How much beer did you drink on a typical day on which you drank beer during the past 30 days?

66. During the past 30 days, how often did you drink wine or wine coolers?
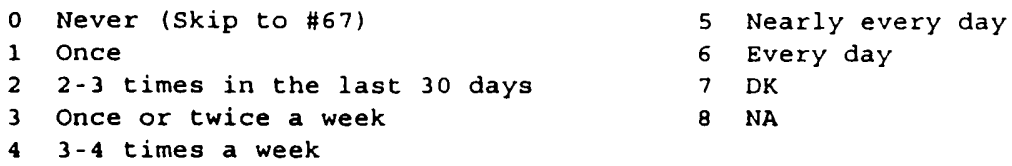

66.1 Did you drink wine, wine coolers, or both?
1. wine
2. wine coolers
3. both
8. NA

66.2 Would you say that your wine or wine cooler drinking during the past 30 days was unusually high, about average for the last 12 months, or unusually low?

\section{UNUSUALLY HIGH}

3
AVERAGE

2

\section{UNUSUALLY \\ LOW}

1

$\begin{array}{cl}\text { DK } & \text { NA } \\ 7 & 8\end{array}$

66.3 How much wine or wine cooler did you drink on a typical day on which you drank wine or wine cooler during the past 30 days? glass (es)

77 DK

88 HA 
67. During the past 30 days, how often did you drink liquor (such as gin, whiskey, vodka, etc.)?
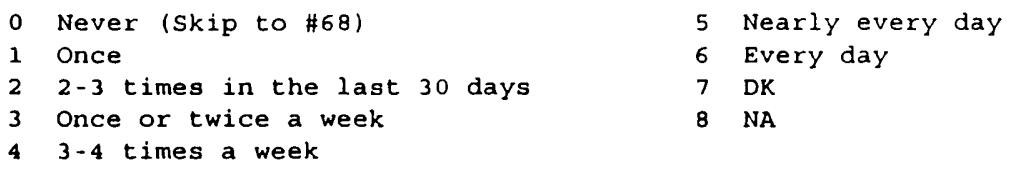

67.1 Would you say that your liquor drinking during the past 30 days was unusually high, about average for the last 12 months, or unusually low?

UNUS. HIGH AVER. UNUS. LOW DK NA

$\begin{array}{lllll}1 & 2 & 7 & 8\end{array}$

67.2 How much liquor did you drink on a typical day on which you drank liquor during the past 30 days?
drink (s)
77 DK
88 NA

68. Have you ever gone on binges or benders, where you kept drinking for a couple of days or more without sobering up?

$\begin{array}{crrr}\text { YES } & \text { NO } & \text { DK } & \text { NA } \\ 1 & 2 & 7 & 8\end{array}$

69. Have you ever received treatment from a physician or other health care professional for problems associated with alcohol?

$\begin{array}{crcr}\text { YES } & \text { NO } & \text { DK } & \text { NA } \\ 1 & 2 & 7 & 8\end{array}$

70. Has anyone in your family ever had an alcohol problem (excessive drinking or alcoholism) that is, where drinking caused problems with relationships, home life, finances, a job, or the law?

\begin{tabular}{c|rrr} 
YES & NO & DK & NA \\
2 & 7 & 8 \\
\hline
\end{tabular}

70.1 Which of your family members?

$\begin{array}{lllll}1 & \text { Mother } & 4 & \text { Brother } & 7 \text { Refused } \\ 2 & \text { Father } & 5 & \text { Grandmother } & 10 \text { Other } \\ 3 & \text { Sister } & 6 & \text { Grandfather } & 8 \text { NA }\end{array}$


These questions are about your drinking experiences. How often did each of these things happen to you in the past 12 months?

In the past 12 months...

$\begin{array}{cccc}\text { NEVER } & \text { ONLY } & 2-3 & 4 \text { ON MORE } \\ \text { ONCE } & \text { TIMES } & \text { TIMES NA }\end{array}$

71.1 How many times were you ripped

off or taken advantage of

while drinking?

0

1

2

4

8

71.2 How often did friends or family members hassle you about your drinking or the way you acted when drinking?

71.3 How often in the past year did you have 6 drinks or more in one day?

71.4 How many times did you argue with a good friend or girlfriend/ boyfriend about your drinking?

71.5 How many times did you do something

while drinking that could get you into trouble, like shoplifting or damaging property?. .0

71.6 How many times were you late to school or work because you had been drinking the night before?. . .0

71.7 In the past year how many

times did you drink two

or more days in a row?. . . . . . 0

71.8 How often did you get hurt or have an accident when you had been drinking?.

71.9 How often in the past year did you get into a fight after drinking?.

71.10 How many times have you had privileges taken away because of drinking?. . . . . . . . 0

71.11 How often did you get into trouble with the law when you had been drinking?. . . . . . . . . 0

71.12 How often did you drink before work or school? 
In the past 12 months...

$\begin{array}{lcccll} & \text { ONLY } & 2-3 & 4 & \text { Or MORE } & \\ \text { NEVER } & \text { ONCE } & \text { TIMES } & \text { TIMES } & \text { NA }\end{array}$

71.13 How many times in the past

month did you get drunk?. . . . . . 0

1

2

4

8

71.14 How often in the past year

did you fight with your parents

about your drinking?. . . . . . . . 0

1

2

4

8

71.15 How often in the past year

did you fight with your

boss/supervisor about drinking?. . .0

1

2

4

8

72. When you have sex, what are the things you think or worry about?

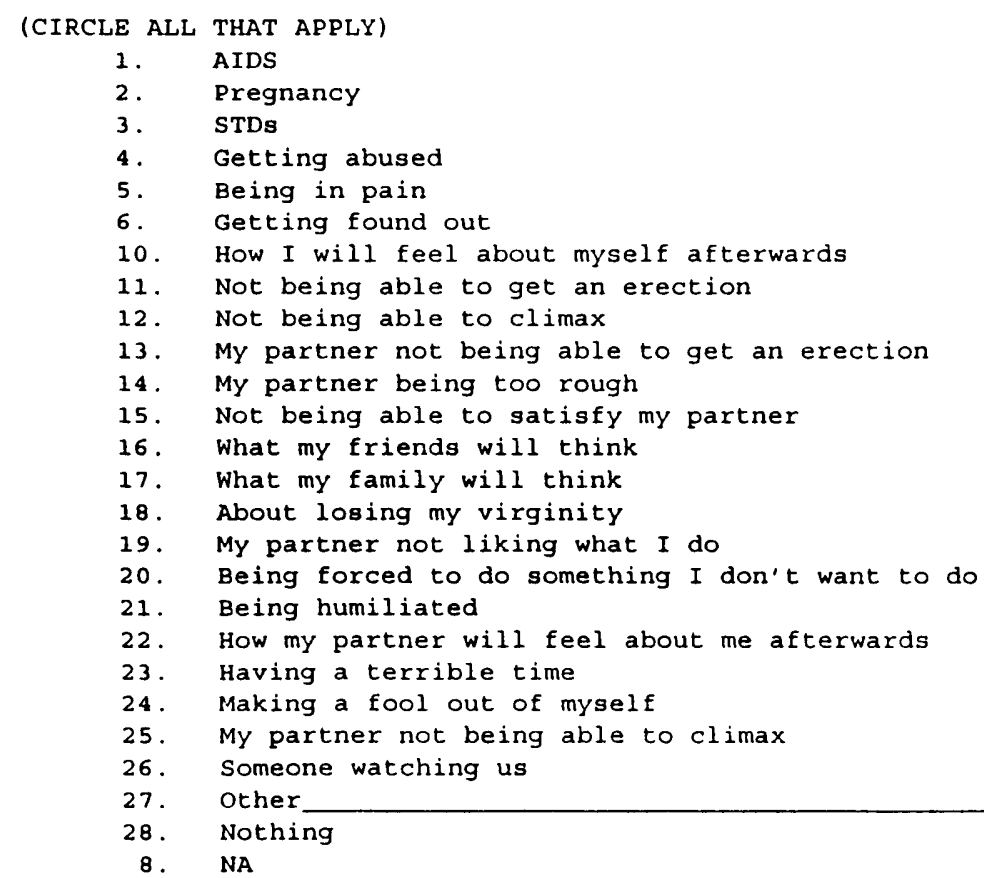

73. When you have had sex, how often have you wanted to find out about your partner's previous drug and alcohol experience?

Would you say:

EVERY TIME

ALMOST EVERY TIME

SOMETIMES

ALMOST NEVER

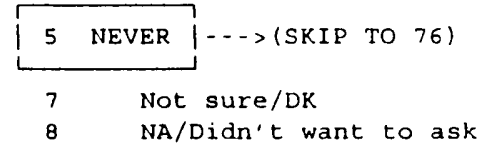


74. When you have had sex, how often have you asked about your partner's previous drug and alcohol experience?

Would you say:

\begin{tabular}{|ll|}
\hline 1 & EVERY TIME \\
2 & ALMOST EVERY TIME \\
3 & SOMETIMES \\
7 & NOt sure/DK
\end{tabular}

75. The times you wanted to ask about your partner's previous drug and alcohol experience and did not, what were the reasons why you didn't?

$8 \quad \mathrm{NA}$

76. When you have had sex, how often have you wanted to talk with your sex partner(s) about whether or not a condom will be used?

Would you say:

$\begin{array}{llll}1 & \text { EVERY TIME } & 4 & \text { ALMOST NEVER, OR } \\ 2 & \text { ALMOST EVERY TIME } & 5 & \text { NEVER (SKIP TO 79.1) } \\ 3 & \text { SOMETIMES } & 8 & \text { NA/Didn't want to ask } \\ 7 & \text { Not Sure/DK } & & \end{array}$

77. When you have had sex, how often have you asked your partner about whether a condom will be used? Would you say. .

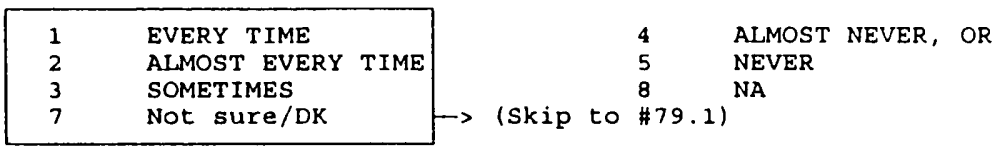

78. The times you wanted to ask your partner about whether a condom would be used and didn't, what were me the reasons why you did not?

8 NA

The following is a list of reasons people sometimes give for drinking alcohol before or during sex with their sex partners. For each one, please answer how true this is for why you drink alcohol before or during sex with your sex partner(s).

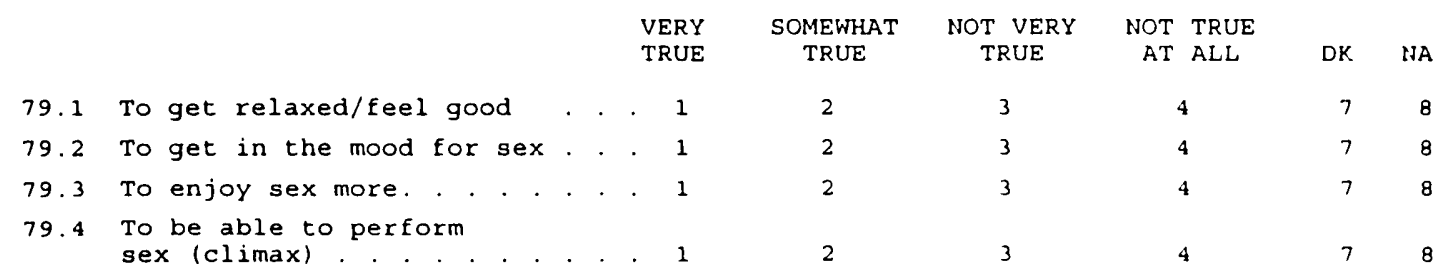




\begin{tabular}{|c|c|c|c|c|c|c|c|c|}
\hline & & & $\begin{array}{l}\text { VERY } \\
\text { TRUE }\end{array}$ & $\begin{array}{l}\text { SOMEWHAT } \\
\text { TRUE }\end{array}$ & $\begin{array}{l}\text { NOT VERY } \\
\text { TRUE }\end{array}$ & $\begin{array}{l}\text { NOT TRUE } \\
\text { AT ALL }\end{array}$ & DK & NA \\
\hline $79 \cdot .5$ & $\begin{array}{l}\text { To be more comfortable with } \\
\text { your partner....... } . .+.\end{array}$ & . & 1 & 2 & 3 & 4 & 7 & 8 \\
\hline 79.6 & To feel closer to your partne & & . 1 & 2 & 3 & 4 & 7 & 8 \\
\hline 79.7 & $\begin{array}{l}\text { To be able to have sex with } \\
\text { someone you really don't } \\
\text { care for very much. } . . . \text {. . }\end{array}$ & . & 1 & 2 & 3 & 4 & 7 & 8 \\
\hline 79.8 & $\begin{array}{l}\text { To be able to express } \\
\text { your feelings. . . . . . . . }\end{array}$ & . & 1 & 2 & 3 & 4 & 7 & 8 \\
\hline 79.9 & To be funnier or wittier. . & . & 1 & 2 & 3 & 4 & 7 & 8 \\
\hline 79.10 & $\begin{array}{l}\text { To be able to get to } \\
\text { know your partner better. }\end{array}$ & . & 1 & 2 & 3 & 4 & 7 & 8 \\
\hline 79.11 & To impress your partner. . . & . & 1 & 2 & 3 & 4 & 7 & 8 \\
\hline 79.12 & $\begin{array}{l}\text { To be able to do whatever } \\
\text { you want to do without } \\
\text { being responsible. }\end{array}$ & & ] & $?$ & 7 & & & \\
\hline 79.13 & $\begin{array}{l}\text { To be able to do what } \\
\text { your friends do. . . . . . . }\end{array}$ & . & 1 & 2 & 3 & 4 & 7 & 8 \\
\hline 79.14 & To drink with your partner. & . & 1 & 2 & 3 & 4 & 7 & 8 \\
\hline 79.15 & $\begin{array}{l}\text { To forget about your worries } \\
\text { about getting a sexually } \\
\text { transmitted disease. . . . . }\end{array}$ & $\cdot$ & 1 & 2 & 3 & 4 & 7 & 8 \\
\hline 79.16 & $\begin{array}{l}\text { To forget about all the } \\
\text { worries in your life... }\end{array}$ & . & . 1 & 2 & 3 & 4 & 7 & 8 \\
\hline 79.17 & $\begin{array}{l}\text { To get rid of the guilt you } \\
\text { have about having sex. }\end{array}$ & . . & 1 & 2 & 3 & 4 & 7 & 8 \\
\hline 79.18 & $\begin{array}{l}\text { To make your partner happy } \\
\text { even though you didn't } \\
\text { want to drink. . . . . . . }\end{array}$ & . . & 1 & 2 & 3 & 4 & 7 & 8 \\
\hline 79.19 & $\begin{array}{l}\text { Just to drink when it has } \\
\text { nothing to do with sex... }\end{array}$ & . & . 1 & 2 & 3 & 4 & 7 & 8 \\
\hline
\end{tabular}

The following is a list of behaviors people sometimes do. For each one, please circle the answer indicating if it is something you have done only when you were drinking, something you have done only when you were not drinking, something you have done whether you were drinking or not, or something you have never done at all.

\begin{tabular}{|c|c|c|c|c|c|c|}
\hline & & $\begin{array}{l}\text { ONLY WHEN } \\
\text { DRINKING }\end{array}$ & $\begin{array}{l}\text { ONLY WHEN } \\
\text { NOT DRINKING }\end{array}$ & $\begin{array}{l}\text { WHEN DRINKING } \\
\text { OR NOT }\end{array}$ & $\underset{\text { NLL }}{\text { NOT }}$ & NA \\
\hline 80.1 & Sex without a condom & . .1 & 2 & 3 & 4 & 8 \\
\hline 80.2 & $\begin{array}{l}\text { Sex with people you } \\
\text { didn't know very well }\end{array}$ & . .1 & 2 & 3 & 4 & 8 \\
\hline 80.3 & $\begin{array}{l}\text { Sex with people who } \\
\text { shoot up drugs. . . . . }\end{array}$ & & 2 & 3 & 4 & 8 \\
\hline 80.4 & $\begin{array}{l}\text { Sex with people before } \\
\text { found out about whether } \\
\text { they had a sexually } \\
\text { transmitted disease. }\end{array}$ & . .1 & 2 & 3 & 4 & 8 \\
\hline 80.5 & Sex with using drugs. &.$\quad .1$ & 2 & 3 & 4 & 8 \\
\hline
\end{tabular}


For the next 1 ist of behaviors, please circle the answer indicating if it is something you have done only when you were using drugs, something you have done only when you were not using drugs, something you have done whether you were using or not, or something you have never done at all.

\section{ONLY WHEN USING DRUGS \\ ONLY WHEN NOT US ING DRUGS}

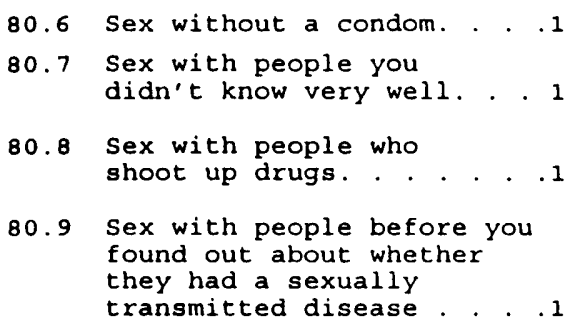

80.10 Sex with alcohol. ......

\section{2}

2

WHEN USING DRUGS OR NOT NOT AT ALL

4

4

The following series of questions is about the last time you had sex when you or your partner had alcohol to drink before or during sex.

81. Thinking of the last time you had sex when you or your partner had alcohol to drink before or during sex, did you have sex with your main sex partner, a new sex partner, or an other sex partner who was not new?

1 MAIN SEX PARTNER
2 NEW SEX PARTNER
3 OTHER SEX PARTNER, NOT NEW
4 Can't remember/NOt sure

4 Can't remember/Not sure

8 NA

How many drinks did you have of... (MARK ALL THAT APPLY)

$\begin{array}{lllllll}82.1 & \text { BEER } & -77 & \text { DK } & 88 & \text { NA } \\ 82.2 & \text { WINE } & - & 77 & \text { DK } & 88 & \text { NA } \\ 82.3 & \text { COOLERS } & - & 77 & \text { DK } & 88 & \text { NA } \\ 82.4 & \text { LIQUOR } & - & 77 \text { DK } & 88 & \text { NA }\end{array}$

82.5 Was this amount less, the same or more than you usually drink?

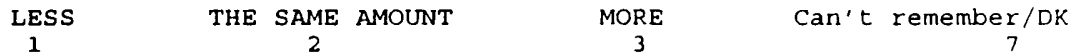

83. How did the alcohol make you feel? Would you say...

$\begin{array}{ll}1 & \text { NO EFFECT } \\ 2 & \text { LOOSE-EASY } \\ 3 & \text { MODERATELY HIGH } \\ 4 & \text { DRUNK, CONFUSED, Or PASSED OUT } \\ 7 & \text { DON't Remember/DK } \\ 8 & \text { NA }\end{array}$


How many drinks did your partner have of...

(MARK ALL THAT APPLY)

$\begin{array}{lllllll}84.1 & \text { BEER } & - & 77 & \text { DK } & 88 & \text { NA } \\ 84.2 & \text { WINE } & - & 77 & \text { DK } & 88 & \text { NA } \\ 84.3 & \text { COOLERS } & - & 77 & \text { DK } & 88 & \text { NA } \\ 84.4 & \text { LIQUOR } & - & 77 & \text { DK } & 88 & \text { NA }\end{array}$

84.5 How many hours did you spend drinking?

$\longrightarrow \begin{array}{ccccc}\text { minutes/hours } & 777 & \text { DK } & 888 & \text { NA }\end{array}$

85. How many hours did your partner spend drinking before and/or during sex with you?

$-\begin{array}{ccccc}\text { minutes/hours } & 777 & \text { DK } & 888 & \text { NA }\end{array}$

86. Did your partner get high, or "buzzed"?

$\begin{array}{cccr}\text { YES } & \text { NO } & \text { DK } & \text { NA } \\ 1 & 2 & 7 & 8\end{array}$

87. How long before or after intercourse did you stop drinking?

$\begin{array}{ll}1 & 2-4 \text { hours before intercourse } \\ 2 & 11 / 2 \text { hours before intercourse } \\ 3 & 1 \text { hour before intercourse } \\ 4 & 1 / 2 \text { hour before intercourse } \\ 5 & \text { minutes before intercourse } \\ 6 & 1-4 \text { hours after intercourse } \\ 7 & \text { Don't remember }\end{array}$

88. Remembering this last time you drank alcohol before or during sex, did you use drugs in addition to alcohol?

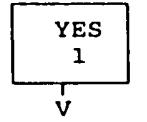

$$
{ }^{\text {NO }} \text { (Skip to \#89) }
$$

$\begin{array}{lr}\text { DK } & \text { NA } \\ 7 & 8\end{array}$

88.1 Which drug(s) did you use?

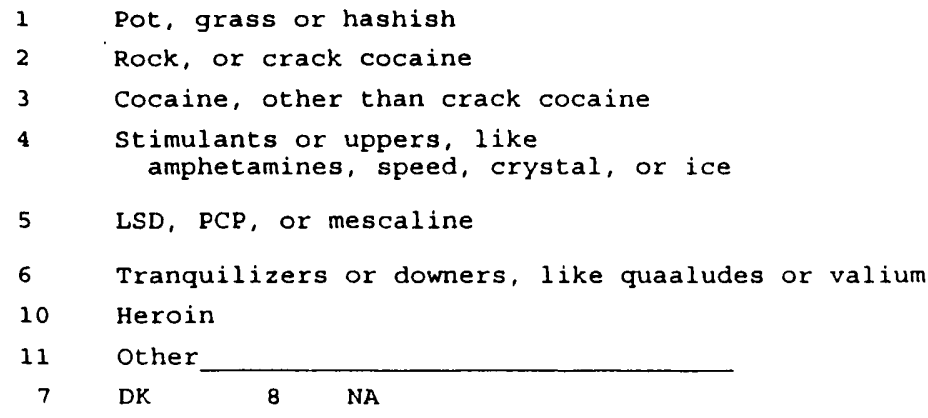


89. Did your partner use drugs in addition to alcohol?

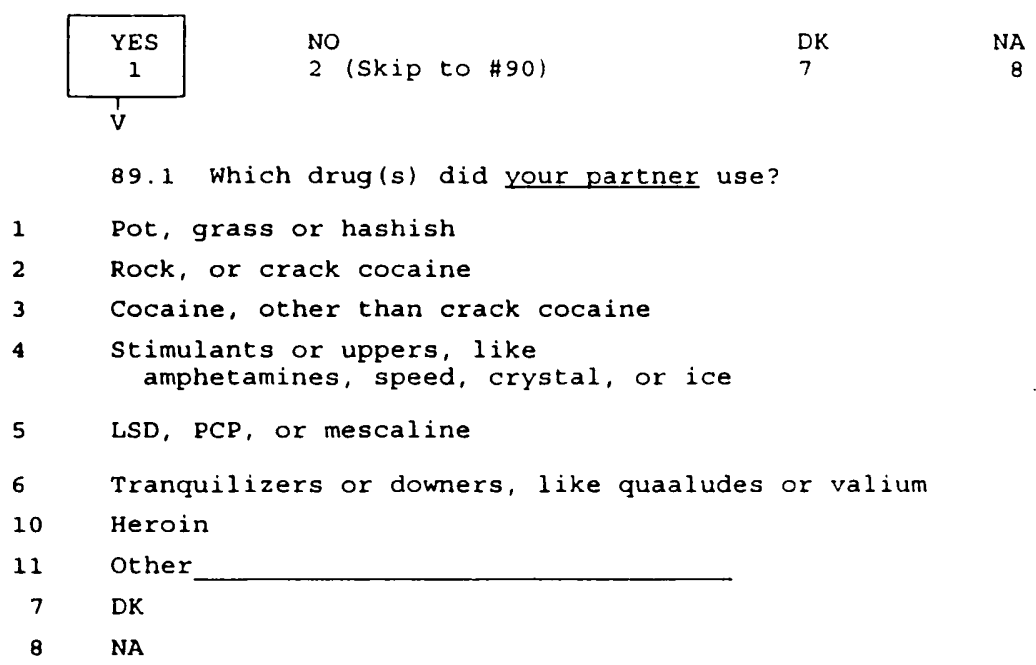

90. Remembering this last time you drank alcohol before or during sex, with whom did you drink? (CIRCLE ALL THAT APPLY)

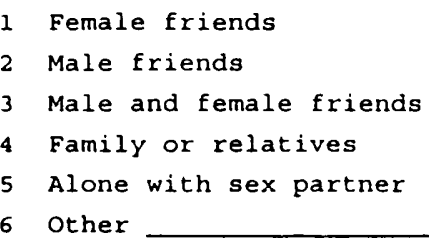

91. Where did you have sex?

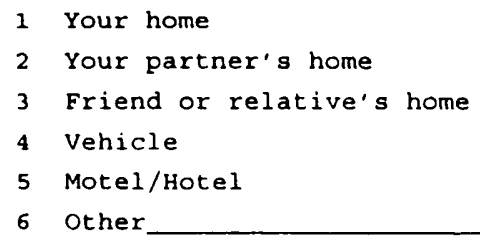

92. What type of sex did you have? (CIRCLE ALL THAT APPLY)

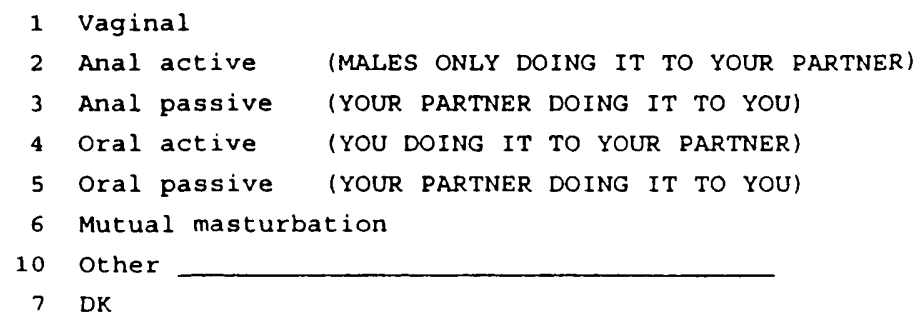


93. What method of contraception, if any, was used?

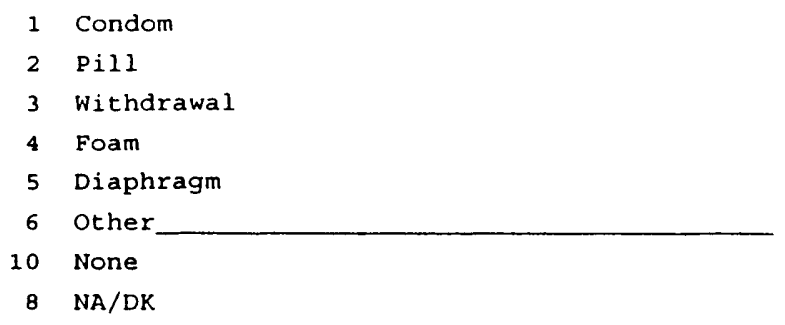

94. How many times before had you had sex with this sex partner?

$$
\begin{array}{lllllllllllll}
0 & 1 & 2 & 3 & 4 & 5 & 6+ & \text { DK } & & 8 & \text { NA }
\end{array}
$$

95. Where did you meet this sex partner?

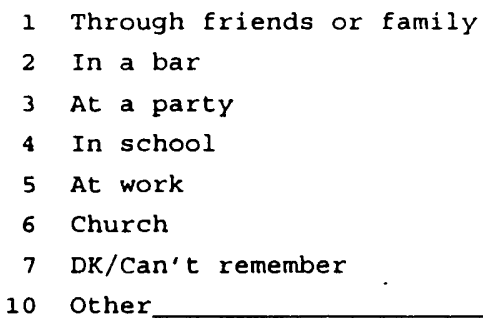

96. How long did you know this person before having sex with him or her? minutes/hours/days/weeks/months/years $777 \mathrm{DK} \quad 888 \mathrm{NA}$

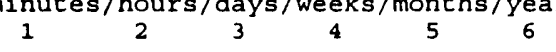

97. How old this was sex partner?

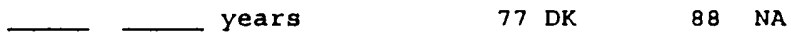

98. Remembering the last time you had alcohol to drink before or during sex, how would you describe the way you were feeling in the situation. (Circle all that apply)

$\begin{array}{rlll}1 & \text { Relaxed in the situation } & 6 & \text { Guilty } \\ 2 & \text { Nervous } & 10 & \text { Dirty/cheap } \\ 3 & \text { Scared/afraid } & 11 & \text { Happy } \\ 4 & \text { Angry } & 12 & \text { Loved } \\ 5 & \text { Resentful } & 13 & \text { Taken advantage of } \\ 14 & \text { Excited } & \text { Other } & \end{array}$

99. When either you or your partner drank alcohol before or during sex, what were your feelings about having sex with this person? Would you say. .

1 You were very sure that you wanted to have sex with this person

2 You were somewhat sure that you wanted to have sex with this person

3 You didn't care either way

4 You were somewhat sure that you didn't want to have sex with this person

5 You were very sure you didn't want to have sex with this person

7 DK 8 NA 
100. Reflecting on your answers to these questions about the last time you had sex when alcohol was used, would you say that this last time was about the same type of sexual experience that you usually have when you drink and have sex?
YES
1 (skip to \#101)
NO
DK
NA

100.1 How would you say it was different?

101. Have you ever had sex when no alcohol was used?
Yes
1
$\begin{aligned} & \text { No } \\ & 2\end{aligned}-\rightarrow$ skip to \#111
NA

The next series of questions is about the last time you had sex when you or your partner did not drink alcohol.

102. Thinking of the last time you had sex when you or your partner did not drink before or during sex, did you have sex with your main sex partner, a new sex partner, or an other sex partner who was not new?
1 Main sex partner
7 Can't remember/Not sure
2 New sex partner
8 NA

3 other sex partner, not new

103. Where did you have sex?

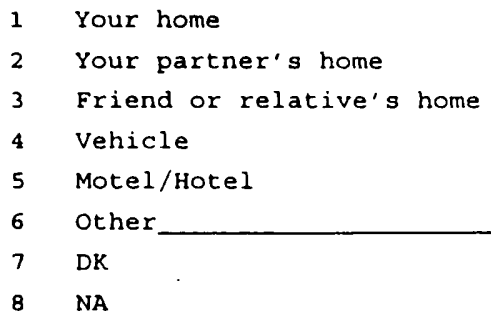

104. Had your partner been drinking?

$\begin{array}{llll}1 & \text { Yes } & 7 & \text { DK } \\ 2 & \text { No } & 8 & \text { NA }\end{array}$


105. Did you use drugs?

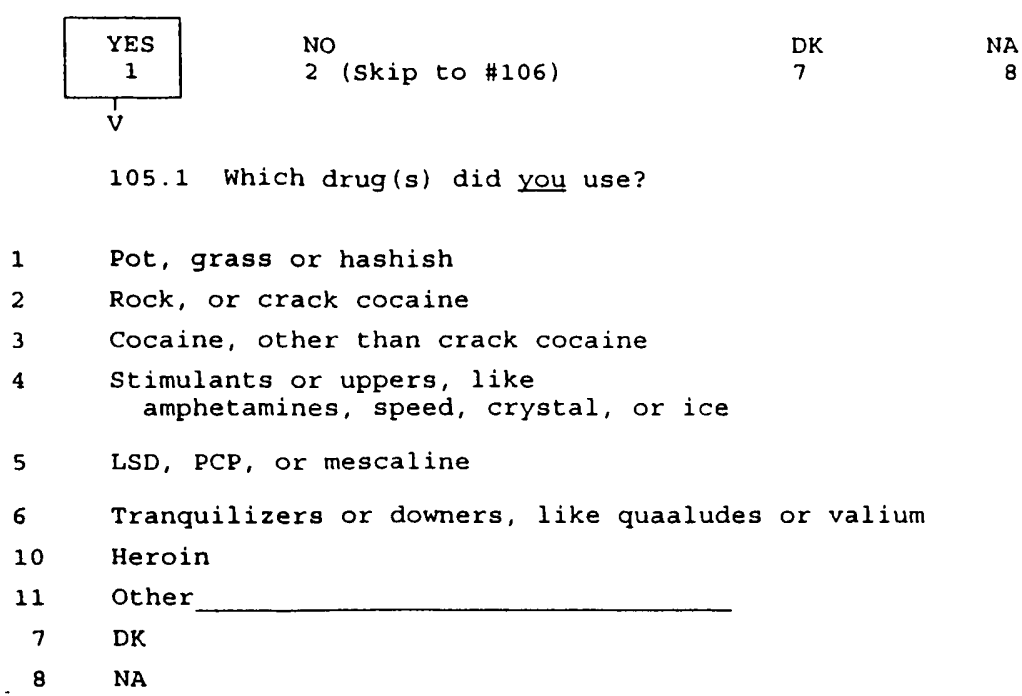

106. Did your partner use drugs?

\begin{tabular}{|c|ccr}
\hline XES & NO & DK & NA \\
1 & $2($ Skip to $\# 107)$ & 7 & B \\
\hline$Y$ & & &
\end{tabular}

106.1 Which drug(s) did your partner use?

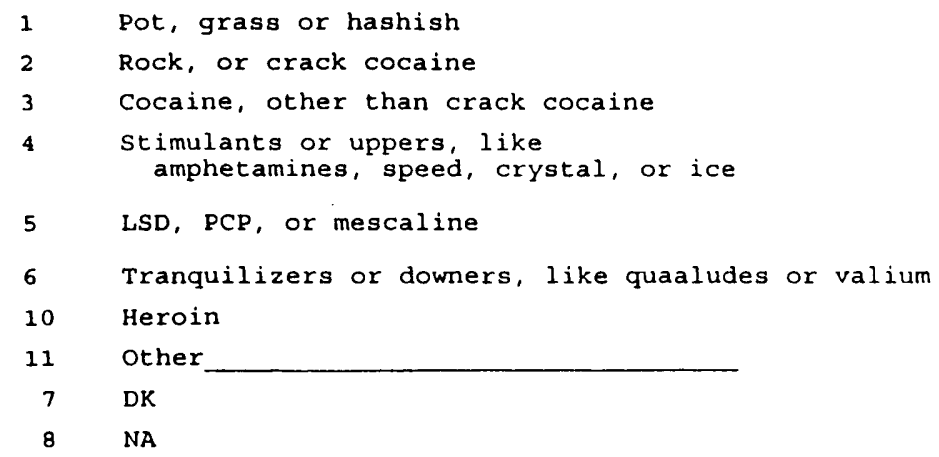


107. The last time you had sex, without alcohol, what type of sex did you have? Did you have: (CIRCLE ALL THAT APPLY BELOW)

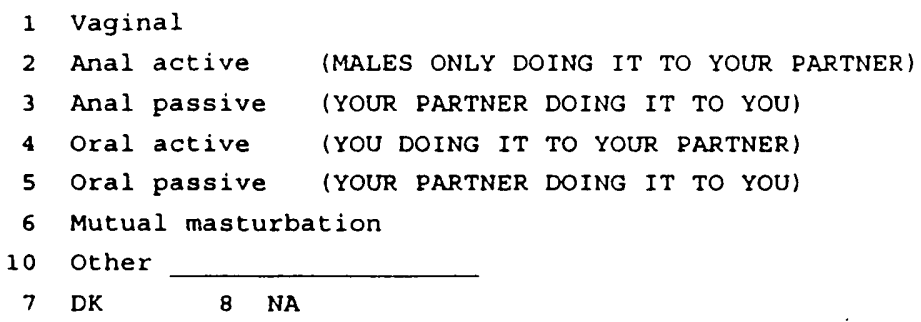

108. What method of contraception, if any, was used?

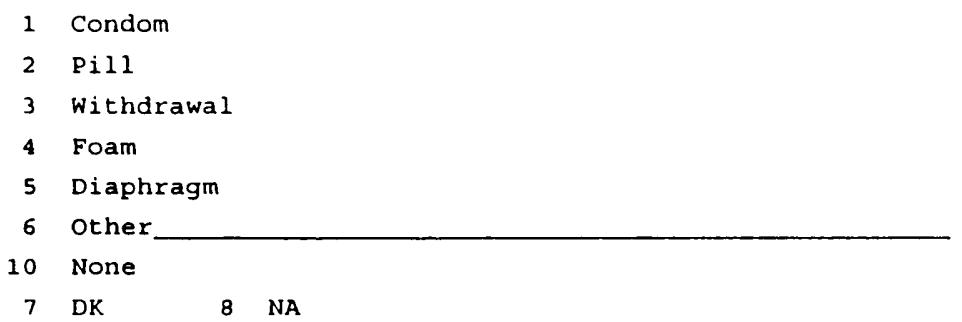

109. How did you feel in the situation? Would you say... (Circle all that apply)

$\begin{array}{llll}1 & \text { Relaxed in the situation } & 6 & \text { Guilty } \\ 2 & \text { Nervous } & 10 & \text { Dirty/cheap } \\ 3 & \text { Scared/afraid } & 11 & \text { Happy } \\ 4 & \text { Angry } & 12 & \text { Loved } \\ 5 & \text { Resentful } & 13 & \text { Taken advantage of } \\ 14 & \text { Excited } & & \\ 15 & \text { Other } & & \\ 7 & \text { DK } & 8 & \text { NA }\end{array}$

110. What were your feelings about having sex with this person? Would you say. . .

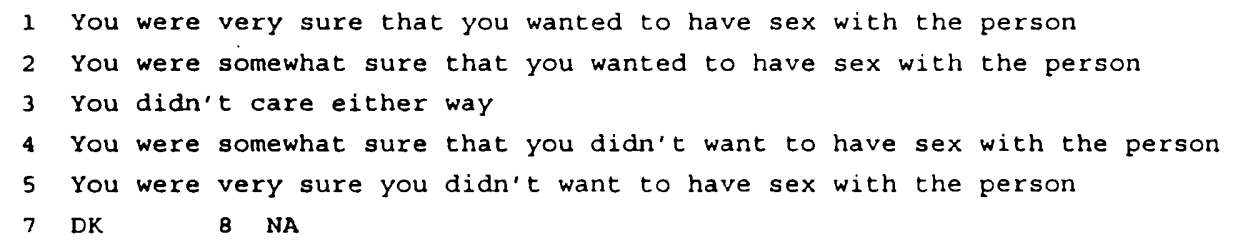

111. Have you ever been forced to have sex when you didn't want to?

\begin{tabular}{|c|c|c|c|}
\hline $\begin{array}{c}\text { YES } \\
1\end{array}$ & $\begin{array}{l}\text { NO } \\
2\end{array}$ & $\begin{array}{l}\text { DK } \\
7\end{array}$ & $--)$ (skip to \#112) \\
\hline
\end{tabular}




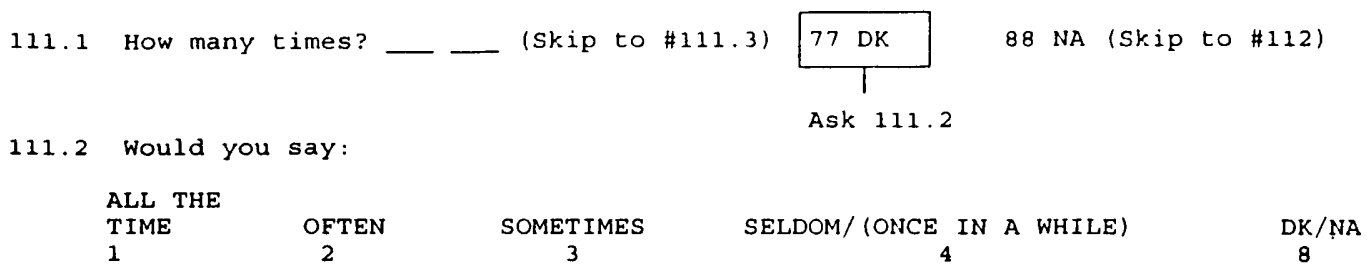

When you were forced to have unwanted sex, how often was it that the person had been:

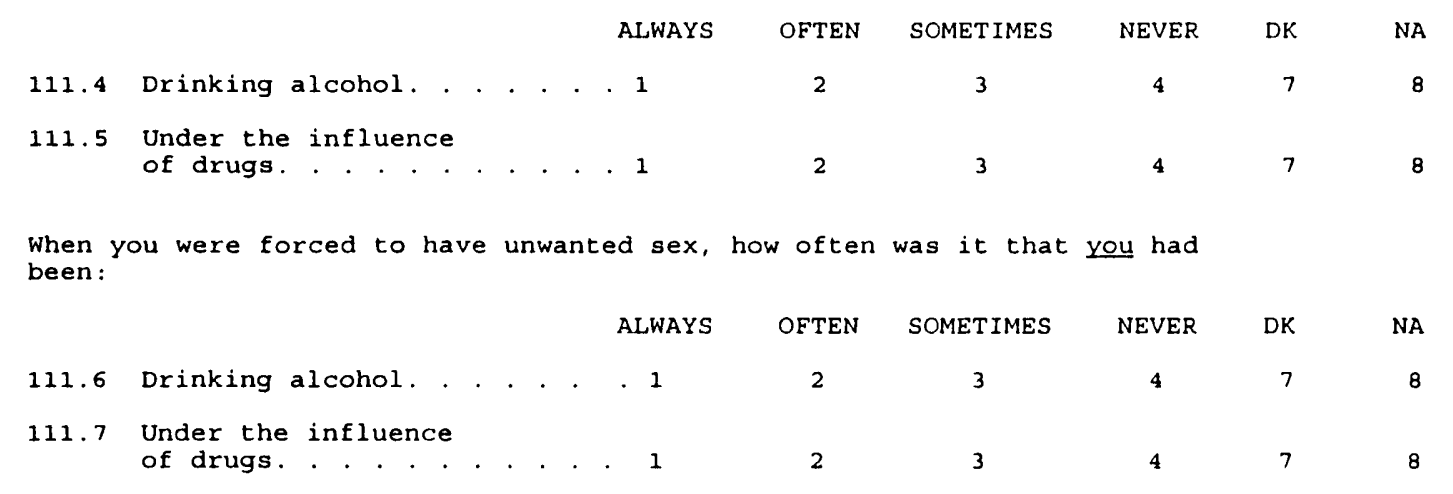

112. When you have sex are there things you just wouldn't do if you haven't been drinking that you would do if you have been drinking?

$\begin{array}{cll}\text { YES } & \text { NO } & \text { DK } \\ 1 & 2 & 7\end{array}$

113. Thinking about the times when you drink and do not drink with sex, would you say that when you drink sex is ....
1. Much more enjoyable
2. Somewhat more enjoyable
3. There was no difference
4. Somewhat less enjoyable
5. Much less enjoyable

$7 \mathrm{DK}$ 
Thinking of the last time you had sex when you or your partner drank alcohol, before you had anything to drink, did you...

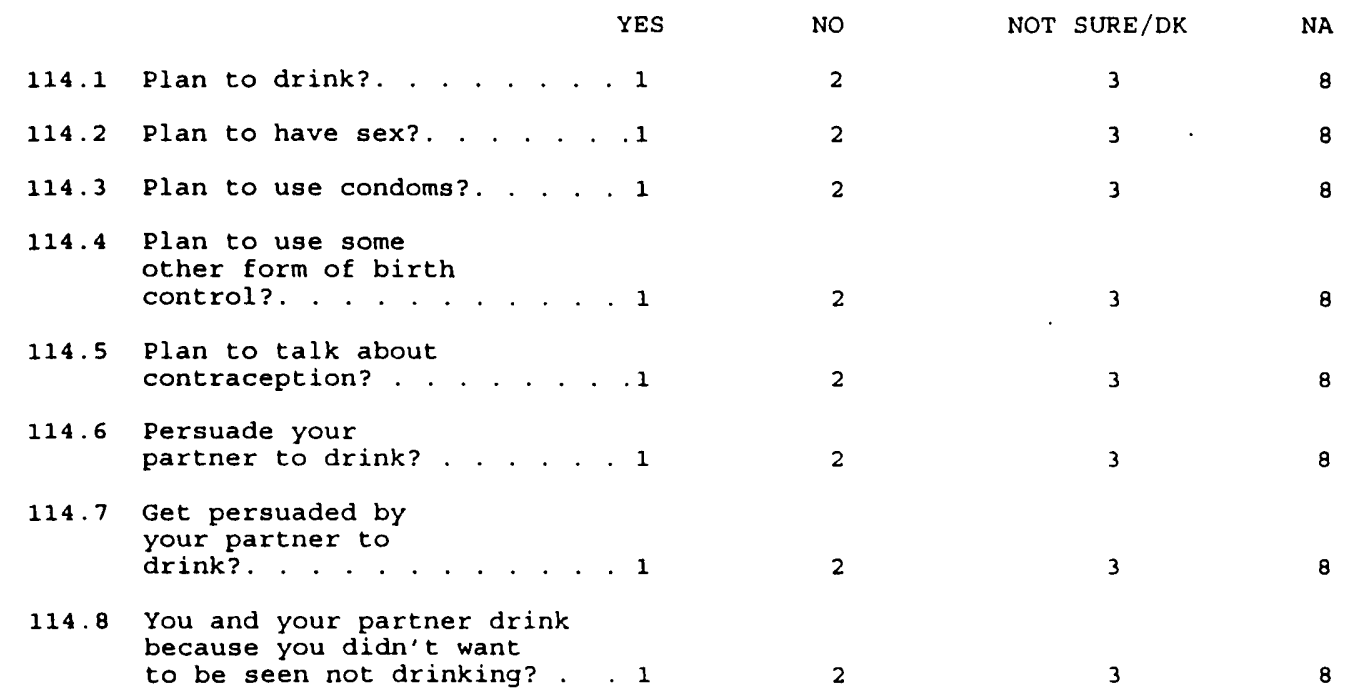

115. Remembering the amount of alcohol you had the last time you drank alcohol and had sex, would you say that if you wanted to drive a car you could drive it...

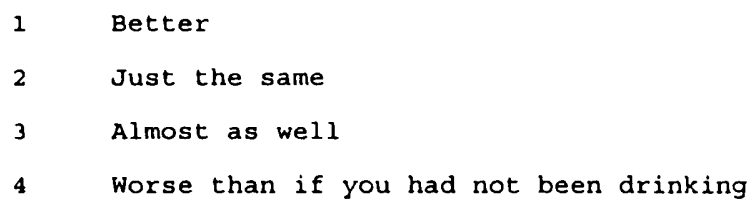

116. Thinking of the last time you had sex when you or your partner drank alcohol, if you could change the experience, what would you want to be different?
6 NOTHING
7 DK
8 NA

The next series of questions are about when you drank, or decided to drink alcohol before having sex...

117. How often do you think about
whether drinking alcohol
would prevent you from being
able to enjoy sex?. . . . . 1


119. How often do you drink alcohol

120. How often do you think about whether you might lose control and be forced to do something you do not want to do?...... . . 1

121. How often do you think about whether you might lose control and force your partner to do something he or she does not want to do?. . . . . . . . . . 1

122. When you have sex how often do you just do it without thinking about the consequences.... . . . . . . . 1

123. When you have sex, how often do you think about all of your choices very carefully?. . . 1

124. When you have sex, how often do you compare all the good things and bad things that might happen?... . 1

125. Some people use drugs to relax or to feel good. Which of the following drugs have you used at some time in your life? Remember, your answers are completely confidential. Have you ever used any drugs like... [CIRCLE ALL THAT APPLY]

1 Pot, grass or hashish

2 Rock, or crack cocaine

3 Cocaine, other than crack cocaine

4 Stimulants or uppers, like amphetamines, speed, crystal, or ice

5 LSD, PCP, or mescaline

6 Tranquilizers or downers, like quaaludes or valium

10 Heroin

11 Never used drugs (skip to \#135)

12 other

7 DK 8 NA

126. Have you ever used a needle to shoot drugs or steroids into a vein or under your skin? (For example, drugs like speed, speedball, heroin, or cocaine.)

$\begin{array}{crcr}\text { YES } & \text { NO } & \text { REFUSED } & \text { NA } \\ 1 & 2 & 9 & 8\end{array}$

127. How often when you drink alcohol before or during sex do you usually use other drugs as wel1?

EVERY TIME OFTEN

ABOUT HALF

1

2 THE TIME

RARELY

4 NEVER

5 (SKIP TO \#135)

NA 
128. Which do you usually have first when you use alcohol and drugs before or during sex?
DRUGS
ALCOHOL
CAN' $T$ REMEMBER/DK
NA
1
2
7

For each of these next statements, please circle if it is VERY TRUE, SOMEWHAT TRUE, NOT VERY TRUE, OR NOT TRUE AT ALL for YOu.

\begin{tabular}{|c|c|c|c|c|}
\hline $\begin{array}{l}\text { VERY } \\
\text { TRUE }\end{array}$ & $\begin{array}{l}\text { SOMEWHAT } \\
\text { TRUE }\end{array}$ & $\begin{array}{l}\text { NOT VERY } \\
\text { TRUE }\end{array}$ & NOT & TRUE \\
\hline
\end{tabular}

129. Being high or stoned on

drugs has kept you

from using condon

130. I only feel comfortable

having sex when I am not high

on drugs. . . . . . . . . .

(1)

131. I get high or stoned on

drugs to please my partner

even though I don't like

to............... . .

1

132. I have really good sex only

when I am high on druqs. . . . . 1

133. When I am high or stoned on drugs I convince my partner to use drugs also. . . . . . . . . 1

134. I have really good sex only when my partner is high on drugs . . . . . . . . . . . .

alcohol has kept you

from using condoms. . . . . . . . . . 1

2

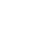

136. I have really good sex only

when I am not high on alcohol... 1

2

2

$$
4
$$$$
78
$$

A

137. I only feel comfortable having sex when I am high on alcohol.

138. I have really good sex only when my partner is high on alcohol. . . . . . . . . . 1

139. Sex without some risk is no fun. . . . . . . . . . .

(2)
140. If a person carries a condom it means that he or she is looking for sex. . . . . . . . 1

141. I have sex to make me feel better when I'm depressed.

. . . 1

$\begin{array}{lllll}2 & 3 & 4 & 7 & 8 \\ 2 & 3 & 4 & 7 & 8 \\ 2 & 3 & 4 & 7 & 8 \\ 2 & 3 & 4 & 7 & 8\end{array}$

For each of these next statements about your friends and partners, please circle if it is true for ALL of THEM, MOST OF THEM, SOME Of THEM, VERY FEW Of THEM, Or NONE Of THEM.

142. How many of your male friends ALL OF
THEM

$\begin{array}{cc}\text { MOST OF } & \text { SOME } \\ \text { THEM } & \text { OF THEM } \\ 2 & 3\end{array}$ $\begin{array}{ccc}\text { VERY FEW } & \text { NONE OF } & \\ \text { OF THEM } & \text { THEM } & \text { NA } \\ 4 & 5 & 8\end{array}$ drink alcohol before sex. 1

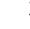

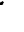




$\begin{array}{cccccc}\text { ALL OF } & \text { MOST OF } & \text { SOME } & \text { VERY FEW } & \text { NONE OF } & \\ \text { THEM } & \text { THEM } & \text { OF THEM } & \text { OF THEM } & \text { THEM } & \text { NA }\end{array}$

143. How many of your female friends

drink alcohol before sex.......

144. How many of your friends use

condoms almost all of the time.

145. How many of your friends think

sex with alcohol and drugs

is a good idea. . . . . . . . . . . 1

2

2

3

4

58

46. How many of your close

female friends use condoms

with a new sex partner.

147. How many of your female friends

carry condoms........... . 1

3

2

3

4

8

148. How many of your close male friends use condoms with

a new sex partner. .......... 1

3

4

8

How many of your male friends

carry condoms. . . . . . . . . . . 1

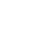

3

3

$\begin{array}{lll}4 & 5 & 8\end{array}$

For each of these next statements, please circle if it is VERY TRUE, SOMEWHAT TRUE, NOT VERY TRUE, OR NOT TRUE AT ALL for you.

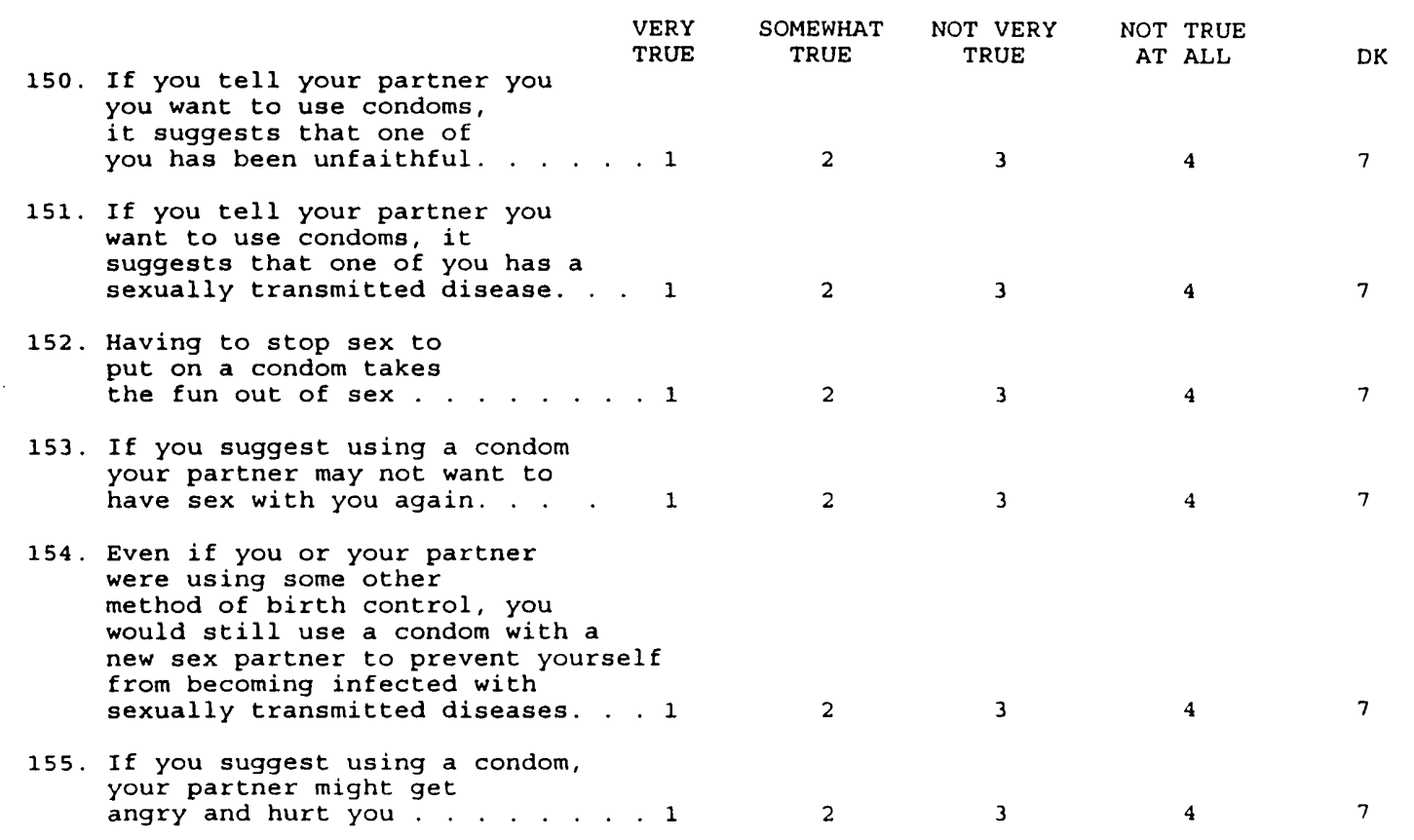


156. The last time you had sex, did you or your main partner use a condom?

$\begin{array}{ccccc}\text { YES } & & \text { NO } & \text { DK } & \text { INA } \\ 1 & \text { (Skip to } \# 156.2) & 2 & 7 & 8\end{array}$

156.1 (IF NO CONDOM USED WITH MAIN PARTNER) since you said that you didn't use a condom with your main sex partner, were there any particular reasons you had for using/not using one?

8 NA

156.2 The last time you had sex did you or your other sex partner use a condom?

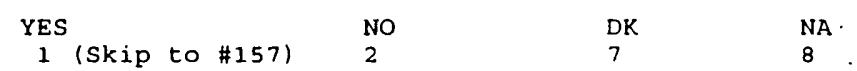

156.3 (IF NO CONDOM USED WITH OTHER PARTNERS) Since you said that you didn't use a condom with your other sex partner, were there any particular reasons you had for using/not using one?

157. Have any of your sex partners ever refused [refused to allow you] to use a condom? YES

1

\begin{tabular}{cc|} 
NO & DK/CAN'T REMEMBER \\
2 & 7
\end{tabular}
(GO TO \# 158)

157.1 What did you say?

157.2 The last time your partner refused to use a condom, was he or she under the influence of alcohol and/or drugs?

$\begin{array}{ccrr}\text { Yes } & \text { No } & \text { DK } & \text { NA } \\ 1 & 2 & 7 & 8\end{array}$

158. When you and your partner use a condom during sex, who usually supplies the condom?

$\begin{array}{cccc}\text { YOU } & \text { YOUR PARTNER } & \text { BOTH } & \text { NA } \\ 1 & 2 & 3 & 8\end{array}$

159. Remembering the times your partner did not want to use a condom and you wanted to protect yourself from being infected with the AIDS virus, what type of sexual activities do you do instead without using a condom: (CIRCLE ALL THAT APPLY)

1 Mutual masturbation (stimulating each other)

2 Active oral sex without swallowing fluids (you do it to partner)

3 Active oral sex with swallowing fluids (you do to partner)

4 Passive oral sex (partner does to you)

5 Active anal sex (men only; you do to partner)

6 Anal sex, pulling out (you do to partner)

10 Passive anal sex (partner does to you)

11 Vaginal sex

12 Vaginal sex, pulling out

13 Didn't have sex 7 DK 8 NA

14 other 
160. Often people engage in unprotected sex and regret it later. For some of these individuals the reason was because they felt so secure with and trusting of the other person that it didn't seem possible that this person could be a danger to them. How true is this reason for you regarding the times you had unprotected sex. (IF No NEw PARTNERS IN PAST 6 MONTHS, SKIP TO \#160.4)

$\begin{array}{lllll}\begin{array}{l}\text { Very } \\ \text { True }\end{array} & \begin{array}{l}\text { Somewhat } \\ \text { True }\end{array} & \text { True } & \begin{array}{l}\text { Not very } \\ \text { True }\end{array} & \begin{array}{l}\text { Not true } \\ \text { at all }\end{array} \\ 5 & 4 & 3 & 2 & 1\end{array}$

The following is a list of statements different people have made about the kinds of things they might discuss with someone before having sex with them the first time. please circle if that is something that you said with ALL OF YOUR NEW SEX PARTNERS IN THE PAST 6 MONTHS, MOST OF THEM, SOME OF THEM, or NONE OF THEM:

160.1 You asked them about the number of sex partners they had unprotected sex with before having sex with you? WOULD YOU SAY:

$\begin{array}{llll}1 & \text { All of your partners } & 4 & \text { None of your partners } \\ 2 & \text { Most of your partners } & 7 & \text { DK } \\ 3 & \text { Some of your partners } & 8 & \text { NA }\end{array}$

160.2 You asked them, whether they had ever used IV drugs or had sex with someone who used IV drugs? WOULD YOU SAY:

$\begin{array}{llll}1 & \text { All of your partners } & 4 & \text { None of your partners } \\ 2 & \text { Most of your partners } & 7 & \text { DK } \\ 3 & \text { Some of your partners } & 8 & \text { NA }\end{array}$

160.3 You told them you wouldn't have sex unless a condom was used? WOULD YOU SAY:

$\begin{array}{llll}1 & \text { All of your partners } & 4 & \text { None of your partners } \\ 2 & \text { Most of your partners } & 7 & \text { DK } \\ 3 & \text { Some of your partners } & 8 & \text { NA }\end{array}$

160.4 Before sexual contact, have you ever looked at your partners genitals for any sores or sign of a sexually transmitted disease?

$\begin{array}{clll}\text { YES } & \text { NO } & \text { DK } & \text { NA } \\ 1 & 2 & 7 & 8\end{array}$

161. How many times do you usually have sex with a partner before you decide that it would be safe to have unprotected sex with that person?

times

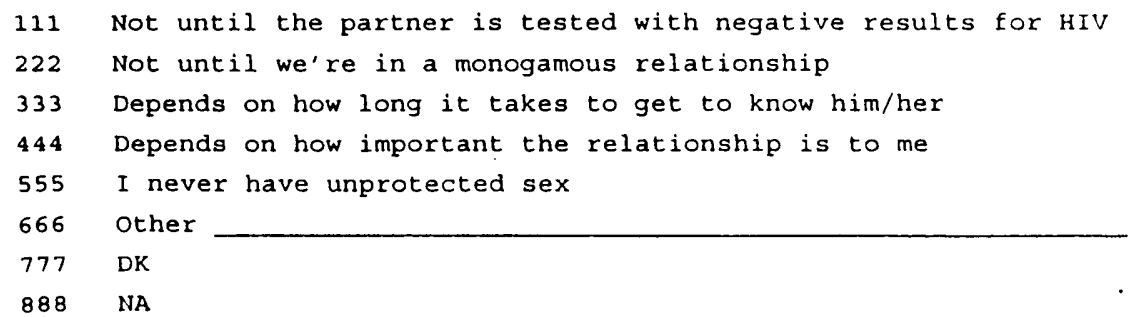


162. What do you think your chances are of getting the AIDS virus? Would you say --

$\begin{array}{ccccccc}\text { VERY } & \text { SOMEWHAT } & \text { SOMEWHAT } & \text { VERY } & \text { NO } & & \\ \text { HIGH } & \text { HIGH } & \text { LOW } & \text { LOW } & \text { CHANCE } & \text { DK } & \text { NA } \\ 1 & 2 & 3 & 4 & 5 & 7 & 8\end{array}$

163. What do you think your chances are of already having the AIDS virus? Would you say --

\begin{tabular}{|c|c|c|c|c|c|c|}
\hline VERY & SOMEWHAT & SOMEWHAT & VERY & NO & & \\
\hline $\mathrm{HIGH}$ & HIGH & LOW & LOW & CHANCE & DK & REFUSED \\
\hline 1 & 2 & 3 & 4 & 5 & 7 & 9 \\
\hline & & ALWAYS & OFTEN & SOMETIMES & NEVER & NA \\
\hline
\end{tabular}

164. When you decide to have sex without a condom, how of ten do you think about whether you could become infected with a sexually transmitted disease other than AIDS?

165. When you decide to have sex without a condom, how of ten do you have sex even though you're worried about becoming infected with the AIDS virus?. . . . . . . 1 2 3

166. Of all your sex partners, how many of them do you think might have been infected with the AIDS virus when you had sex with them?

$\begin{array}{ll}1 & \text { All of your partners } \\ 2 & \text { Most of your partners } \\ 3 & \text { Some of your partners } \\ 4 & \text { None of your partners } \\ 7 & \text { DK } \\ 8 & \text { NA }\end{array}$

167. How likely do you think it is that you would become infected with the AIDS virus if you had sex only one time with an infected person and did not use a condom?

$\begin{array}{cccc}\text { DEFINITELY WOULD } & \text { SOMEWHAT } & \text { SOMEWHAT } & \text { NOT LIKELY } \\ \text { BE INFECTED } & \text { LIKELY } & \text { UNLIKELY } & \text { AT ALL }\end{array}$

1

4

168. Have you ever been tested for the AIDS virus (HIV test)?

$\begin{array}{ll}1 & \text { YES } \\ 2 & \text { NO } \\ 7 & \text { DK }\end{array}$

169. Do you plan to get an AIDS virus test (HIV test) within the next 6 months?

$\begin{array}{crcc}\text { Yes } & \text { No } & \text { DK } & \text { NA } \\ 1 & 2 & 7 & 8\end{array}$


Have any of your friends or family members:

$\begin{array}{lllcccc}170.1 & \text { YES } & \text { NO } & \text { DK } & \text { REFUSED } \\ 170.2 & \text { Have AIDS. . . . . . . . . . . . . . . . . . . . } & 1 & 1 & 7 & 9 \\ 170.3 & \begin{array}{l}\text { Been infected with the AIDS } \\ \text { virus. . . . . . . . . . . . }\end{array} & 2 & 7 & 9\end{array}$

Thinking of all the times you have had sex in the past 6 months, have you. . .

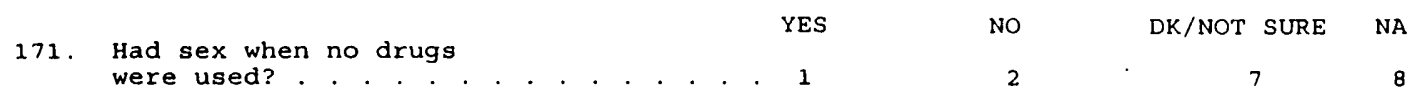

The following are some questions about different activities. For each one, please circle if you had the opportunity, would this be something you would like to do A LOT, SOMEWHAT, VERY LITTLE OR NOT AT ALL. HOW much would you like..

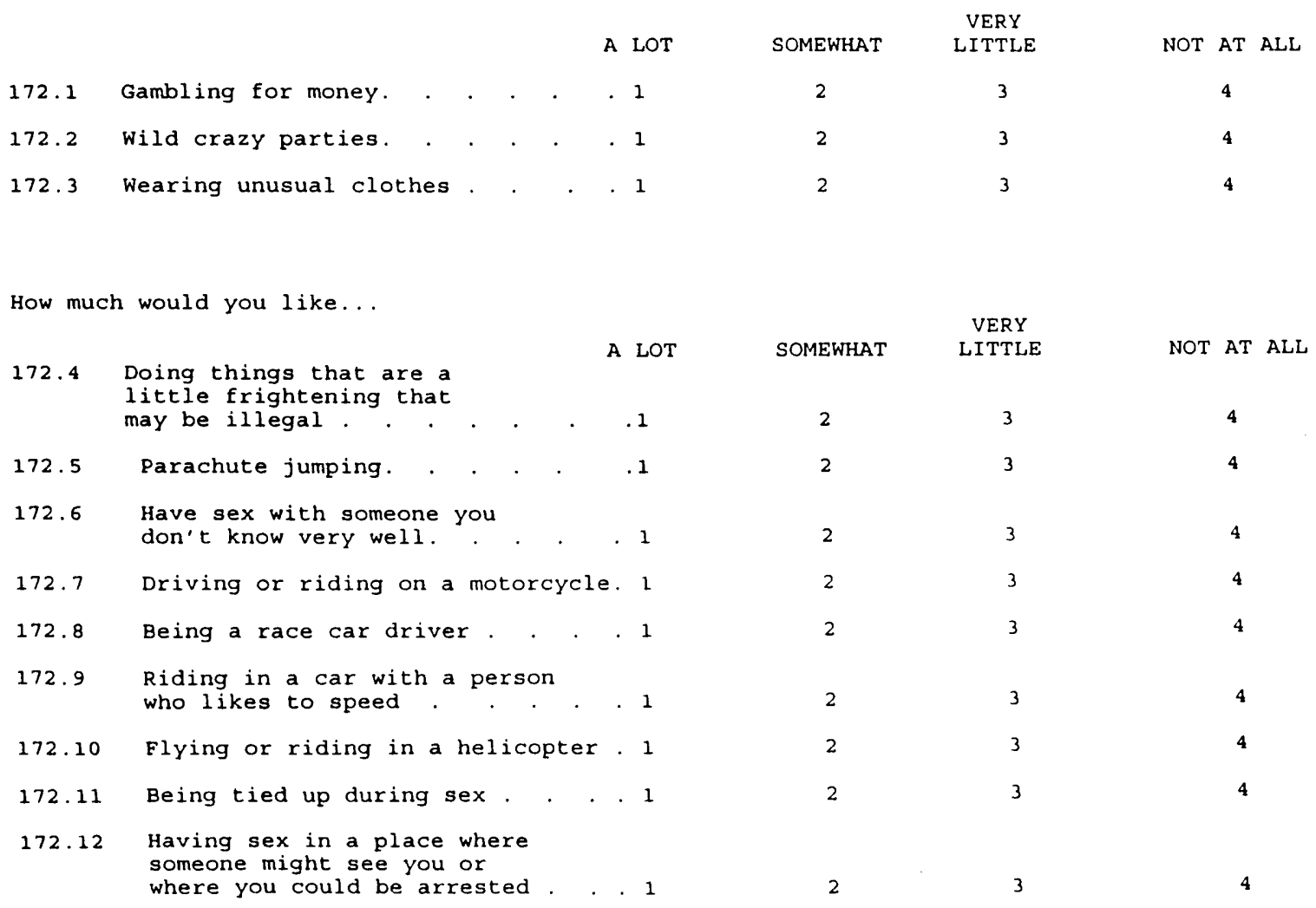


The following questions are about how you feel about yourself and your life.

173. If the line below represents your lifetime, where would you place yourself right now? Put an $X$ at the point you feel you are on this line.

BIRTH DEATH

174. How likely do you think it is that you will die within the next 15 years?

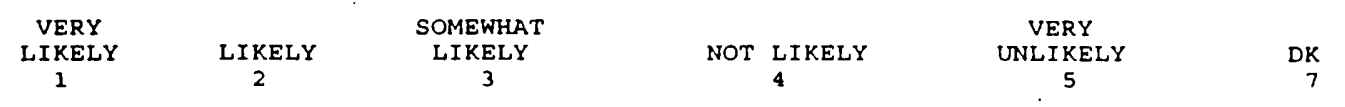

174.0 How do you think you will die? (Circle all that apply)

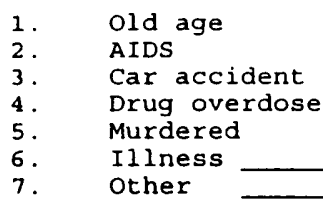

175. In general, how would you rate your mental health? Would you say. .
1 EXCELLENT
3 FAIR
2 GOOD
4 POOR

176. Have you ever been treated for mental or emotional concerns by a physician, counselor, or at a clinic?

$\begin{array}{ccc}\text { YES } & \text { NO } & \text { Refused } \\ 1 & 2 & 9\end{array}$

177. Have you seriously thought about killing yourself?
YES
1
No
Refused

178. Have you ever tried to kill yourself?

$\begin{array}{ccc}\text { YES } & \text { NO } & \text { Refused } \\ 1 & 2 & 9\end{array}$


The next group of questions are about how you felt during the last 6 months. Using the following answer list, please mark how often you felt each of the following ways in the last 6 months (mark the numbers of the appropriate response from the answer key next to each question):

ANSWER LIST

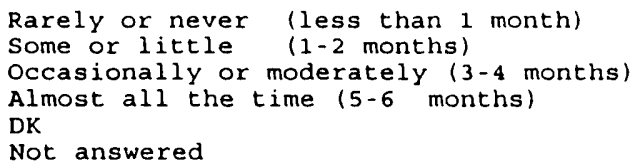

How often during the last 6 months:

179.1 Were you bothered by things that usually don't bother you?

179.2 Did you not feel like eating; your appetite was poor?

179.3 Did you feel that you would not shake off the blues even with help from your family and friends?

179.4 Did you feel that you were just as good as other people?

179.5 Did you have trouble keeping your mind on what you were doing?

179.6 Did you feel depressed?

179.7 Did you feel that everything you did was an effort?

179.8 Did you feel hopeful about the future?

179.9. Did you think your life had been a failure?

179.10 Did you feel fearful?

179.11 Was your sleep restless?

179.12 Were you happy?

179.13 Did you talk less than usual?

179.14 Did you feel lonely?

179.15 Were people unfriendly?

179.16 Did you enjoy life?

179.17 Did you have crying spells?

179.18 Did you feel sad?

179.19 Did you feel that people disliked you?

179.20 You could not get going.

THANK YOU, YOU HAVE BEEN VERY PATIENT. THERE ARE JUST A FEW MORE QUESTIONS.

For each of the next questions, please circle how true each of these are for you. Would you say never true, seldom true, sometimes true, often true, or almost always true?

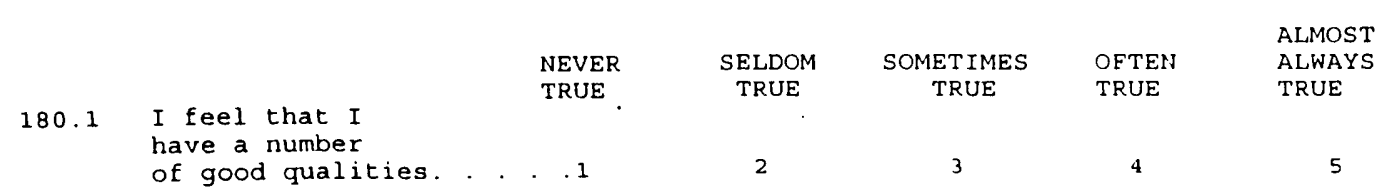




\begin{tabular}{|c|c|c|c|c|c|c|}
\hline & & $\begin{array}{l}\text { NEVER } \\
\text { TRUE }\end{array}$ & $\begin{array}{l}\text { SELDCM } \\
\text { TRUE }\end{array}$ & $\begin{array}{c}\text { SOMETIMES } \\
\text { TRUE }\end{array}$ & $\begin{array}{l}\text { OFTEN } \\
\text { TRUE }\end{array}$ & $\begin{array}{l}\text { ALMOST } \\
\text { ALWAYS } \\
\text { TRUE }\end{array}$ \\
\hline 180.2 & $\begin{array}{l}\text { I wish I could have } \\
\text { more respect for myself. }\end{array}$ & , & & & & \\
\hline 180.3 & $\begin{array}{l}\text { I feel that I'm a } \\
\text { person of worth, at } \\
\text { least on an equal }\end{array}$ & & & & & \\
\hline 180.4 & $\begin{array}{l}\text { I feel I do not have } \\
\text { much to be proud of. }\end{array}$ & $\begin{array}{r}\cdot \\
\cdot \\
\cdot \\
\cdot \\
\cdot 1\end{array}$ & 2 & 3 & 4 & 5 \\
\hline 180.5 & $\begin{array}{l}\text { I take a positive } \\
\text { attitude toward myself. }\end{array}$ & · 1 & 2 & 3 & 4 & 5 \\
\hline 180.6 & $\begin{array}{l}\text { I certainly feel } \\
\text { useless at times: . . . }\end{array}$ & . 1 & 2 & 3 & 4 & 5 \\
\hline 180.7 & $\begin{array}{ll}\text { All in all, } & \text { ' } m \\
\text { inclined to feel } \\
\text { that I am a failure. }\end{array}$ & . 1 & 2 & 3 & 4 & 5 \\
\hline 180.8 & $\begin{array}{l}\text { I am able to do } \\
\text { things as well as } \\
\text { most other people. . . . }\end{array}$ & .1 & 2 & 3 & 4 & 5 \\
\hline 180.9 & $\begin{array}{l}\text { At times I think I } \\
\text { am no good at all. . . . }\end{array}$ & $\cdot .1$ & 2 & 3 & 4 & 5 \\
\hline 180.10 & $\begin{array}{l}\text { On the whole, I'm } \\
\text { satisfied with myself. }\end{array}$ &. .1 & 2 & 3 & 4 & 5 \\
\hline
\end{tabular}

181.1 Did anything happen to you IN THE PAST YEAR that upset you a lot for several weeks?

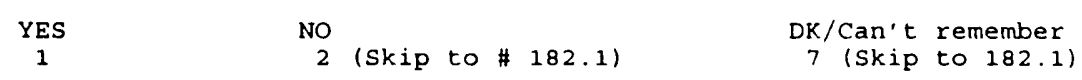

181.2 What was it?

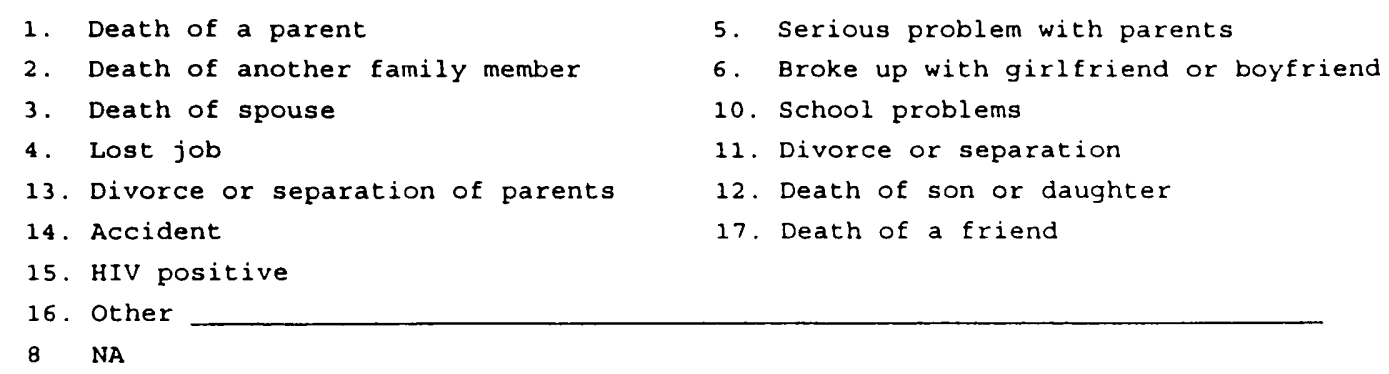

The following questions are about AIDS and the virus that causes AIDS.

For each of the following questions, please circle how true you think each one is:

\begin{tabular}{|c|c|c|c|c|c|c|c|}
\hline & & $\begin{array}{l}\text { VERY } \\
\text { TRUE }\end{array}$ & $\begin{array}{l}\text { SOMEWHAT } \\
\text { TRUE }\end{array}$ & $\begin{array}{l}\text { IOT VERY } \\
\text { TRUE }\end{array}$ & $\begin{array}{r}\text { NOT } \\
\text { AT }\end{array}$ & $\begin{array}{l}\text { TRUE } \\
\text { ALL }\end{array}$ & DK \\
\hline 82.1 & $\begin{array}{l}\text { To protect yourself or your } \\
\text { partner from getting AIDS, } \\
\text { it is important to use a condom } \\
\text { made of natural materials. }\end{array}$ & 1 & 2 & 3 & 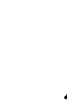 & 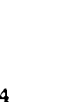 & 7 \\
\hline
\end{tabular}




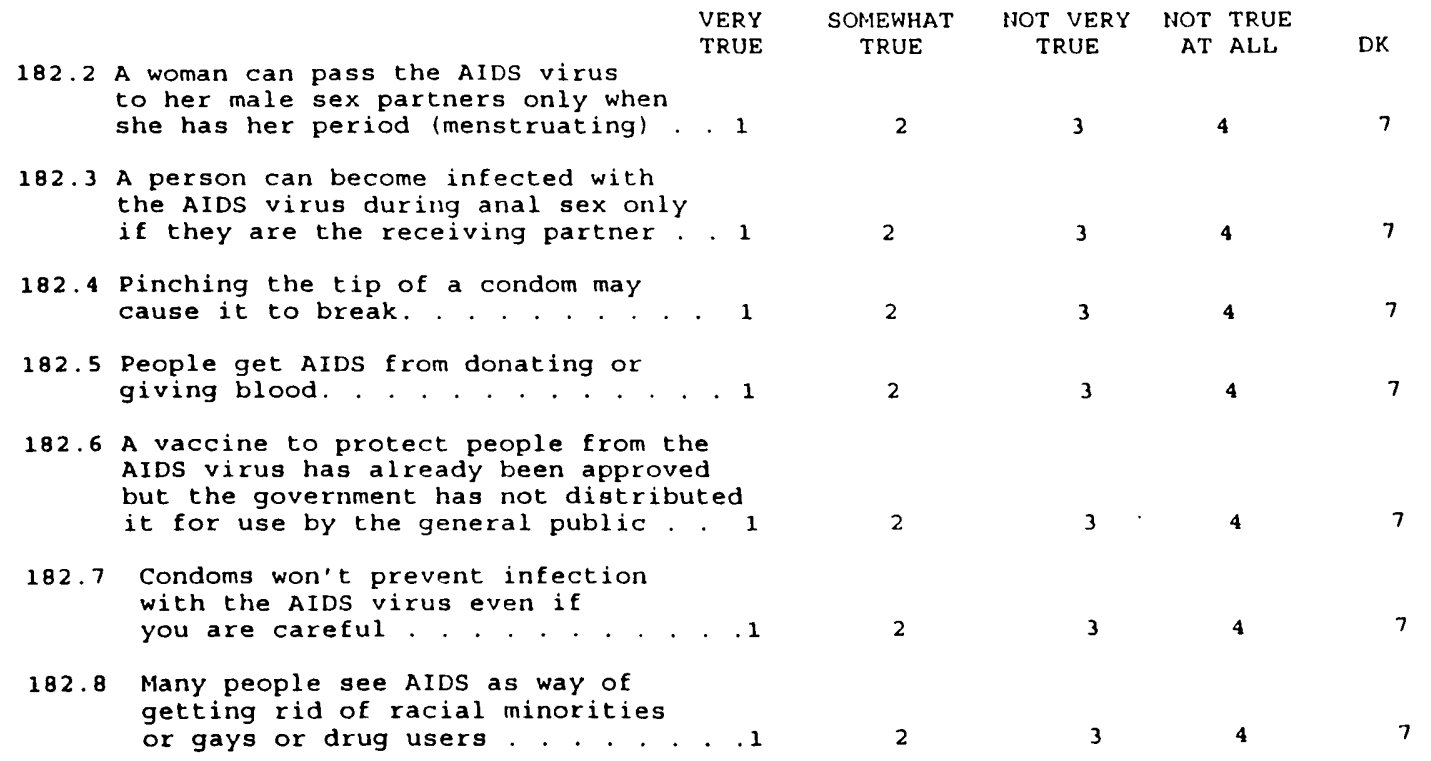

183. What is your height? feet inches

184. How may pounds do you weigh?
pounds
9 Refused
7 DK

184.1 Would you say that you are...

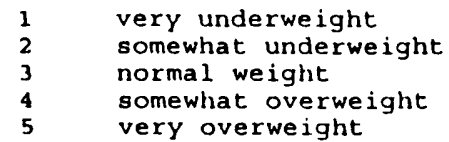

184.2 How often do you perform any of the following types of aerobic exercises (walking, running, swimming, rowing, stair climbing, skipping rope, bicycling or vigorous dance)?

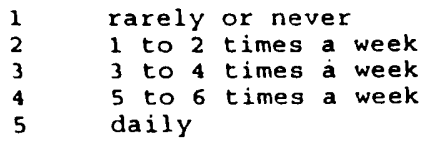

184.3 How often do you perform the following self-examinations:

\begin{tabular}{|c|c|c|c|c|c|c|}
\hline & & Never & Rarely & $\begin{array}{l}\text { Every few } \\
\text { monthg }\end{array}$ & Monthly & NA \\
\hline 185.0 & skin. . & $\cdot \quad \cdot 1$ & $\begin{array}{l}2 \\
2\end{array}$ & 3 & $\begin{array}{l}4 \\
4\end{array}$ & 8 \\
\hline $\begin{array}{l}185 \cdot 1 \\
185 \cdot 2\end{array}$ & $\begin{array}{l}\text { breast. } \\
\text { testicular }\end{array}$ & $\begin{array}{r}\therefore \quad 1 \\
\therefore \quad 1\end{array}$ & 2 & 3 & 4 & B \\
\hline
\end{tabular}




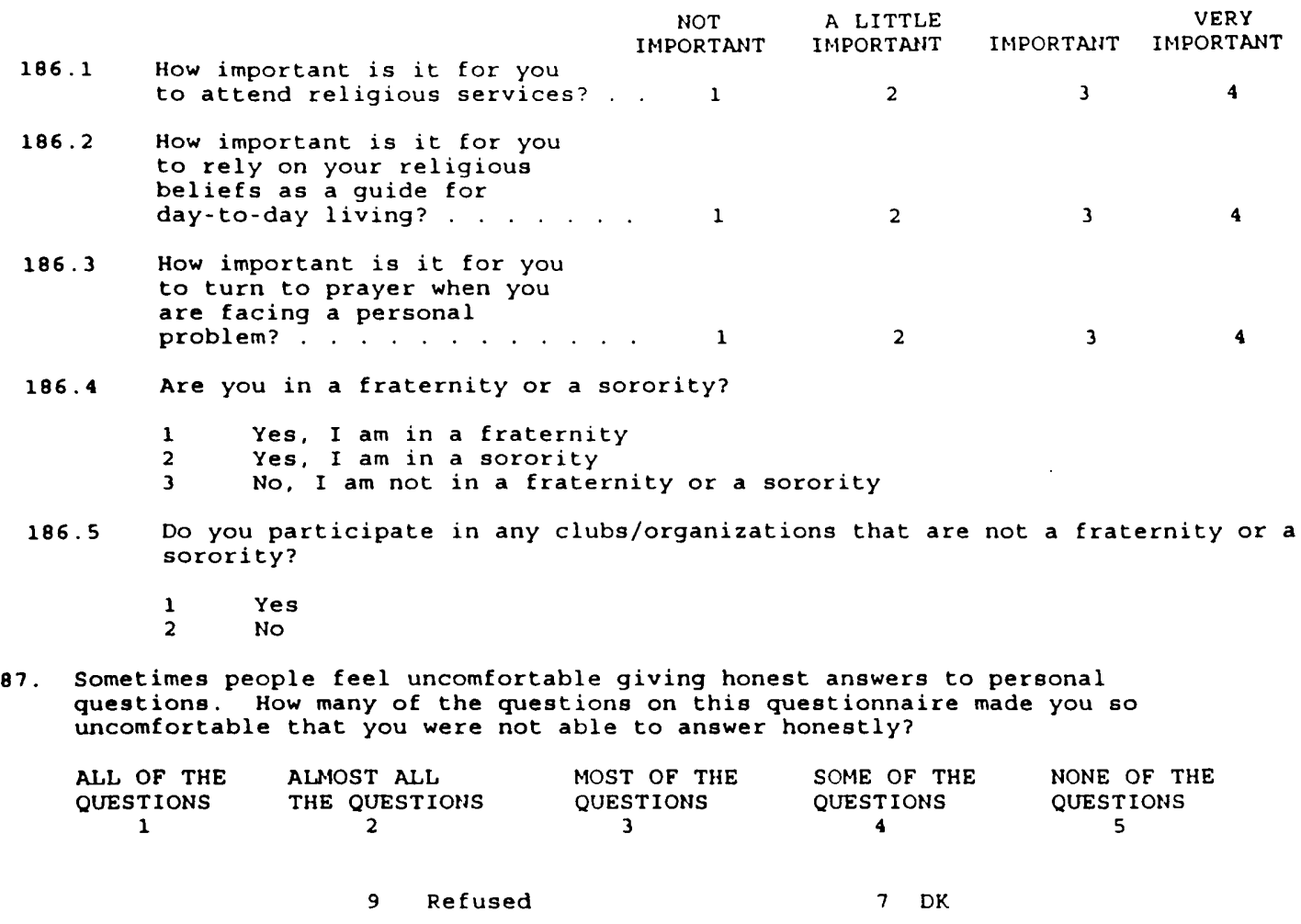

Thank you very much for your time and help.

Time completed: $\quad \ldots:$ _ Date: $\frac{}{\text { month }} / \frac{}{\text { day }} / 94$

Please share any comments, suggestions or corrections which you feel would be helpful: 


\section{VITA}

\section{MORRIS F. BURNHAM}

1946

1966-1968

1971

1972

1972-1992

1991-1992

1994

1995

1995

1996-1997
Born, New Orleans, Louisiana

US Navy Seabees, Republic of Vietnam

B.S.B.A., Accounting

University of Florida

Gainesville, Florida

Graduate School of Business, Finance

University of Florida

Gainesville, Florida

CPA, Financial Controller, Real Estate Executive, Certified Internal Auditor, Director of Internal Audit, Business Manager \& Consultant Florida and New York

Volunteer, Children's Home Society of Florida

Miami, Florida

M.S.W.

Florida International University

Miami, Florida

Adjunct Instructor

Florida International University

Miami, Florida

Research Associate

Institute on Children and Families at Risk

Florida International University

Miami, Florida

Visiting Instructor and Title IV-E Program Coordinator

Florida International University

Miami, Florida

\section{PUBLICATIONS}

Cook, S. P., Briar, S., Abruzzino, E., Harris, N., Dodge, K., \& Burnham, M. (1996). Partnership to Empower Parents: Treatment Model for Substance Abusing Women: Replication Guide. North Miami: Florida International University, Institute on Children and Families at Risk. 